\title{
Dactylogyrids (Monogenoidea: Polyonchoinea) parasitizing the gills of snappers (Perciformes: Lutjanidae): Revision of Euryhaliotrema with new and previously described species from the Red Sea, Persian Gulf, the eastern and Indo-west Pacific Ocean, and the Gulf of Mexico
}

\author{
Delane C. Kritsky \\ Health Education Program, School of Health Professions, Campus Box 8090, Idaho State University, Pocatello, Idaho 83209, \\ U.S.A. E-mail: kritdela@isu.edu
}

\begin{abstract}
Twenty one of 29 species of snappers (Lutjanidae), examined for dactylogyrids (Monogenoidea) from the Red Sea, Persian Gulf, the Indo-west and eastern Pacific Ocean, the Gulf of Mexico, and Caribbean Sea were parasitized by 16 new and 11 previously described species of Euryhaliotrema: Euryhaliotrema adelpha sp. nov., Euryhaliotrema anecorhizion sp. nov., Euryhaliotrema cardinale sp. nov., Euryhaliotrema chrysotaeniae, Euryhaliotrema cognatus sp. nov., Euryhaliotrema cryptophallus sp. nov., Euryhaliotrema diplops sp. nov., Euryhaliotrema distinctum sp. nov., Euryhaliotrema fajeravilae sp. nov., Euryhaliotrema fastigatum, Euryhaliotrema fatuum sp. nov., Euryhaliotrema ferocis sp. nov., Euryhaliotrema hainanense, Euryhaliotrema longibaculum, Euryhaliotrema mehen comb. nov., Euryhaliotrema paracanthi, Euryhaliotrema paululum sp. nov., Euryhaliotrema perezponcei, Euryhaliotrema ramulum sp. nov., Euryhaliotrema seyi sp. nov., Euryhaliotrema simplicis sp. nov., Euryhaliotrema spirotubiforum, Euryhaliotrema tormocleithrum sp. nov., Euryhaliotrema torquecirrus, Euryhaliotrema tubocirrus, Euryhaliotrema xinyingense, and Euryhaliotrema youngi sp. nov. Six species of Euryhaliotrema, previously reported from lutjanid hosts, were not collected: Euryhaliotrema anguiformis comb. nov., Euryhaliotrema guangdongense, Euryhaliotrema johni, Euryhaliotrema lutiani, Euryhaliotrema lutjani, and Euryhaliotrema nanaoense comb. nov. The diagnosis of Euryhaliotrema was emended to include species having tandem or slightly overlapping gonads, a pretesticular germarium, a globose haptor with morphologically similar anchors and hooks, a coiled or meandering male copulatory organ, a dextral vaginal pore, and hooks with upright acute thumbs and slender shanks comprised of one subunit. A bulbous base of the MCO and presence of an accessory piece in the copulatory complex were no longer considered features defining the genus. As a result, Euryhaliotrematoides and Aliatrema were placed in subjective synonymy with Euryhaliotrema, and the following transfers were proposed: Euryhaliotrema annulocirrus comb. nov., Euryhaliotrema aspistis comb. nov., Euryhaliotrema berenguelae comb. nov., Euryhaliotrema cribbi comb. nov., Euryhaliotrema grandis comb. nov., Euryhaliotrema mehen comb. nov., Euryhaliotrema microphallus comb. nov., Euryhaliotrema pirulum comb. nov., and Euryhaliotrema triangulovagina comb. nov. In addition, the following new combinations were proposed based on the revised diagnosis of the genus: Euryhaliotrema anguiformis comb. nov., Euryhaliotrema eukurodai comb. nov., Euryhaliotrema kurodai comb. nov., Euryhaliotrema monoporosum comb. nov., and Euryhaliotrema nanaoense comb. nov. The dactylogyrids, Protancyrocephalus rangusi (from a lutjanid host) and Daitreosoma chaetodontis (from a chaetodontid host), were considered species inquirendae. Haliotrematoides tukerhamatus comb. nov. is considered the senior subjective synonym of Haliotrematoides nagabinae. New host records for some previously described species of Euryhaliotrema from lutjanid and chaetodontid hosts were reported.
\end{abstract}

KEY WORDS. Aliatrema; Dactylogyridae; Euryhaliotrema; Euryhaliotrematoides; Lutjanidae; Lutjanus spp.; Monogenoidea; Ocyurus chrysurus; Rhomboplites aurorubens.

The Lutjanidae (Perciformes) includes 108 primarily reefdwelling marine species (EsCHMEYer \& FrICKe 2011) occurring in the tropical and subtropical waters of the eastern Pacific, Indowest Pacific, and eastern and western Atlantic Oceans (Allen 1985). These fishes, commonly called snappers, are known to harbor a comparatively high number of dactylogyrid species on their gills (see KrITSKY et al. 2009a). In 2001, a survey was initiated to determine the diversity of dactylogyrids from lutjanid hosts worldwide. The first installment stemming from this investigation included the proposal of Haliotrematoides Kritsky, 
Yang \& Sun, 2009 with 24 species (12 new) infesting lutjanid hosts; two dactylogyrid species from caesionid hosts and four from sparid hosts were also included in Haliotrematoides by KRITSKY et al. (2009a). The present paper represents the second installment stemming from this investigation and includes a revision of Euryhaliotrema Kritsky \& Boeger, 2002 and descriptions and reports of 27 new and previously described species from lutjanid hosts.

\section{MATERIAL AND METHODS}

The gills of twenty nine species of snappers (Lutjanidae) were examined for dactylogyrids: yellowbanded snapper, Lutjanus adettii (Castelnau); mutton snapper, Lutjanus analis (Cuvier); schoolmaster snapper, Lutjanus apodus (Walbaum); mangrove red snapper, Lutjanus argentimaculatus (Forsskål); yellow snapper, Lutjanus argentiventris (Peters); mullet snapper, Lutjanus auratus (Günther); two-spot red snapper, Lutjanus bohar (Forsskål); northern red snapper, Lutjanus campechanus (Poey); Spanish red snapper, Lutjanus carponotatus (Richardson); Colorado snapper, Lutjanus colorado Jordan \& Gilbert; cubera snapper, Lutjanus cyanopterus (Cuvier); blackspot snapper, Lutjanus ehrenbergii (Peters); dory snapper, Lutjanus fulviflamma (Forsskål); blacktail snapper, Lutjanus fulvus (Forster); humpback snapper, Lutjanus gibbus (Forsskål); grey snapper, Lutjanus griseus (Linnaeus); spotted rose snapper, Lutjanus guttatus (Steindachner); dog snapper, Lutjanus jocu (Bloch \& Schneider); common blue stripe snapper, Lutjanus kasmira (Forsskål); mahogony snapper, Lutjanus mahogoni (Cuvier); Malabar blood snapper, Lutjanus malabaricus (Bloch \& Schneider); five-lined snapper, Lutjanus quinquelineatus (Bloch); blubberlip snapper, Lutjanus rivulatus (Cuvier); Russell's snapper, Lutjanus russellii (Bleeker); emperor red snapper, Lutjanus sebae (Cuvier); lane snapper, Lutjanus synagris (Linnaeus); brownstripe snapper, Lutjanus vitta (Quoy \& Gaimard); yellowtail snapper, Ocyurus chrysurus (Bloch); and vermillion snapper, Rhomboplites aurorubens (Cuvier).

Snappers were collected by a variety of methods from marine waters off China, New Caledonia, Australia, the Maldive Islands, Egypt, Kuwait, Mexico, Nicaragua, Panama, and the USA by colleagues and friends (see Acknowledgments). Fish hosts were identified by the collectors using various resources available at the respective collection sites and facilities; scientific and common names of fishes are those provided in FishBase (Froese \& Pauly 2011) and verified in Eschmeyer \& Fricke (2011). In most cases, the host's gill basket was removed soon after capture at the site of collection and placed in hot $\left(60^{\circ} \mathrm{C}\right) 4 \%$ formalin to relax and fix the parasites. Fixed gills from each fish were pooled or placed individually in vials; vials containing the gills and respective fluids were labeled and shipped to Idaho State University for study. Dactylogyrids were subsequently removed from the gills or sediment using a small probe and dissecting microscope. Some specimens were mounted unstained in Gray and Wess medium (HUMASON 1979) or in ammonium picrate glycerine (MALMBERG 1970) for study of sclerotized structures; other specimens were stained with Gomori's trichrome or VanCleave's hematoxylin (КRITSKY et al. 1978, BULLARD et al. 2004) and mounted in Canada balsam for observing internal anatomy. Illustrations were prepared with the aid of a camera lucida or microprojector. Measurements, all in micrometers, represented straight-line distances between extreme points and were expressed as the mean followed by the range and number (n) of structures measured in parentheses; body length included that of the haptor; the measured dimension of the male copulatory organ (MCO) was that represented in the respective drawings as the distance between the parallel lines. Numbering of hook pairs followed that proposed by Mizelle (1936) (see Mizelle \& Price 1963); direction of the coil (clockwise vs. counterclockwise) of the MCO was determined using the method suggested by KrITSKY et al. (1985). Descriptions of new species were based on specimens collected from the type locality and type host; all other specimens of the respective species were considered voucher specimens. Unless otherwise indicated, measurements of the new species are from specimens collected from the type host and type locality. Type and voucher specimens collected during the present study were deposited in the U.S. National Parasite Collection (USNPC), Beltsville, Maryland, the Florida Fish and Wildlife Conservation Commissions's Fish and Wildlife Research Institutes' Invertebrate Specimen Collection (FSBC-I), St. Petersburg, Florida, and the helminth collections of the Queensland Museum (QM), Brisbane, Australia; and the Muséum national d'Histoire naturelle (MNHN), Paris, France, as indicated in the respective species accounts. In addition, the following museum specimens were examined: paratype, Euryhaliotrema xinyingense Pan \& Zhang, 2006 [Natural History Museum, London, UK (NHMUK 2005.10.18.3-4)]; paratype, Euryhaliotrema hainanense Pan \& Zhang, 2006 (NHMUK 2005.10.18.1-2); 3 voucher specimens, Euryhaliotrema torquecirrus (Zhukov, 1976) Kritsky \& Boeger, 2002 (USNPC 91432); 2 voucher specimens, Euryhaliotrema tubocirrus (Zhukov, 1976) Kritsky \& Boeger, 2002 (USNPC 91431); and 4 paratypes, Euryhaliotrematoides mehen SolerJiménez, Garcia-Gasca \& Fajer-Ávila, 2012 (USNPC 104737, 104738, $104739 \& 104740)$.

\section{TAXONOMY}

Twenty one of 29 species of snappers (Lutjanidae), examined from the Red Sea, Persian Gulf, the Indo-west and eastern Pacific Ocean, the Gulf of Mexico and Caribbean Sea, were parasitized by 16 new and 11 previously described species of Euryhaliotrema (Tab. I). A specimen of an unidentified species of Euryhaliotrema (species 1, USNPC 105462) was also collected from a yellowbanded snapper, Lutjanus adettii, off Australia; and along with new and previously described species, two unidentified species of Euryhaliotrema (species 2 and 3, USNPC 
Table I. Occurrence of Euryhaliotrema species on the gills of snappers (Lutjanidae).

\begin{tabular}{|c|c|c|}
\hline Euryhaliotrema species & Host & Locality \\
\hline E. adelpha Kritsky \& Justine sp. nov. & Lutjanus quinquelineatus & New Caledonia \\
\hline E. anecorhizion Kritsky \& Mendoza-Franco sp. nov. & Lutjanus argentiventris & Eastern Pacific \\
\hline \multirow[t]{2}{*}{ E. cardinale Kritsky \& Justine sp. nov. } & Lutjanus fulviflamma & New Caledonia, Australia, Red Sea \\
\hline & Lutjanus ehrenbergii & Red Sea \\
\hline \multirow[t]{5}{*}{ E. chrysotaeniae (Young, 1968) Kritsky \& Boeger, 2002} & Lutjanus carponotatus & Australia \\
\hline & Lutjanus russellii & New Caledonia \\
\hline & Lutjanus quinquelineatus & New Caledonia \\
\hline & Lutjanus fulviflamma & New Caledonia \\
\hline & Lutjanus fulvus & New Caledonia \\
\hline \multirow[t]{2}{*}{ E. cognatus Kritsky \& Galli sp. nov. } & Lutjanus bohar & Republic of Maldives \\
\hline & Lutjanus gibbus & Republic of Maldives \\
\hline E. cryptophallus Kritsky \& Yang sp. nov. & Lutjanus argentimaculatus & China \\
\hline E. diplops Kritsky, Yang \& Justine sp. nov. & Lutjanus argentimaculatus & New Caledonia, China \\
\hline E. distinctum Kritsky \& Galli sp. nov. & Lutjanus bohar & Republic of Maldives \\
\hline E. fajeravilae Kritsky \& Mendoza-Franco sp. nov. & Lutjanus argentiventris & Eastern Pacific \\
\hline \multirow[t]{4}{*}{ E. fastigatum (Zhukov, 1976) Kritsky \& Boeger, 2002} & Lutjanus griseus & Gulf of Mexico \\
\hline & Lutjanus apodus & Gulf of Mexico \\
\hline & Lutjanus jocu & Gulf of Mexico \\
\hline & Lutjanus argentiventris & Eastern Pacific \\
\hline \multirow[t]{2}{*}{ E. fatuum Kritsky \& Justine sp. nov. } & Lutjanus fulviflamma & New Caledonia, Australia \\
\hline & Lutjanus fulvus & New Caledonia \\
\hline E. ferocis Kritsky \& Yang sp. nov. & Lutjanus malabaricus & China \\
\hline E. hainanense Pan \& Zhang, 2006 & Lutjanus argentimaculatus & New Caledonia, China \\
\hline E. longibaculum (Zhukov, 1976) Kritsky \& Boeger, 2002 & Lutjanus synagris & Gulf of Mexico \\
\hline E. mehen (Solar-Jiménez, Garcia-Gasca \& Fajer-Ávila, 2012) comb. nov. & Lutjanus guttatus & Eastern Pacific \\
\hline \multirow[t]{3}{*}{ E. paracanthi (Zhukov, 1976) Kritsky \& Boeger, 2002} & Lutjanus griseus & Gulf of Mexico \\
\hline & Lutjanus jocu & Gulf of Mexico \\
\hline & Lutjanus argentiventris & Eastern Pacific \\
\hline E. paululum Kritsky \& Justine sp. nov. & Lutjanus kasmira & New Caledonia \\
\hline E. perezponcei Garcia-Vargas, Fajer-Ávila \& Lamothe-Argumedo, 2008 & Lutjanus guttatus & Eastern Pacific \\
\hline E. ramulum Kritsky \& Galli sp. nov. & Lutjanus gibbus & Republic of Maldives \\
\hline \multirow[t]{2}{*}{ E. seyi sp. nov. } & Lutjanus fulviflamma & Red Sea \\
\hline & Lutjanus russellii & Persian Gulf \\
\hline E. simplicis Kritsky \& Justine sp. nov. & Lutjanus quinquelineatus & New Caledonia \\
\hline \multirow[t]{7}{*}{ E. spirotubiforum (Zhang, 2001) Wu, Zhu, Xie \& Li, 2006} & Lutjanus vitta & New Caledonia \\
\hline & Lutjanus russellii & New Caledonia \\
\hline & Lutjanus fulviflamma & Red Sea, Australia \\
\hline & Lutjanus ehrenbergii & Red Sea \\
\hline & Lutjanus carponotatus & Australia \\
\hline & Lutjanus quinquelineatus & New Caledonia \\
\hline & Lutjanus fulvus & New Caledonia \\
\hline E. tormocleithrum Kritsky \& Galli sp. nov. & Lutjanus gibbus & Republic of Maldives \\
\hline E. torquecirrus (Zhukov, 1976) Kritsky \& Boeger, 2002 & Ocyurus chrysurus & Gulf of Mexico \\
\hline
\end{tabular}


Table I. Continued.

\begin{tabular}{|c|c|c|}
\hline Euryhaliotrema species & Host & Locality \\
\hline \multirow[t]{5}{*}{ E. tubocirrus (Zhukov, 1976) Kritsky \& Boeger, 2002} & Lutjanus campechanus & Gulf of Mexico \\
\hline & Lutjanus griseus & Gulf of Mexico \\
\hline & Lutjanus jocu & Gulf of Mexico \\
\hline & Lutjanus synagris & Gulf of Mexico \\
\hline & Rhomboplites aurorubens & Gulf of Mexico \\
\hline E. xinyingense Pan \& Zhang, 2006 & Lutjanus argentimaculatus & China, New Caledonia \\
\hline \multirow[t]{2}{*}{ E. youngi sp. nov. } & Lutjanus carponotatus & Australia \\
\hline & Lutjanus fulviflamma & Australia \\
\hline Euryhaliotrema sp. 1 & Lutjanus adetti & Australia \\
\hline Euryhaliotrema sp. 2 & Lutjanus argentiventris & Eastern Pacific \\
\hline Euryhaliotrema sp. 3 & Lutjanus argentiventris & Eastern Pacific \\
\hline
\end{tabular}

105463,105464 , respectively) occurred on yellow snapper, $L$. argentiventris, in the eastern Pacific Ocean off Panama. L. sebae from Australia, L. analis from the Gulf of Mexico, L. aratus and L. colorado from the eastern Pacific Ocean, L. cyanopterus from the Gulf of Mexico and Caribbean Sea, L. mahogoni from the Caribbean Sea, and L. rivulatus from New Caledonia were uninfected with species of the genus.

\section{Class Monogenoidea Bychowsky, 1937 Subclass Polyonchoinea Bychowsky, 1937 Order Dactylogyridea Bychowsky, 1937 Dactylogyridae Bychowsky, 1933}

\section{Euryhaliotrema Kritsky \& Boeger, 2002}

Syns Euryhaliotrematoides Plaisance \& Kritsky, 2004; Aliatrema

Plaisance \& Kritsky, 2004

Emended diagnosis: Body fusiform or slightly flattened dorsoventrally, comprising body proper (cephalic region, trunk, peduncle) and haptor. Tegument usually smooth. Terminal and two bilateral cephalic lobes; three pairs of bilateral head organs; cephalic glands unicellular, lateral or posterolateral to pharynx. Eyespots two to four; granules small, ovate. Mouth subterminal, midventral, prepharyngeal; pharynx comprising muscular, glandular bulb; esophagus short; intestinal ceca two, confluent posterior to gonads, lacking diverticula. Common genital pore midventral near level of intestinal bifurcation. Gonads intercecal, tandem or slightly overlapping; germarium pretesticular, ventral. Vas deferens looping left intestinal cecum; seminal vesicle a simple dilation of vas deferens; one or two prostatic reservoirs. Copulatory complex comprising $\mathrm{MCO}$ and accessory piece; accessory piece may be lacking. MCO tubular, coiled or meandering, with bulbous or funnel-shaped base; coil with counterclockwise rings. Accessory piece, when present, serving as guide for distal portion of MCO, with or without articulation process attached to base of MCO. Seminal receptacle pregermarial; vaginal pore dextral, marginal or submarginal; vagina sclerotized. Vitellaria in trunk, absent from regions of other reproductive organs. Haptor globose, armed with dorsal and ventral anchor/bar complexes, seven pairs of similar hooks. Hook distribution normal; hook with upright acute thumb, slender shank comprised of one subunit. Parasites of marine and freshwater teleosts.

Type species: Euryhaliotrema chaoi Kritsky \& Boeger, 2002 from Plagioscion sp. and P. squamosissimus (Heckel), Sciaenidae. Other species:

1. E. adelpha Kritsky \& Justine sp. nov. from Lutjanus quinquelineatus (Bloch), Lutjanidae.

2. E. ambassisi Pan \& Lu, 2005 from Ambassis gymnocephalus (Lacepède), Ambassidae.

3. E. amydrum Kritsky \& Bakenhaster, 2011 from Archosargus probatocephalus (Walbaum), Sparidae.

4. E. anecorhizion Kritsky \& Mendoza-Franco sp. nov. from Lutjanus argentiventris (Peters), Lutjanidae.

5. E. anguiformis (Zhang, 2001) comb. nov. from Lutjanus vaigiensis (Quoy \& Gaimard) [now L. fulvus (Forster)], Lutjanus kasmira (Forsskål), Lutjanus russellii (Bleeker), and Lutjanus monostigma (Cuvier), all Lutjanidae.

6. E. annulocirrus (Yamaguti, 1968) comb. nov. from Chaetodon auriga Forsskål, Chaetodon lunula (Lacepède), Chaetodon modestus Temminck \& Schlegel [now Roa modesta (Temminck \& Schlegel)], Chaetodon bellamaris Seale (now C. wiebeli Kaup), and Chaetodon vagabundus Linnaeus, all Chaetodontidae.

7. E. aspistis (Plaisance \& Kritsky, 2004) comb. nov. from Chaetodon auriga Forsskål, Chaetodon citrinellus Cuvier, Chaetodon lunula (Lacepède), Chaetodon reticulatus Cuvier, Chaetodon ulietensis Cuvier, and Chaetodon vagabundus Linnaeus, all Chaetodontidae.

8. E. atlanticum Kritsky \& Boeger, 2002 from Paralonchurus brasiliensis (Steindachner), Sciaenidae.

9. E. berenguelae (Plaisance \& Kritsky, 2004) comb. nov. from 
Forcipiger flavisissimus Jordan \& McGregor, Chaetodontidae. 10. E. bychowskyi (Obodnikova, 1976) Kritsky \& Boeger, 2002 from Hapalogenys mucronatus (Eydoux \& Souleyet), Haemulidae.

11. E. carbuncularium Kritsky \& Bakenhaster, 2011 from Archosargus probatocephalus (Walbaum), Sparidae.

12. E. carbunculus (Hargis, 1955) Kritsky \& Boeger, 2002 from Lagodon rhomboides (Linnaeus), Sparidae.

13. E. cardinale Kritsky \& Justine sp. nov. from Lutjanus fulviflamma (Forsskål) and Lutjanus ehrenbergii (Peters), both Lutjanidae.

14. E. chrysotaeniae (Young, 1968) Kritsky \& Boeger, 2002 from Lutjanus carponotatus (Richardson), Lutjanus fulviflamma (Forsskål), Lutjanus fulvus (Forster), Lutjanus kasmira (Forsskål), Lutjanus quinquelineatus (Bloch), and Lutjanus russellii (Bleeker), all Lutjanidae.

15. E. cognatus Kritsky \& Galli sp. nov. from Lutjanus bohar (Forsskål) and Lutjanus gibbus (Forsskål), both Lutjanidae.

16. E. cribbi (Plaisance \& Kritsky, 2004) comb. nov. from Chaetodon vagabundus Linnaeus, Chaetodon auriga Forsskål, Chaetodon lunula (Lacepède), Chaetodon trifasciatus Park, Chaetodon ulietensis Cuvier, Forcipiger flavisissimus Jordan \& McGregor, and Heniochus chrysostomus Cuvier, all Chaetodontidae.

17. E. cryptophallus Kritsky \& Yang sp. nov. from Lutjanus argentimaculatus (Forsskål), Lutjanidae.

18. E. diplops Kritsky, Yang \& Justine sp. nov. from Lutjanus argentimaculatus (Forsskål), Lutjanidae.

19. E. distinctum Kritsky \& Galli sp. nov. from Lutjanus bohar (Forsskål), Lutjanidae.

20. E. dontykoleos Fehlauer \& Boeger, 2005 from Pachyurus junki Soares \& Casatti, Sciaenidae.

21. E. dunlapae Kritsky \& Bakenhaster, 2011 from Archosargus probatocephalus (Walbaum), Sparidae.

22. E. eukurodai (Zhang, Ding, Lin \& Yu, 1994) comb. nov. from Acanthopagrus s. schlegelii (Bleeker), Sparidae.

23. E. fajeravilae Kritsky \& Mendoza-Franco sp. nov. from Lutjanus argentiventris (Peters), Lutjanidae.

24. E. fastigatum (Zhukov, 1976) Kritsky \& Boeger, 2002 from Lutjanus apodus (Walbaum), Lutjanus jocu (Bloch \& Schneider), Lutjanus griseus (Linnaeus), Lutjanus argentiventris (Peters), and Lutjanus analis (Cuvier), all Lutjanidae.

25. E. fatuum Kritsky \& Justine sp. nov. from Lutjanus fulviflamma (Forsskål) and Lutjanus fulvus (Forster), both Lutjanidae.

26. E. ferocis Kritsky \& Yang sp. nov. from Lutjanus malabaricus (Bloch \& Schneider), Lutjanidae.
27. E. grandis (Mizelle \& Kritsky, 1969) comb. nov. from Chaetodon auriga Forsskål, Chaetodon chrysurus Ahl (now C. paucifasciatus Ahl), Chaetodon citrinellus Cuvier, Chaetodon ephippium Cuvier, Chaetodon kleinii Bloch, Chaetodon lineolatus Cuvier, Chaetodon lunula (Lacepède), Chaetodon ornatissimus Cuvier, Chaetodon setifer Bloch (now C. auriga), Chaetodon trifasciatus Park, Chaetodon vagabundus Linnaeus, and Heniochus chrysostomus Cuvier, all Chaetodontidae.

28. E. guangdongense Li, Yan, Yul, Lan \& Huang, 2005 from Lutjanus argentimaculatus (Forsskål), Lutjanidae.

29. E. guangzhouense Li, 2005 from Sparus macrocephalus (Basilewsky) (now Acanthopagrus s. schlegelii), Sparidae.

30. E. hainanense Pan \& Zhang, 2006 from Lutjanus argentimaculatus (Forsskål), Lutjanidae.

31. E. johni (Tripathi, 1959) Kritsky \& Boeger, 2002 from Lutjanus johnii (Bloch), Lutjanus fulviflamma (Forsskål), Lutjanus rhodopterus ${ }^{1}$, Lutjanus russellii (Bleeker), and L. vaigiensis (Quoy \& Gaimard) (now L. fulvus), all Lutjanidae; and Sparus macrocephalus (Basilewsky) (now Acanthopagrus s. schlegelii), Sparidae.

32. E. kurodai (Ogawa \& Egusa, 1978) comb. nov. from Acanthopagrus schlegelii (Bleeker), Acanthopagrus berda (Forsskål), and Acanthopagrus latus (Houttuyn), all Sparidae.

33. E. longibaculum (Zhukov, 1976) Kritsky \& Boeger, 2002 from Lutjanus mahogoni (Cuvier) and Lutjanus synagris (Linnaeus), both Lutjanidae.

34. E. lovejoyi Kritsky \& Boeger, 2002 from Plagioscion sp. and Plagioscion squamosissimus (Heckel), both Sciaenidae.

35. E. lutiani (Yamaguti, 1953) Kritsky \& Boeger, 2002 from Lutjanus sp. and Lutjanus vitta (Quoy \& Gaimard), both Lutjanidae.

36. E. lutjani Li, 2006 from Lutjanus argentimaculatus (Forsskål), Lutjanidae, and Sparus macrocephalus (Basilewsky) (now Acanthopagrus s. schlegelii), Sparidae.

37. E. mehen (Soler-Jiménez, Garcia-Gasca \& Fajer-Ávila, 2012) comb. nov. from Lutjanus guttatus (Steindachner), Lutjanidae.

38. E. microphallus (Yamaguti, 1968) comb. nov. from Chaetodon auriga Forsskål, Chaetodon citrinellus Cuvier, Chaetodon ephippium Cuvier, Chaetodon kleinii Bloch, Chaetodon lunula (Lacepède), Chaetodon ornatissimus Cuvier, Chaetodon reticulatus Cuvier, Chaetodon trifascialis Quoy \& Gaimard, Chaetodon trifasciatus Park, Chaetodon vagabundus Linnaeus, Forcipiger flavisissimus Jordan \& McGregor, and Heniochus chrysostomus Cuvier, all Chaetodontidae.

39. E. monacanthus Kritsky \& Boeger, 2002 from Plagioscion sp. and Plagioscion squamosissimus (Heckel), both Sciaenidae.

\footnotetext{
${ }^{1}$ No listings for the nominal species, Lutjanus rhodopterus, reported as host of Euryhaliotrema johni by Wu et al. (2006) and of Euryhaliotrematoides sp. HQDD by Wu et al. (2007), were found in Fishbase (FroESE \& PAULY 2011) or in the California Academy of Sciences Catalog of Fishes (EschmeYer \& FrICKE 2011). The specific epithet "rhodopterus" has only been used for fishes assigned to Apogon (Apogonidae), Gobius (Gobiidae), Triacanthus (Triacanthidae) and Lethrinus (Lethrinidae). Thus, the host of the two species reported by these authors is uncertain.
} 
40. E. monoporosum (Pan \& Zhang, 2000) comb. nov. from Chaetodon wiebeli Kaup and Chaetodon ornatissimus Cuvier, both Chaetodontidae.

41. E. nanaoense (Li, Yan, Yul, Lan \& Huang, 2005) comb. nov. from Lutjanus argentimaculatus (Forsskål), Lutjanidae.

42. E. paracanthi (Zhukov, 1976) Kritsky \& Boeger, 2002 from Lutjanus apodus (Walbaum), Lutjanus griseus (Linnaeus), Lutjanus jocu (Bloch \& Schneider), and Lutjanus argentiventris (Peters), all Lutjanidae.

43. E. paralonchuri (Luque \& Iannacone, 1989) Kritsky \& Boeger, 2002 from Paralonchurus peruanus (Steindachner), Sciaenidae.

44. E. paululum Kritsky \& Justine sp. nov. from Lutjanus kasmira (Forsskål), Lutjanidae.

45. E. perezponcei García-Vargas, Fajer-Ávila \& LamotheArgumedo, 2008 from Lutjanus guttatus (Steindachner), Lutjanidae.

46. E. pirulum (Plaisance \& Kritsky, 2004) comb. nov. from Chaetodon auriga Forsskål, Chaetodon citrinellus Cuvier, Chaetodon lunula (Lacepède), Chaetodon trifasciatus Park, and Chaetodon vagabundus Linnaeus, all Chaetodontidae.

47. E. potamocetes Kritsky \& Boeger, 2002 from Plagioscion sp. and Plagioscion squamosissimus (Heckel), both Sciaenidae.

48. E. ramulum Kritsky \& Galli sp. nov. from Lutjanus gibbus (Forsskål), Lutjanidae.

49. E. sagmatum Kritsky \& Boeger, 2002 from Umbrina xanti Gill, Sciaenidae.

50. E. seyi sp. nov. from Lutjanus fulviflamma (Forsskål) and Lutjanus russellii (Bleeker), both Lutjanidae.

51. E. simplicis Kritsky \& Justine sp. nov. from Lutjanus quinquelineatus (Bloch), Lutjanidae.

52. E. spirotubiforum (Zhang, 2001) Wu, Zhu, Xie \& Li, 2006 from Lutjanus vitta (Quoy \& Gaimard), Lutjanus russellii (Bleeker), Lutjanus fulviflamma (Forsskål), Lutjanus ehrenbergii (Peters), Lutjanus carponotatus (Richardson), Lutjanus kasmira (Forsskål), Lutjanus quinquelineatus (Bloch), Lutjanus fulvus (Forster), Lutjanus stellatus Akazaki, and Lutjanus vaigiensis (Quoy \& Gaimard) (now L. fulvus), all Lutjanidae.

53. E. spirulum Kritsky \& Bakenhaster, 2011 from Archosargus probatocephalus (Walbaum), Sparidae.

54. E. succedaneus Kritsky \& Boeger, 2002 from Plagioscion sp. and Plagioscion squamosissimus (Heckel), both Sciaenidae.

55. E. thatcheri Kritsky \& Boeger, 2002 from Plagioscion sp. and Plagioscion squamosissimus (Heckel), both Sciaenidae.

56. E. tormocleithrum Kritsky \& Galli sp. nov. from Lutjanus gibbus (Forsskål), Lutjanidae.

57. E. torquecirrus (Zhukov, 1976) Kritsky \& Boeger, 2002 from Lutjanus synagris (Linnaeus), Lutjanus griseus (Linnaeus), Lutjanus mahogoni (Cuvier), Lutjanus analis (Cuvier), and Ocyurus chrysurus (Bloch), all Lutjanidae.

58. E. triangulovagina (Yamaguti, 1968) comb. nov. from Chaetodon auriga Forsskål, Chaetodon citrinellus Cuvier, Chaetodon kleinii Bloch, Chaetodon lunula (Lacepède),
Chaetodon multicinctus Garrett, Chaetodon ornatissimus Cuvier, Chaetodon vagabundus Linnaeus, Chaetodon wiebeli Kaup, Forcipiger flavisissimus Jordan \& McGregor, Forcipiger longirostris (Broussonet), Hemitaurichthys polylepis (Bleeker), and Heniochus chrysostomus Cuvier, all Chaetodontidae.

59. E. tubocirrus (Zhukov, 1976) Kritsky \& Boeger, 2002 from Lutjanus analis (Cuvier), Lutjanus apodus (Walbaum), Lutjanus cyanopterus (Cuvier), Lutjanus synagris (Linnaeus), Lutjanus jocu (Bloch \& Schneider), Lutjanus campechanus (Poey), Lutjanus griseus (Linnaeus), Lutjanus mahogoni (Cuvier), Lutjanus buccanella (Cuvier), Lutjanus vivanus (Cuvier), and Rhomboplites aurorubens (Cuvier), all Lutjanidae.

60. E. xinyingense Pan \& Zhang, 2006 from Lutjanus argentimaculatus (Forsskål), Lutjanidae.

61. E. youngi sp. nov. from Lutjanus carponotatus (Richardson) and Lutjanus fulviflamma (Forsskål), both Lutjanidae.

62. E. zhangiianyingi Pan \& Lu, 2005 from Ambassis gymnocephalus (Lacepède), Ambassidae.

Remarks: Euryhaliotrema was proposed by KRITSKY \& BoEger (2002) for some new and previously described species of Dactylogyridae from snappers (Lutjanidae), drums and croakers (Sciaenidae), porgies (Sparidae) and grunts (Haemulidae). The genus was primarily characterized by dactylogyrids having a bulbous base of the MCO. Plaisance \& KRITSKy (2004) subsequently proposed Euryhaliotrematoides Plaisance \& Kritsky, 2004 and Aliatrema Plaisance \& Kritsky, 2004 for similar species parasitizing butterflyfishes (Chaetodontidae) but having "funnel-shaped" bases of the MCO; species of Aliatrema also lack an accessory piece in the copulatory complex (accessory pieces present in species of Euryhaliotrema and Euryhaliotrematoides). However, some of the dactylogyrids collected from snappers during the present survey possessed a mix of these morphological features, suggesting that re-evaluation of the three genera was necessary.

Species currently assigned to Euryhaliotrema, Euryhaliotrematoides and Aliatrema share many morphological features, including tandem or slightly overlapping gonads, a pretesticular germarium, a globose haptor with morphologically similar anchors/bar complexes and hooks, a coiled or meandering MCO, a dextral vaginal pore, and hooks with an upright acute thumb and slender shank comprised of one subunit. However, the three genera can no longer be justified based solely on the morphology of the copulatory complex. In the species recovered from snappers, the aperture in the base of the MCO allowing entry of the spermatic and prostatic ducts, varies from inconspicuous in some species with bulbous bases to comparatively large in those with funnel-shaped bases (compare the MCOs of E. chrysotaeniae, Fig. 108 and E. distinctum, Fig. 120), while in some species (i.e., E. anecorhizion, Fig. 59) with bulbous bases, the basal aperture is intermediate in size. In addition, the absence of an accessory piece in the copulatory complex appears to represent a secondary evolutionary loss within this group of parasites. For example, the MCOs of species lacking an accessory piece, such as in $E$. 
spirotubiforum (Fig. 164), E. adelpha (Figs 168, 169), E. paululum (Fig. 180), and E. youngi (Figs 186, 187), appear most similar to those of E. ferocis (Fig. 146) and E. fatuum (Fig. 94), both species of which possess an $\mathrm{MCO}$ associated with a small accessory piece. Because morphology of the copulatory complex no longer appears diagnostic at the generic level, the diagnosis of Euryhaliotrema was expanded to include the valid species of Euryhaliotrematoides and Aliatrema, and the two latter genera were considered subjective synonyms of Euryhaliotrema. As a result of the proposed synonymies, the species previously assigned to Euryhaliotrematoides and Aliatrema were transferred to Euryhaliotrema as new combinations.

Studies involving phylogenetic analyses using molecular data have provided minimal and often conflicting evidence regarding the validities of Euryhaliotrema, Aliatrema and Euryhaliotrematoides. While some of these studies have suggested possible monophyly of species parasitizing particular host groups, all have been based on comparatively few taxa that clearly underestimated species diversity. As a result, potential bias toward closely related species parasitizing specific host groups has likely occurred. For example, the analysis conducted by PLAISANCE et al. (2005) using 28S rDNA sequences of only seven species of Euryhaliotrematoides and Aliatrema cribbi (all from chaetodontid hosts) and Euryhaliotrema chrysotaeniae (from a lutjanid host), suggested that Euryhaliotrematoides was monophyletic, with Euryhaliotrema (represented by E. chrysotaeniae) serving as sister group of Euryhaliotrematoides + Aliatrema (see their fig. 2B). On the other hand, their analysis using $18 \mathrm{~S}$ rDNA sequences showed Euryhaliotrematoides to be polyphyletic (see fig. 2A in Plaisance et al. 2005). Wu et al. (2006) found Euryhaliotrema johni, Haliotrema spirotubiforum and Euryhaliotrema sp. ZHDDb (all parasites of lutjanids) to form a "monophyletic" clade in their analysis of rDNA and, as a result, transferred $H$. spirotubiforum, a species lacking an accessory piece and having a funnel-shaped base of the MCO, to Euryhaliotrema. Later, Wu et al. (2007), using sequences from fifteen dactylogyrid species herein assigned to Euryhaliotrema (sensu lato), suggested that the species infesting chaetodontid, lutjanid and sparid hosts represented a major clade (their lineage 2). While their analysis suggested a monophyletic Euryhaliotrematoides, which included 7 species infesting chaetodontids and 1 from a lutjanid, it did not provide support for the monophyly of either Euryhaliotrema or Aliatrema (Wu et al. 2007). Finally, KRITSKY et al. (2009a) suggested a monophyletic Euryhaliotrematoides comprising only four species from chaetodontid hosts but failed to justify Euryhaliotrema, while DANG et al. (2010), using sequences available in GenBank, indicated that Aliatrema and Euryhaliotrematoides were monophyletic within a clade containing a paraphyletic Euryhaliotrema and two species of Haliotrema Johnston \& Tiegs, 1922.

A common relationship that emerged from all of the studies employing molecular data, however, was a major clade comprising the species of all three genera, suggesting that Euryhaliotrema, Euryhaliotrematoides and Aliatrema together com- prised a monophyletic taxon. These findings further support the proposed synonymies of the three genera, with Euryhaliotrema having priority.

The phylogenetic analyses of Wu et al. (2007) and KRITSKY et al. (2009a) suggested that two species of Haliotrema from a non-lutjanid or chaetodontid host should be transferred to Euryhaliotrema. In these studies, H. eukurodai Zhang, Ding, Lin \& Yu, 1994 and H. kurodai Ogawa \& Egusa, 1978, both from Sparus macrocephalus (Basilewsky) (now Acanthopagrus s. schlegelii), Sparidae, fell within respective clades of species herein assigned to Euryhaliotrema. Haliotrema eukurodai and $H$. kurodai lack an accessory piece in the MCO and otherwise possess all features of Euryhaliotrema as defined herein (see also OgaWA \& EgUSA 1978, ZHANG et al. 1994). These features were verified for H. kurodai through examination of 10 voucher specimens collected from A. s. schlegelii in the South China Sea (USNPC 105466) by Dr. Yang Tingbao. Thus, the two species are transferred to Euryhaliotrema as E. eukurodai (Zhang, Ding, Lin \& Yu, 1994) comb. nov. and E. kurodai (Ogawa \& Egusa, 1978) comb. nov., respectively.

Haliotrema monoporosum Pan \& Zhang, 2000 was described in PAN (2000) from Chaetodon wiebeli (Chaetodontidae) collected off Wanning, Hainan Island (South China Sea), China, and characterized in part by possessing a perforation through a "swelling" near the midregion of the ventral bar. Plaisance \& KRITSKY (2004) suggested that the species was probably valid, that it was differentiated from the similar Euryhaliotrematoides grandis (now Euryhaliotrema grandis) by the perforated ventral bar, and although a transfer was not made, that the species probably belonged to Euryhaliotrematoides. Examination of 19 voucher specimens (USNPC 105461) obtained from the gills of Chaetodon ornatissimus collected off Moorea, French Polynesia, by L. Plaisance and colleagues for their studies on the Monogenoidea of chaetodontid fishes, revealed that the species possessed the morphological features required to place it in Euryhaliotrema as revised herein. Thus, it is transferred as Euryhaliotrema monoporosum (PAN \& ZHANG 2000) comb. nov. Chaetodon ornatissimus represents a new host record for the species.

Two other dactylogyrid species, previously described from lutjanid or chaetodontid hosts, are herein considered species inquirendae. The original descriptions of both Protancyrocephalus rangusi Gupta \& Khanna, 1974 from the gills of Lutjanus rangus (Cuvier) (now L. bohar), Lutjanidae, off Port Blair (Andaman and Nicobar islands), India, and Daitreosoma chaetodontis Reichenbach-Klinke, 1959 from the gills of Chaetodon collare, Chaetodontidae, imported into Germany in 1958 are inadequate for species identification and appropriate generic placement. Attempts to locate type specimens of both species failed and it is presumed that they have been lost or destroyed (S. Klimpel and N. Agrawal, personal communications).

The assignment of the species from $C$. collare to Daitreosoma Johnston \& Tiegs, 1922 by ReichenbaCH-KLINKE (1959) is clearly erroneous. Daitreosoma is a subjective synonym 
of Protogyrodactylus Johnston \& Tiegs, 1922, which is characterized in part by species having an accessory sclerite associated with the tip of the superficial root of the ventral anchor (see Galli \& KRITSKy 2008). Reichenbach-KLINKE's (1959) illustration clearly shows that an accessory sclerite is absent in $D$. chaetodontis. Although GupTA \& Khanna (1974) indicate that haptoral bars are absent in $P$. rangusi, the original drawings are so incomplete and diagrammatic that assignment of the species to Protancyrocephalus Bychowsky, 1957 is also problematical. Based on GupTA \& KHANNA's (1974) description of the species, P. rangusi could just as easily be assigned to Euryhaliotrema, Haliotrematoides or Tetrancistrum Goto \& Kikuchi, 1917, all of which contain species parasitizing lutjanid hosts (KRITsKy et al. 2007, 2009a, nobis). That the type species of Protancyrocephalus, Protancyrocephalus strelkowi Bychowsky, 1957, was described from a member of the Pleuronectidae, a pleuronectiform family unrelated to the Lutjanidae, further suggests that the original assignment of $P$. rangusi to the genus is erroneous.

Because type specimens would be required to establish the validity and taxonomic position of both $D$. chaetodontis and $P$. rangusi and that these specimens have apparently been lost or destroyed, demonstrates the importance of preserving such specimens (including voucher specimens) used in development of published reports in an established museum. Without the original reference material, it is highly unlikely that the status of the two species as species inquirendae will ever change and that they will ever be rediscovered during surveys of parasites of their respective hosts. Indeed, examination of $L$. bohar for the present study did not reveal any dactylogyrid specimens that could be assigned to $P$. rangusi based on the description by Gupta and Khanna (1974). Deposition of voucher specimens in established museums should not only occur for studies dealing with the taxonomy of respective groups but also should be done when species are recorded from various hosts and localities in ecological and phylogenetic studies. For example, the geographic records of Euryhaliotrema species reported in Vignon et al. (2009) for their investigation on ecological affects of alien introductions and those reported by $\mathrm{Wu}$ et al. $(2006,2007)$ for their phylogenetic studies using molecular data, cannot be verified because representative voucher specimens were not preserved.

\section{Euryhaliotrema tubocirrus (Zhukov, 1976) Kritsky \& Boeger, 2002} Figs 1-10

Syn. Haliotrema tubocirrus Zhukov, 1976

Redescription (based on 25 voucher specimens from $L$. campechanus, USNPC 105476, FSBC-I 093790): Body proper fusiform; greatest width usually in posterior trunk at level of testis. Tegument usually smooth, infrequently with transverse ridges or indistinct scales on posterior trunk and peduncle. Cephalic region narrow, with well-developed medial and two bilateral cephalic lobes. Eyespots four, subequal in size; members of respective pairs equidistant; accessory chromatic granules scattered throughout cephalic region. Pharynx subovate. Peduncle tapered posteriorly; haptor subhexagonal, with welldeveloped lateral lobes. Anchors similar; each with moderately developed superficial root, short deep root, slightly arced shaft, elongate point extending past level of tip of superficial root. Ventral bar rod shaped, with wave-like ventral surface imparting a broad W shape; dorsal bar variable, generally broadly $\mathrm{V}$ shaped, with variably developed anteromedial knob and posterior expansion or shield-like process. Hook with uniform shank, upright acute thumb; FH loop about shank length. MCO with bulbous base and coiled tubular shaft having about two and a half counterclockwise rings. Accessory piece multibranched, with one branch enclosing and serving as guide for distal portion of shaft of MCO; articulation process absent. Testis elongate ovate; seminal vesicle pyriform; prostatic reservoir small. Germarium subovate; oviduct, ootype not observed; Mehlis' gland well developed, lying on both sides of anterior end of germarium; uterus delicate, ventral, frequently containing developing egg. Vaginal pore marginal on papilla lying within indentation of lateral surface of anterior trunk; vaginal canal short, extending to pyriform pregermarial seminal receptacle. Vitellaria dense, coextensive with gut; transverse vitelline duct at level of or anterior to seminal receptacle. Egg ovate, with proximal filament.

Type host and locality: Lane snapper, Lutjanus synagris (Linnaeus), Lutjanidae: Campeche Bay (Area Havana).

Source of current specimens: Northern red snapper, Lutjanus campechanus, Lutjanidae (new host record): northern Gulf of Mexico, about $80 \mathrm{~km}$ off the Mississippi Coast $\left(30^{\circ} 05^{\prime} 51.4^{\prime \prime} \mathrm{N}, 88^{\circ} 40^{\prime} 46.2^{\prime \prime} \mathrm{W}\right), 3$ July 2007 and $\left(29^{\circ} 26^{\prime} 33^{\prime \prime} \mathrm{N}\right.$, $\left.88^{\circ} 32^{\prime} 06^{\prime \prime} \mathrm{W}\right), 4$ August 2007; charter-boat landing, Pensacola Beach, Florida, 3 August 2007; Florida Middle Grounds, Gulf of Mexico $\left(28^{\circ} 25^{\prime} \mathrm{N}, 84^{\circ} 12^{\prime} \mathrm{W}\right), 4$-5 May 2009, 6 October 2009. Grey snapper, Lutjanus griseus, Lutjanidae: Rock jetty, Keys Marine Laboratory, Marathon Key (Florida Keys), Florida, 12 July 2003; Florida Middle Grounds, Gulf of Mexico $\left(28^{\circ} 25^{\prime} \mathrm{N}\right.$, $\left.84^{\circ} 12^{\prime} \mathrm{W}\right), 2$ October 2009; Florida Bay, Everglades National Park, Florida $\left(25.143^{\circ} \mathrm{N}, 80.703^{\circ} \mathrm{W}\right), 6-9$ June 2009 . Dog snapper, Lutjanus jocu, Lutjanidae (new host record): Rock jetty, Keys Marine Laboratory, Marathon Key (Florida Keys), Florida $\left(24^{\circ} 42^{\prime} 04^{\prime \prime} \mathrm{N}, 81^{\circ} 07^{\prime} 30^{\prime \prime} \mathrm{W}\right), 12$ July 2003. Lane snapper, Lutjanus synagris, Lutjanidae: charter-boat landing, Pensacola Beach, Florida, 3 August 2007; Florida Middle Grounds, Gulf of Mexico $\left(28^{\circ} 25^{\prime} \mathrm{N}, 84^{\circ} 12^{\prime} \mathrm{W}\right), 11$ May $2009,1-5$ October 2009. Vermilion snapper, Rhomboplites aurorubens, Lutjanidae: charter-boat landing, Pensacola Beach, Florida, 3 August 2007; Florida Middle Grounds, Gulf of Mexico $\left(28^{\circ} 25^{\prime} \mathrm{N}, 84^{\circ} 12^{\prime} \mathrm{W}\right), 6-8$ May 2009, 2 October 2009.

Site of infection: Gills.

Specimens studied: 47 voucher specimens (from $L$. campechanus), USNPC 105475, 105476, 105477, 105478, 105479, 




Figures 1-10. Euryhaliotrema tubocirrus from the northern red snapper, Lutjanus campechanus, in the Gulf of Mexico. 1. Whole mount (composite, ventral view). 2. Ventral bar. 3, 4, 5. Dorsal bars. 6. Copulatory complex (dorsal view). 7. Vagina and distal seminal receptacle. 8. Ventral anchor. 9. Hook. 10. Dorsal anchor. All figures are to the $25 \mu \mathrm{m}$ scale except Fig. 1 (200 $\mu \mathrm{m}$ scale).

FSBC-I 093790, 093791; 26 voucher specimens (from L. griseus), USNPC 105474, 105480, 105481, FSBC-I 093792; 6 voucher specimens (from L. jocu), USNPC 105470; 43 voucher specimens (from L. synagris), USNPC 91431, 105467, 105468, 105469, FSBC-I
093788; 16 voucher specimens (from $R$. aurorubens), USNPC 105471, 105472, 105473, FSBC-I 093789.

Previous records: Lutjanus analis: Campeche Bay (Area Havana) (as Haliotrema tubocirrus) (ZhUкоv 1976); Puerto Rico 
(as Euryhaliotrema tubocirrus) (Bosques RodRíguez 2004). Lutjanus apodus: Campeche Bay (Area Havana) (as Haliotrema tubocirrus) (Zhuкоv 1976). Lutjanus buccanella: Puerto Rico (as Euryhaliotrema tubocirrus) (Bosques Rodríguez 2004). Lutjanus cyanopterus: Campeche Bay (Area Havana) (as Haliotrema tubocirrus) (Zнuкоv 1976). Lutjanus griseus: Puerto Rico (as Euryhaliotrema tubocirrus) (Bosques Rodríguez 2004). Lutjanus mahogoni: Puerto Rico (as Euryhaliotrema tubocirrus) (Bosques Rodríguez 2004). Lutjanus synagris: Campeche Bay (Area Havana) (as Haliotrema tubocirrus) (Zhukov 1976); Puerto Rico (as Euryhaliotrema tubocirrus) (Bosques RodríguEz 2004). Lutjanus vivanus: Puerto Rico (as Euryhaliotrema tubocirrus) (Bosques Rodríguez 2004). Rhomboplites aurorubens: Campeche Bay (Area Havana) (as Haliotrema tubocirrus) (Zhukov 1976).

Measurements: Table II.
Remarks: This species was originally described as Haliotrema tubocirrus from the gills of Lutjanus synagris (type species), L. analis, L. apodus, L. cyanopterus and Rhomboplites aurorubens from the environs of Havana, Cuba by Zнuкоv (1976). Three other lutjanid species from Puerto Rico, L. vivanus, $L$. griseus and L. buccanella, were recorded as new hosts for the parasite by Bosques Rodríguez (2004), who regarded E. tubocirrus to be the least host specific of the dactylogyrid species infesting lutjanids in the region. Two additional hosts, L. campechanus and $L$. jocu, were recorded for the parasite during the present survey, which would appear to support the hypothesis of BosQues Rodríguez (2004).

Kritsky \& Boeger (2002) transferred this species to Euryhaliotrema based on the description and drawings provided in the original description by Zникоv (1976). Euryhaliotrema

Table II. Measurements of Euryhaliotrema tubocirrus from four species of Lutjanus and Rhomboplites aurorubens.

\begin{tabular}{|c|c|c|c|c|c|}
\hline & L. campechanus & L. griseus & L. jocu & L. synagris & R. aurorubens \\
\hline \multicolumn{6}{|l|}{ Body } \\
\hline Length & $584(499-724 ; n=14)$ & $519(431-710 ; \mathrm{n}=9)$ & $425-426(n=1)$ & $485(427-507 ; \mathrm{n}=5)$ & $490(429-516 ; n=4)$ \\
\hline Width $^{1}$ & $98(84-119 ; n=14)$ & $86(76-94 ; n=9)$ & $67-68(n=1)$ & $111(96-134 ; \mathrm{n}=5)$ & $110(94-124 ; n=4)$ \\
\hline \multicolumn{6}{|l|}{ Haptor } \\
\hline Length & $59(48-68 ; n=15)$ & $54(45-61 ; \mathrm{n}=9)$ & $60-61(n=1)$ & $58(46-68 ; n=5)$ & $64(57-75 ; n=4)$ \\
\hline Width & $79(65-87 ; n=14)$ & $71(48-83 ; n=9)$ & $53-54(n=1)$ & $78(67-85 ; n=5)$ & $87(70-97 ; \mathrm{n}=4)$ \\
\hline \multicolumn{6}{|l|}{ Pharynx } \\
\hline Width & $32(29-36 ; n=14)$ & $27(25-30 ; n=9)$ & $30-31(n=1)$ & $28(25-31 ; n=4)$ & $33(30-40 ; n=4)$ \\
\hline \multicolumn{6}{|l|}{$\mathrm{MCO}$} \\
\hline Ring diameter & $30(25-33 ; n=8)$ & $30(25-32 ; n=13)$ & $29(26-30 ; n=5)$ & $29(23-33 ; n=26)$ & $28(23-31 ; \mathrm{n}=12)$ \\
\hline \multicolumn{6}{|l|}{ Testis } \\
\hline Length & $56(47-68 ; n=10)$ & $42(36-48 ; n=5)$ & - & $44(43-45 ; n=2)$ & - \\
\hline Width & $23(16-29 ; \mathrm{n}=10)$ & $22(20-28 ; \mathrm{n}=5)$ & - & $24(23-25 ; n=2)$ & - \\
\hline \multicolumn{6}{|l|}{ Germarium } \\
\hline Length & $44(31-60 ; n=10)$ & $46(29-72 ; n=6)$ & - & $56(37-79 ; \mathrm{n}=3)$ & $43-44(n=1)$ \\
\hline Width & $24(17-33 ; n=10)$ & $24(20-29 ; n=6)$ & - & $28(23-31 ; \mathrm{n}=3)$ & $26-27(n=1)$ \\
\hline \multicolumn{6}{|l|}{ Ventral anchor } \\
\hline Length & $32(30-35 ; \mathrm{n}=9)$ & $31(28-35 ; n=13)$ & $29(27-32 ; \mathrm{n}=5)$ & $31(29-34 ; n=22)$ & $32(28-33 ; n=12)$ \\
\hline \multicolumn{6}{|l|}{ Dorsal anchor } \\
\hline Length & $34(33-36 ; \mathrm{n}=9)$ & $31(27-36 ; n=13)$ & $30(28-32 ; \mathrm{n}=5)$ & $33(30-35 ; \mathrm{n}=23)$ & $32(29-35 ; \mathrm{n}=12)$ \\
\hline \multicolumn{6}{|l|}{ Ventral bar } \\
\hline Length & $43(42-44 ; n=9)$ & $41(35-45 ; n=12)$ & $39(37-41 ; n=4)$ & $42(38-45 ; n=17)$ & $40(35-42 ; \mathrm{n}=10)$ \\
\hline \multicolumn{6}{|l|}{ Dorsal bar } \\
\hline Length & $32(30-35 ; \mathrm{n}=9)$ & $32(30-38 ; n=12)$ & $31(29-33 ; n=4)$ & $33(29-35 ; \mathrm{n}=19)$ & $34(32-38 ; n=11)$ \\
\hline \multicolumn{6}{|l|}{ Hook } \\
\hline Length & $15(14-16 ; n=14)$ & $15(14-16 ; n=27)$ & $15(14-17 ; \mathrm{n}=10)$ & $15(13-16 ; n=33)$ & $15(14-16 ; n=20)$ \\
\hline \multicolumn{6}{|l|}{ Egg } \\
\hline Length & $61(57-65 ; \mathrm{n}=2)$ & - & - & - & - \\
\hline Width & $50(46-54 ; \mathrm{n}=2)$ & - & - & - & - \\
\hline
\end{tabular}

${ }^{1}$ Excluding haptor. 
tubocirrus most closely resembles E. torquecirrus in the comparative morphology of the haptoral sclerites but is differentiated from the latter species by having two complete rings in the MCO (three or more complete rings in E. torquecirrus) and by possessing an accessory piece having a subequal length and width (accessory piece longer than wide in E. torquecirrus).

\section{Euryhaliotrema fastigatum (Zhukov, 1976) Kritsky \& Boeger, 2002}

\section{Figs 11-17}

Syns Haliotrema fastigatum Zhukov, 1976; Euryhaliotrema griseus Fuentes Zambrano \& Silva Rojas, 2006

Redescription (based on 19 voucher specimens from $L$. griseus, USNPC 105482, 105483): Body proper fusiform; greatest width in posterior trunk at level of gonads. Tegument smooth. Cephalic region broad; cephalic lobes moderately developed. Usually two pairs of eyespots; members of posterior pair with lens usually visible, larger, closer together than members of anterior pair; accessory chromatic granules uncommon in cephalic, anterior trunk regions. Pharynx spherical. Peduncle broad, tapered posteriorly; haptor subhexagonal, with well-developed lateral lobes. Ventral anchor with elongate slightly depressed tip of superficial root, small knob-like deep root, short heavy shaft, elongate point extending past level of tip of superficial root; shaft and point with longitudinal superficial grooves. Dorsal anchor thinned and frequently bent at union of base and shaft, with elongate superficial root, inconspicuous deep root, evenly curved shaft and elongate point; shaft and point with longitudinal superficial grooves; point extending past level of tip of superficial root. Bars similar, straight rods with expanded ends; ventral bar with small posteromedial projection usually visible. Hook with uniform shank, upright acute thumb; FH loop nearly shank length. MCO with bulbous base and coiled, delicate, tubular shaft having slightly more than two counterclockwise rings. Accessory piece comprising variable sheath along distal shaft of MCO; articulation process absent. Gonads slightly overlapping. Testis ovate; vas deferens looping left intestinal cecum anterior to germarium; seminal vesicle pyriform; small prostatic reservoir lying posterior to base of MCO. Germarium pyriform; oviduct, ootype not observed; Mehlis' gland well developed anterior to germarium; uterus delicate, ventral; vaginal pore marginal; vaginal canal delicate, with small distal funnel, extending to pregermarial seminal receptacle. Vitellaria dense, coextensive with gut; transverse vitelline duct anterior to seminal receptacle. Egg not observed.

Type host and locality: Schoolmaster snapper, Lutjanus apodus (Walbaum), Lutjanidae: Gulf of Mexico (Area Havana).

Source of current specimens: Grey snapper, Lutjanus griseus, Lutjanidae: Rock jetty, Keys Marine Laboratory, Marathon Key (Florida Keys), Florida $\left(24^{\circ} 42^{\prime} 04^{\prime \prime} \mathrm{N}, 81^{\circ} 07^{\prime} 30^{\prime \prime} \mathrm{W}\right), 12$ July 2003; Gulf of Mexico, $80 \mathrm{~km}$ off Mississippi coast $\left(30^{\circ} 05^{\prime} 51^{\prime \prime} \mathrm{N}, 88^{\circ} 40^{\prime} 46^{\prime \prime} \mathrm{W}\right), 3$ July 2007; Florida Bay, Everglades
National Park, Florida $\left(25.143^{\circ} \mathrm{N}, 80.703^{\circ} \mathrm{W}\right), 6-9$ June 2009. Schoolmaster snapper, Lutjanus apodus, Lutjanidae: Rock jetty, Keys Marine Laboratory, Marathon Key (Florida Keys), Florida $\left(24^{\circ} 42^{\prime} 04^{\prime \prime} \mathrm{N}, 81^{\circ} 07^{\prime} 30^{\prime \prime} \mathrm{W}\right), 12$ July 2003. Dog snapper, Lutjanus jocu, Lutjanidae: Rock jetty, Keys Marine Laboratory, Marathon Key (Florida Keys), Florida $\left(24^{\circ} 42^{\prime} 04^{\prime \prime N}, 81^{\circ} 07^{\prime} 30^{\prime \prime} \mathrm{W}\right), 12$ July 2003. Yellow snapper, Lutjanus argentiventris, Lutjanidae (new host record): off Taboga Island, Panama $\left(8^{\circ} 49^{\prime} \mathrm{N}, 79^{\circ} 34^{\prime} \mathrm{W}\right), 24$ May 2007; Perlas Archipelago, Panama $\left(8^{\circ} 22^{\prime} \mathrm{N}, 79^{\circ} 01^{\prime} \mathrm{W}\right), 24$ May 2007; Isla Saboga, Panama $\left(8^{\circ} 38^{\prime} \mathrm{N}, 79^{\circ} 04^{\prime} \mathrm{W}\right)$; Isla Tabugilla, Panama $\left(8^{\circ} 48^{\prime} \mathrm{N}, 79^{\circ} 31^{\prime} \mathrm{W}\right)$.

Site of infection: Gills.

Specimens studied: 34 voucher specimens (from $L$. griseus), USNPC 105482, 105483, 105484, FSBC-I 093793; 3 voucher specimens (from L. apodus), USNPC 105486; 17 voucher specimens (from $L$. jocu), USNPC 105490; 28 voucher specimens (from L. argentiventris), USNPC 105485, 105487, 105488, 105489. 105491.

Previous records: Lutjanus analis: Puerto Rico (as Euryhaliotrema fastigatum) (Bosques Rodríguez 2004). Lutjanus apodus: Gulf of Mexico (Area Havana) (as Haliotrema fastigatum) (Zhuкоv 1976). Lutjanus jocu: Gulf of Mexico (Area Havana) (as Haliotrema fastigatum) (Zhuкоv 1976); Puerto Rico (as Euryhaliotrema fastigatum) (BosQUEs Rodríguez 2004). Lutjanus griseus: Puerto Rico (as Euryhaliotrema fastigatum) (BosQues Rodríguez 2004); Laguna de la Restinga, Isla de Margarita, Venezuela (as Euryhaliotrema sp. and E. griseus, respectively) (FuENTES Zambrano et al. 2003, Fuentes Zambrano \& Silva Rojas 2006).

Measurements: Table III.

Remarks: Euryhaliotrema fastigatum was originally described from the gills of grey snapper from the southern Gulf of Mexico near Havana, Cuba, by Zhuкov (1976), who also reported it from Lutjanus apodus, L. jocu and L. analis. During the present survey, morphological distinctions between specimens of E. fastigatum collected from grey snapper and the yellow snapper, $L$. argentiventris, were not evident. Nonetheless, the identification of those from L. argentiventris as E. fastigatum was considered provisional. Specimens of the yellow snapper were obtained from the eastern Pacific off Panama and it is unlikely that conspecific specimens of a species of Euryhaliotrema would naturally occur on opposite sides of North America, areas that have been isolated since the uprising of the Panamanian Isthmus about 3.2 mya. The possibility exists that the eastern Pacific populations of the helminth represent a cryptic sisterspecies of $E$. fastigatum occurring on the Atlantic side of North America. That the populations occurring in the Gulf of Mexico and eastern Pacific Ocean probably represent separate species is supported by evidence that the host fishes have speciated following the Panamanian uprising and that geminate species pairs in other monogenoidean groups apparently occur along the Pacific and Atlantic sides of North America (KRITSKY \& Mendoza-Franco 2008, Kritsky et al. 2009b, Mendoza-Franco et al. 2009, Kritsky 2012). Assignment of a new species name to 


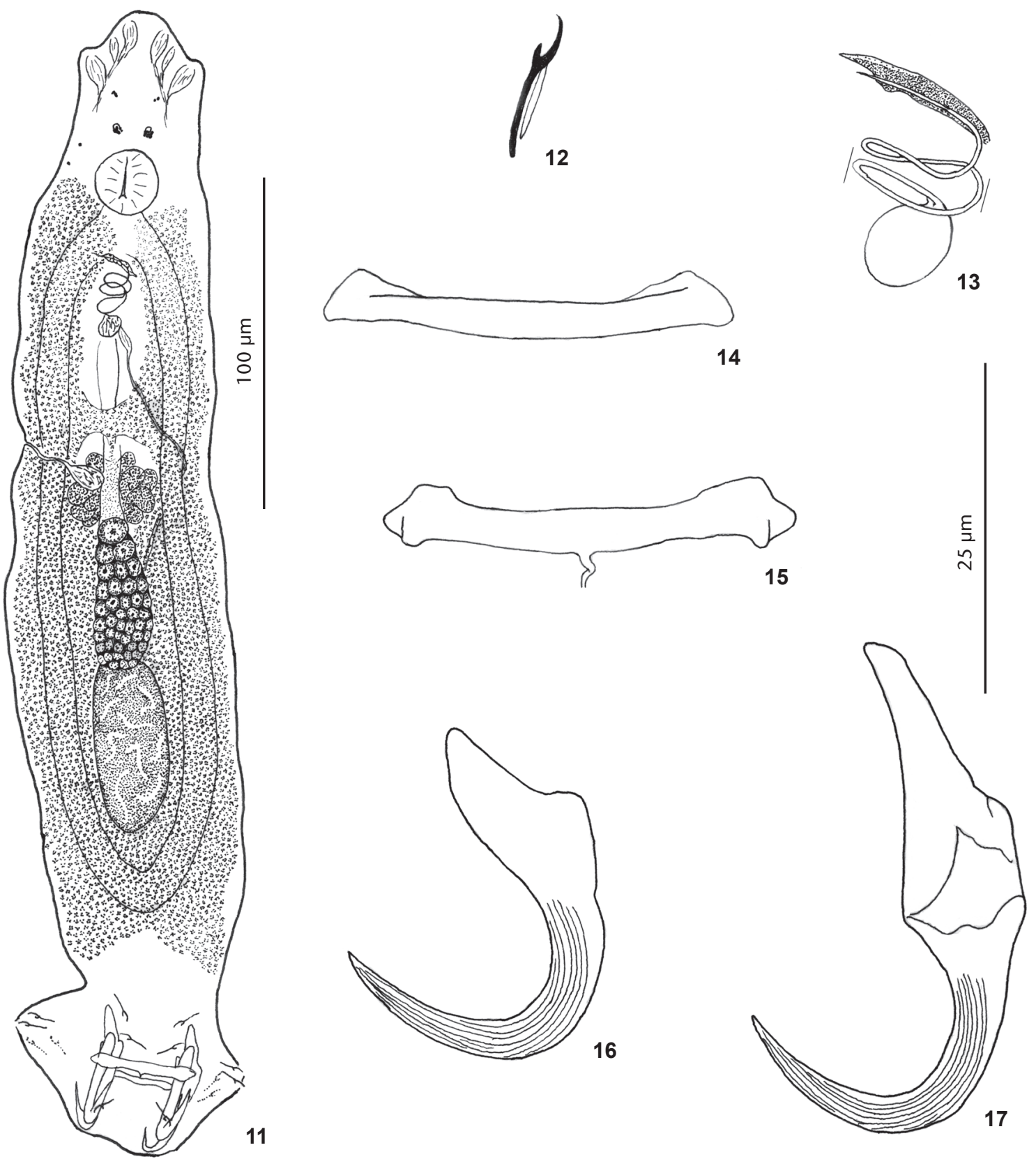

Figures 11-17. Euryhaliotrema fastigatum from the grey snapper, Lutjanus griseus, in the Gulf of Mexico. 11. Whole mount (composite, ventral view). 12. Hook. 13. Copulatory complex (ventral view). 14. Dorsal bar. 15. Ventral bar. 16. Ventral anchor. 17. Dorsal anchor. All figures are to the $25 \mu \mathrm{m}$ scale except Fig. 11 (100 $\mu \mathrm{m}$ scale).

the Pacific counterpart is not made at this time in order to minimize possible unnecessary synonyms.

Euryhaliotrema fastigatum resembles a number of congenerics, including E. cardinale, E. cognatus, E. diplops and E. tormocleithrum, by having a thinning of the base of the dorsal anchor near its junction with the anchor shaft. It most closely resembles E. diplops by having longitudinal grooves along the surfaces of the anchor points and shafts but differs from this and other similar species by lacking an articulation process in the copulatory complex.

Fuentes Zambrano \& Silva Rojas (2006) described Euryhaliotrema griseus from the grey snapper, L. griseus, off Venezuela. 
Table III. Measurements of Euryhaliotrema fastigatum from four species of Lutjanus.

\begin{tabular}{|c|c|c|c|c|}
\hline & L. griseus & L. apodus & L. jocu & L. argentiventris \\
\hline \multicolumn{5}{|l|}{ Body } \\
\hline Length & $310(260-358 ; \mathrm{n}=8)$ & $274(273-275 ; \mathrm{n}=2)$ & $303(287-328 ; n=6)$ & $270(222-294 ; \mathrm{n}=7)$ \\
\hline Width ${ }^{1}$ & $60(44-71 ; n=10)$ & $48(41-55 ; n=2)$ & $60(50-69 ; \mathrm{n}=6)$ & $55(47-64 ; \mathrm{n}=8)$ \\
\hline \multicolumn{5}{|l|}{ Haptor } \\
\hline Length & $53(42-60 ; n=11)$ & $54(50-57 ; \mathrm{n}=2)$ & $55(47-64 ; \mathrm{n}=8)$ & $50(44-57 ; \mathrm{n}=7)$ \\
\hline Width & $68(57-79 ; n=10)$ & $66(54-78 ; n=2)$ & $69(57-79 ; n=5)$ & $70(61-79 ; \mathrm{n}=8)$ \\
\hline \multicolumn{5}{|l|}{ Pharynx } \\
\hline Width & $20(17-27 ; \mathrm{n}=9)$ & $19(17-21 ; n=2)$ & $20(19-21 ; n=7)$ & $19(16-21 ; n=7)$ \\
\hline \multicolumn{5}{|l|}{$\mathrm{MCO}$} \\
\hline Ring diameter & $12(10-14 ; \mathrm{n}=10)$ & $12(11-13 ; n=2)$ & $12(10-14 ; n=7)$ & $14(12-17 ; n=13)$ \\
\hline \multicolumn{5}{|l|}{ Testis } \\
\hline Length & $60(45-69 ; n=8)$ & - & $58(47-77 ; \mathrm{n}=3)$ & $36(27-44 ; n=6)$ \\
\hline Width & $21(15-25 ; \mathrm{n}=8)$ & - & $21(20-23 ; n=3)$ & $20(15-23 ; n=6)$ \\
\hline \multicolumn{5}{|l|}{ Germarium } \\
\hline Length & $37(30-42 ; \mathrm{n}=5)$ & - & $45(33-57 ; n=4)$ & $36(28-48 ; n=4)$ \\
\hline Width & $17(14-20 ; n=5)$ & - & $22(21-25 ; n=4)$ & $18(16-20 ; n=4)$ \\
\hline \multicolumn{5}{|l|}{ Ventral anchor } \\
\hline Length & $29(25-32 ; n=17)$ & $29(28-30 ; n=2)$ & $29(27-31 ; n=7)$ & $27(24-30 ; n=15)$ \\
\hline \multicolumn{5}{|l|}{ Dorsal anchor } \\
\hline Length & $40(35-44 ; n=15)$ & $39(37-41 ; n=2)$ & $40(36-43 ; n=8)$ & $39(36-42 ; n=13)$ \\
\hline \multicolumn{5}{|l|}{ Ventral bar } \\
\hline Length & $34(27-38 ; n=16)$ & $35(34-37 ; \mathrm{n}=2)$ & $34(28-36 ; n=8)$ & $35(33-38 ; n=13)$ \\
\hline \multicolumn{5}{|l|}{ Dorsal bar } \\
\hline Length & $35(28-39 ; n=15)$ & $34-35(n=1)$ & $35(33-38 ; \mathrm{n}=7)$ & $36(33-39 ; n=14)$ \\
\hline \multicolumn{5}{|l|}{ Hook } \\
\hline Length & $13(12-15 ; \mathrm{n}=38)$ & $13-14(n=4)$ & $13-14(n=15)$ & $14(13-15 ; \mathrm{n}=25)$ \\
\hline
\end{tabular}

${ }^{1}$ Excluding haptor.

This species is considered a junior subjective synonym of $E$. fastigatum based on their mutual host and likeness of the original drawings of E. griseus and those of E. fastigatum.

\section{Euryhaliotrema paracanthi (Zhukov, 1976) Kritsky \& Boeger, 2002 \\ Figs 18-23}

Syn. Haliotrema paracanthi Zhukov, 1976

Redescription (based on 10 voucher specimens from $L$. jocu): Body proper fusiform to pyriform; greatest width in posterior trunk. Tegument smooth. Cephalic region broad; cephalic lobes poorly developed. Eyespots usually absent or poorly developed; accessory chromatic granules sparsely scattered in cephalic, anterior trunk regions. Pharynx spherical. Peduncle broad; haptor subhexagonal, usually longitudinally shortened. Anchors similar; each with elongate superficial root, prominent deep root, curved shaft, moderately long point extending just past level of tip of superficial root; superficial root of dorsal anchor delicate, somewhat depressed. Ventral bar an elongate rod generally of uniform diameter, appearing as a broad $\mathrm{V}$ or W shape. Dorsal bar rod shaped, with slight submedial twists. Hook with uniform shank, upright acute thumb; FH loop about shank length. Genital pore with heavy muscular margins. MCO with bulbous base and coiled tubular shaft of about two counterclockwise rings. Accessory piece comprising sheath along distal shaft of MCO, with proximal flattened flange, subterminal hook or spine; articulation process absent. Gonads slightly overlapping. Testis elongate ovate; seminal vesicle a fusiform dilation of vas deferens; single pyriform prostatic reservoir lying posterior to base of MCO. Germarium subspherical to ovate; oviduct, ootype not observed; uterus delicate, ventral; vaginal pore marginal; distal vaginal vestibule with internal finger-like protuberance issuing from proximal wall; vaginal canal a sigmoid tube extending to large medioventral seminal receptacle. Vitellaria dense, coextensive with gut; transverse vitelline duct 

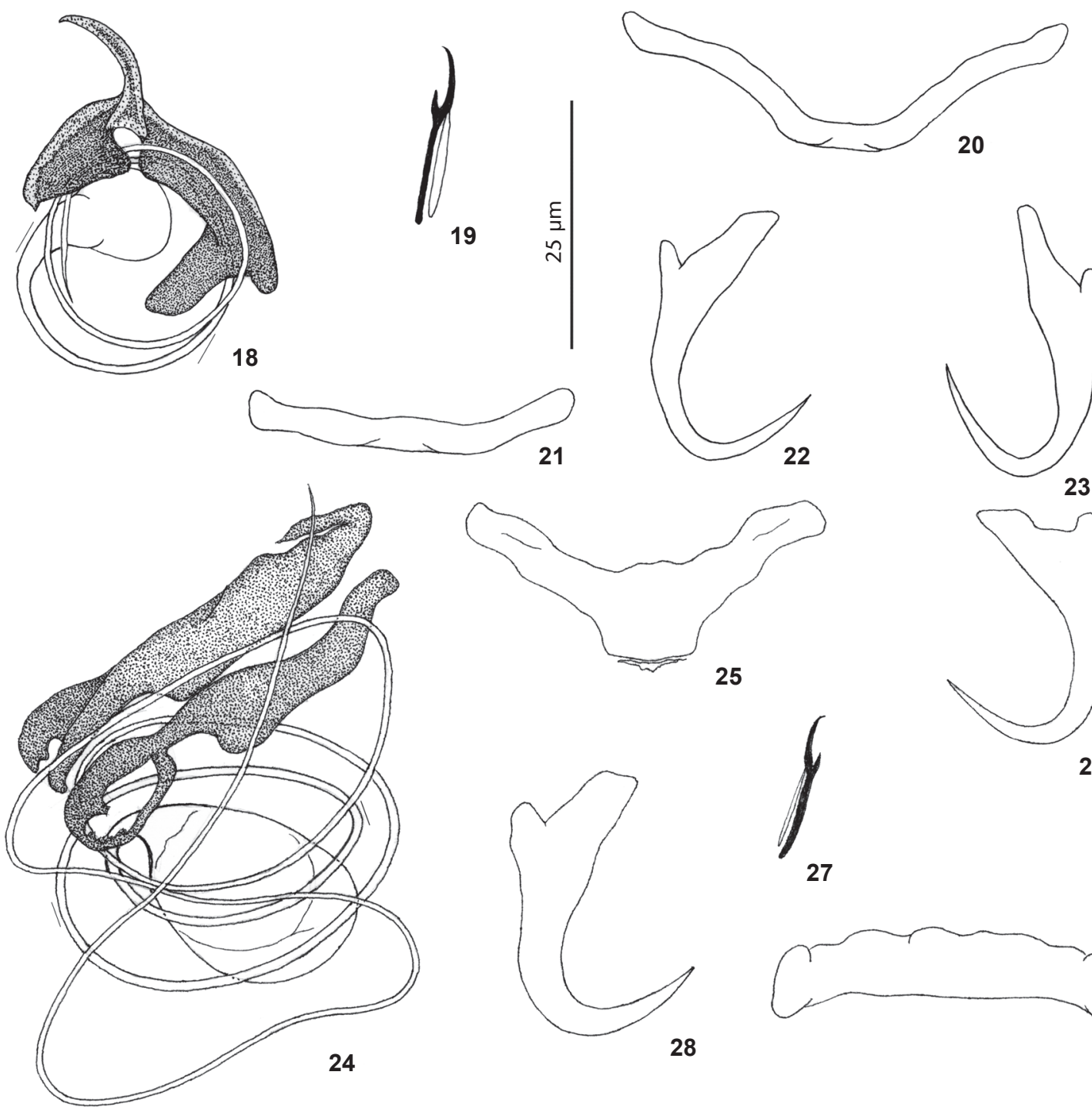

Figures 18-29. Haptoral and copulatory sclerites of two species of Euryhaliotrema from snappers in the western hemisphere. 18-23. Euryhaliotrema paracanthi from the dog snapper, Lutjanus jocu, from the Gulf of Mexico. 18. Copulatory complex (ventral view). 19. Hook. 20. Ventral bar. 21. Dorsal bar. 22. Ventral anchor. 23. Dorsal anchor. 24-29. Euryhaliotrema torquecirrus from the yellowtail snapper, Ocyurus chrysurus, from the Gulf of Mexico. 24. Copulatory complex (ventral view). 25. Dorsal bar. 26. Dorsal anchor. 27. Hook. 28. Ventral anchor. 29. Ventral bar. All figures are to the $25 \mu \mathrm{m}$ scale.

at level of or slightly posterior to seminal receptacle. Egg not observed.

Type host and locality: Schoolmaster snapper, Lutjanus apodus (Walbaum), Lutjanidae: Gulf of Mexico (Area Havana).

Source of current specimens: Grey snapper, Lutjanus griseus, Lutjanidae (new host record): Florida Bay, Everglades National Park, Florida $\left(25.143^{\circ} \mathrm{N}, 80.703^{\circ} \mathrm{W}\right), 7$ June 2009. Dog snapper, Lutjanus jocu, Lutjanidae (new host record): Rock jetty, Keys Marine Laboratory, Marathon Key (Florida Keys), Florida $\left(24^{\circ} 42^{\prime} 04^{\prime \prime} \mathrm{N}, 81^{\circ} 07^{\prime} 30^{\prime \prime} \mathrm{W}\right), 12$ July 2003 . Yellow snapper, Lutjanus argentiventris, Lutjanidae (new host record): off Taboga Island, Panama $\left(8^{\circ} 49^{\prime} \mathrm{N}, 79^{\circ} 34^{\prime} \mathrm{W}\right), 24$ May 2007; Perlas Archipelago, Panama $\left(8^{\circ} 22^{\prime} \mathrm{N}, 79^{\circ} 01^{\prime} \mathrm{W}\right), 24$ May 2007.

Site of infection: Gills.

Specimens studied: 3 voucher specimens (from $L$. griseus), USNPC 105492, FSBC-I 093794; 10 voucher specimens (from $L$. jocu), USNPC 105493; 20 voucher specimens (from $L$. argentiventris), USNPC 105494, 105495. 
Previous record: Lutjanus apodus: Gulf of Mexico (Area Havana) (as Haliotrema paracanthi) (Zhukov 1976).

Measurements: Table IV.

Remarks: This species has not been reported since its original description from L. apodus off Havana, Cuba, by Zнuкоv (1976). Although Bosquez Rodríguez (2004) examined 7 specimens of $L$. apodus as well as members of twelve other lutjanid species for helminth parasites, E. paracanthi was not found on these hosts from the marine waters off Puerto Rico. Euryhaliotrema paracanthi is easily differentiated from other species of Euryhaliotrema infesting lutjanid hosts by possessing a subterminal spine or hook on the accessory piece.

The identification of specimens collected from $L$. argentiventris from the eastern Pacific off Panama as E. paracanthi during the present study was considered provisional. Like $E$. fastigatum on this host, the specimens from western Panama may represent a cryptic species that is nearly identical morphologically to E. paracanthi from the Gulf of Mexico. The two species may represent another example of a geminate species pair off North America that developed as a result of the uprising of the Panamanian Isthmus. Assignment of a new species name to the Pacific counterpart is not made at this time in order to minimize possible unnecessary synonyms.

\section{Euryhaliotrema torquecirrus}

\section{(Zhukov, 1976) Kritsky \& Boeger, 2002}

$$
\text { Figs 24-29 }
$$

Syn. Haliotrema torquecirrus Zhukov, 1976

Type host and locality: Yellowtail snapper, Ocyurus chrysurus (Bloch), Lutjanidae: Campeche Bay (Area Havana).

Source of current specimens: Yellowtail snapper, Ocyurus chrysurus, Lutjanidae: open Gulf of Mexico off Florida, 29 April 2008.

Site of infection: Gills.

Specimens studied: 4 voucher specimens (from $O$. chrysurus), USNPC 105496, FSBC-I 093795; 3 voucher specimens from O. chrysurus collected near Havana, Cuba, and identified by E. V. Zhukov, USNPC 91432.

Table IV. Measurements of Euryhaliotrema paracanthi from three species of Lutjanus.

\begin{tabular}{|c|c|c|c|}
\hline & L. jocu & L. argentiventris & L. griseus \\
\hline \multicolumn{4}{|l|}{ Body } \\
\hline Length & $278(234-299 ; n=5)$ & $272(246-287 ; \mathrm{n}=6)$ & - \\
\hline Width $^{1}$ & $62(52-71 ; n=5)$ & $60(48-78 ; n=8)$ & - \\
\hline \multicolumn{4}{|l|}{ Haptor } \\
\hline Length & $42(33-49 ; \mathrm{n}=5)$ & $39(34-45 ; n=6)$ & - \\
\hline Width & $67(48-79 ; n=5)$ & $67(61-81 ; n=6)$ & - \\
\hline \multicolumn{4}{|l|}{ Pharynx } \\
\hline Width & $20(19-21 ; n=2)$ & $19(17-21 ; n=5)$ & - \\
\hline \multicolumn{4}{|l|}{$\mathrm{MCO}$} \\
\hline Ring diameter & $22(20-23 ; n=4)$ & $19(17-23 ; n=7)$ & $22(18-25 ; n=3)$ \\
\hline \multicolumn{4}{|l|}{ Testis } \\
\hline Length & $41-42(n=1)$ & $32-33(n=1)$ & - \\
\hline Width & $18-19(n=1)$ & $16-17(n=1)$ & - \\
\hline \multicolumn{4}{|l|}{ Germarium } \\
\hline Length & $38-39(n=1)$ & $31-32(n=1)$ & - \\
\hline Width & $19-20(n=1)$ & $20-21(n=1)$ & - \\
\hline \multicolumn{4}{|l|}{ Ventral anchor } \\
\hline Length & $24(22-26 ; n=5)$ & $23(22-25 ; \mathrm{n}=7)$ & $24(22-25 ; n=3)$ \\
\hline \multicolumn{4}{|l|}{ Dorsal anchor } \\
\hline Length & $26(25-27 ; n=5)$ & $28(25-30 ; n=7)$ & $26(24-27 ; n=3)$ \\
\hline \multicolumn{4}{|l|}{ Ventral bar } \\
\hline Length & $39(36-40 ; n=5)$ & $41(36-47 ; n=7)$ & $40(36-44 ; n=3)$ \\
\hline \multicolumn{4}{|l|}{ Dorsal bar } \\
\hline Length & $28(26-31 ; n=5)$ & $29(25-32 ; \mathrm{n}=6)$ & $27(23-31 ; n=2)$ \\
\hline \multicolumn{4}{|l|}{ Hook } \\
\hline Length & $15(14-16 ; n=10)$ & $15(14-16 ; n=11)$ & $15(14-16 ; n=6)$ \\
\hline
\end{tabular}

${ }^{1}$ Excluding haptor. 
Previous records: Ocyurus chrysurus: Campeche Bay (Area Havana) (as Haliotrema torquecirrus) (Zhukov 1976); Puerto Rico (as Euryhaliotrema torquecirrus) (Bosques Rodríguez 2004). Lutjanus synagris: Campeche Bay (Area Havana) (as Haliotrema torquecirrus) (Zнuкоv 1976); Puerto Rico (as Euryhaliotrema torquecirrus) (Bosques Rodríguez 2004). Lutjanus griseus: Puerto Rico (as Euryhaliotrema torquecirrus) (Bosques Rodríguez 2004). Lutjanus mahogoni: Puerto Rico (as Euryhaliotrema torquecirrus) (Bosques Rodríguez 2004). Lutjanus analis: Puerto Rico (as Euryhaliotrema torquecirrus) (BosQues Rodríguez 2004).

Measurements: MCO (proximal ring diameter) 29 (26$35 ; \mathrm{n}=4)$. Ventral anchor $25(24-27 ; \mathrm{n}=3)$ long; dorsal anchor $23(22-25 ; \mathrm{n}=3)$ long. Ventral bar 32-33 ( $\mathrm{n}=2)$ long; dorsal bar $34(31-37 ; n=3)$ long. Hook $15(14-16 ; n=5)$ long.

Remarks: Four E. torquecirrus were recovered in association with several Haliotrematoides heteracantha (Zhukov, 1976) Kritsky, Yang \& Sun, 2009 (USNPC 105465, FSBC-I 093787) from the gills of its type host, Ocyurus chrysurus, collected from the open Gulf of Mexico off Florida. The morphology of the haptoral and copulatory sclerites of these specimens corresponded to that originally described for the species by ZHuкоv (1976) and that of available specimens collected by Dr. Zhukov near Havana, Cuba (USNPC 91432). Although satisfactory for specific identification, the specimens were insufficient to provide a needed redescription of the species.

Euryhaliotrema torquecirrus most closely resembles $E$. perezponcei from the spotted rose snapper, L. guttatus, from off the western coast of southern North America and also may be confused with $E$. tubocirrus parasitizing various lutjanids occurring off the eastern coast of the continent. It differs from $E$. perezponcei by lacking a submedial branch on one component of the accessory piece and by having slightly more robust haptoral anchors. It is easily distinguished from $E$. tubocirrus by the comparative morphologies of the respective copulatory complexes. In E. torquecirrus, the coil of the MCO comprises a minimum of three rings (about two rings in E. tubocirrus), and the accessory piece includes two (apparently unarticulated) components (accessory piece of E. tubocirrus with multiple branches). Euryhaliotrema torquecirrus and E. perezponcei apparently represent another example of a geminate species pair occurring off the eastern and western coasts of North America, respectively.

\section{Euryhaliotrema longibaculum (Zhukov, 1976) Kritsky \& Boeger, 2002}

\section{Figs 30-36}

Syn. Haliotrema longibaculum Zhukov, 1976

Redescription: Body proper fusiform to subtriangular, slightly flattened dorsoventrally; greatest width in posterior trunk at level of testis. Tegument smooth. Cephalic region broad; cephalic lobes poorly developed. Four eyespots; members of posterior pair of eyespots slightly larger, closer together than those of anterior pair; accessory chromatic granules un- common in cephalic and anterior trunk regions. Pharynx spherical. Peduncle broad, slightly tapered posteriorly; haptor subrectangular to trapezoidal. Ventral anchor with broad superficial root, small to nonexistent deep root, elongate point extending past level of tip of superficial root; dorsal anchor with elongate straight superficial root, short to nonexistent deep root, delicate elongate point extending past level of tip of superficial root; shaft of both anchors with irregular diameter, angular bend near its midlength. Ventral bar an elongate broadly V-shaped rod, inverted or not. Dorsal bar a straight rod with slight twist near midlength and with expanded ends. Hook with uniform shank, upright acute thumb; FH loop about shank length. MCO a U-shaped tube with funnel-shaped base. Accessory piece comprising variably flattened rod attached to base of MCO by articulation process. Gonads tandem or slightly overlapping (germarium ventral when overlapped). Testis ovate; seminal vesicle an elongate dilation of distal vas deferens; prostatic reservoir small, lying to right and posterior to MCO. Germarium ovate; oviduct, ootype, uterus and Mehlis' gland not observed; vaginal pore marginal; vaginal vestibule with internal sclerotized wall; vaginal canal indistinct along most of its length; seminal receptacle small, lying immediately anterior to germarium. Vitellaria dense, coextensive with gut; transverse vitelline duct anterior to seminal receptacle. Egg not observed.

Type host and locality: Mahogony snapper, Lutjanus mahogoni (Cuvier), Lutjanidae: Campeche Bay (Area Havana).

Source of current specimens: Lane snapper, Lutjanus synagris, Lutjanidae: Florida Middle Grounds, Florida $\left(28^{\circ} 25^{\prime} \mathrm{N}\right.$, $\left.84^{\circ} 12^{\prime} \mathrm{W}\right), 1$ October 2009.

Site of infection: Gills.

Specimens studied: 20 voucher specimens (from $L$. synagris), USNPC 105497, FSBC-I 093796.

Previous records: Lutjanus synagris: Campeche Bay (Area Havana) (as Haliotrema longibaculum) (Zhukov 1976). Lutjanus mahogoni: Campeche Bay (Area Havana) (as Haliotrema longibaculum) (Zhukov 1976).

Measurements: Body $219(191-236 ; \mathrm{n}=8)$ long; greatest width (excluding haptor) $67(55-80 ; n=7)$. Haptor $36(31-44 ; n$ =9) long, $78(71-82 ; \mathrm{n}=7)$ wide. Pharynx $20(18-21 ; \mathrm{n}=7)$ wide. MCO 26 (22-26; n = 7) long. Ventral anchor 28 (26-30; $\mathrm{n}=10)$ long; dorsal anchor $43(40-46 ; n=10)$ long. Ventral bar 31 (29$33 ; \mathrm{n}=8)$ long; dorsal bar $37(32-43 ; \mathrm{n}=9)$ long. Hook 15 (14$16 ; \mathrm{n}=18)$ long. Germarium $33(32-34 ; \mathrm{n}=3)$ long, $16(14-18 ; \mathrm{n}$ = 3) wide; testis $23(20-26 ; \mathrm{n}=5)$ long, $14(11-21 ; \mathrm{n}=5)$ wide.

Remarks: Haliotrema longibaculum was described by Zhukov (1976) from the gills of L. synagris and L. mahogoni from the Gulf of Mexico off Havana, Cuba. The species was transferred to Euryhaliotrema by KRITSKY \& BOEgER (2002) based solely on Zhukov's original description and drawings, the latter of which suggested that the MCO had a bulbous base, at that time, the defining character of Euryhaliotrema. However, specimens of this species collected for the present study indi- 

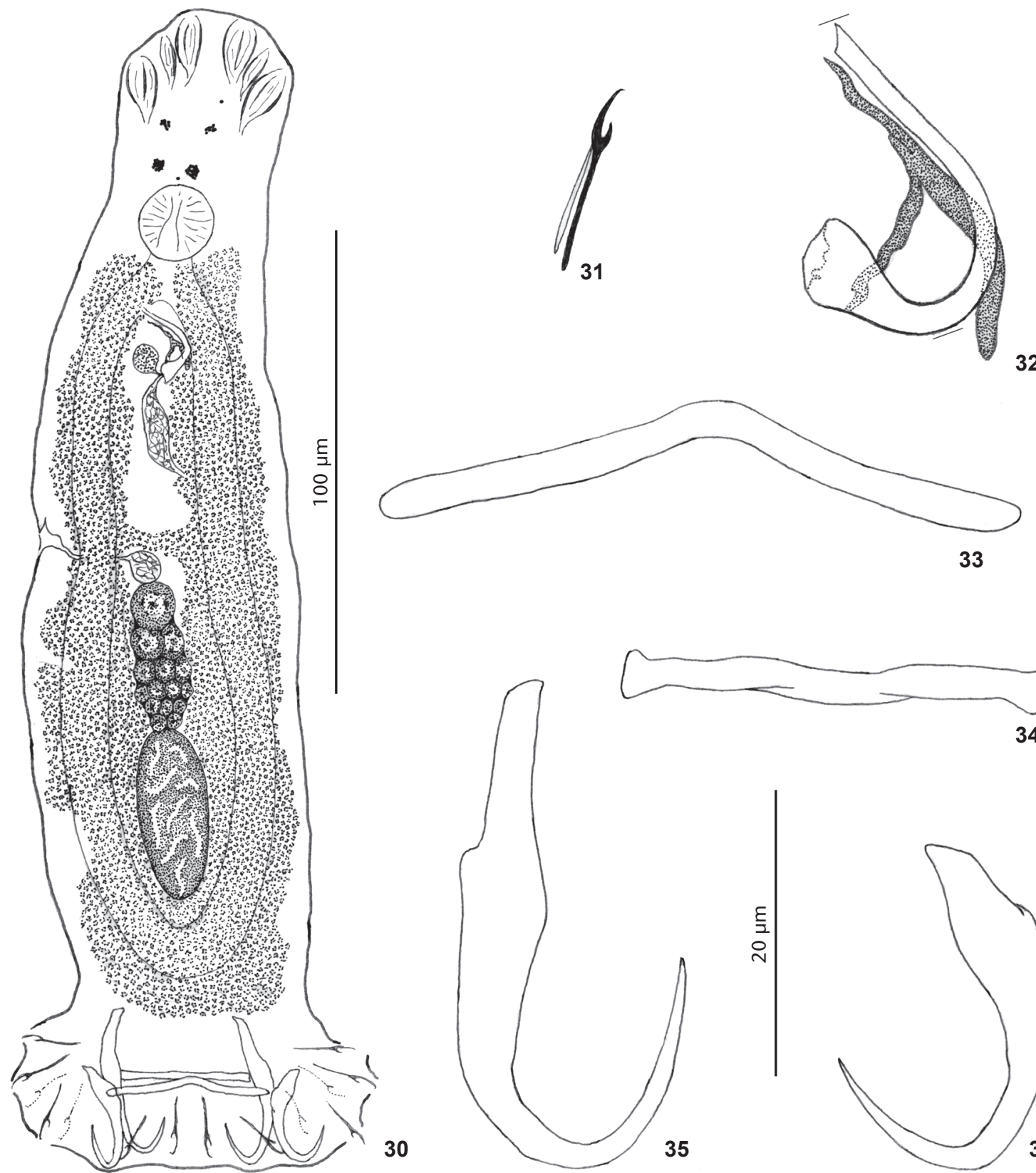

32
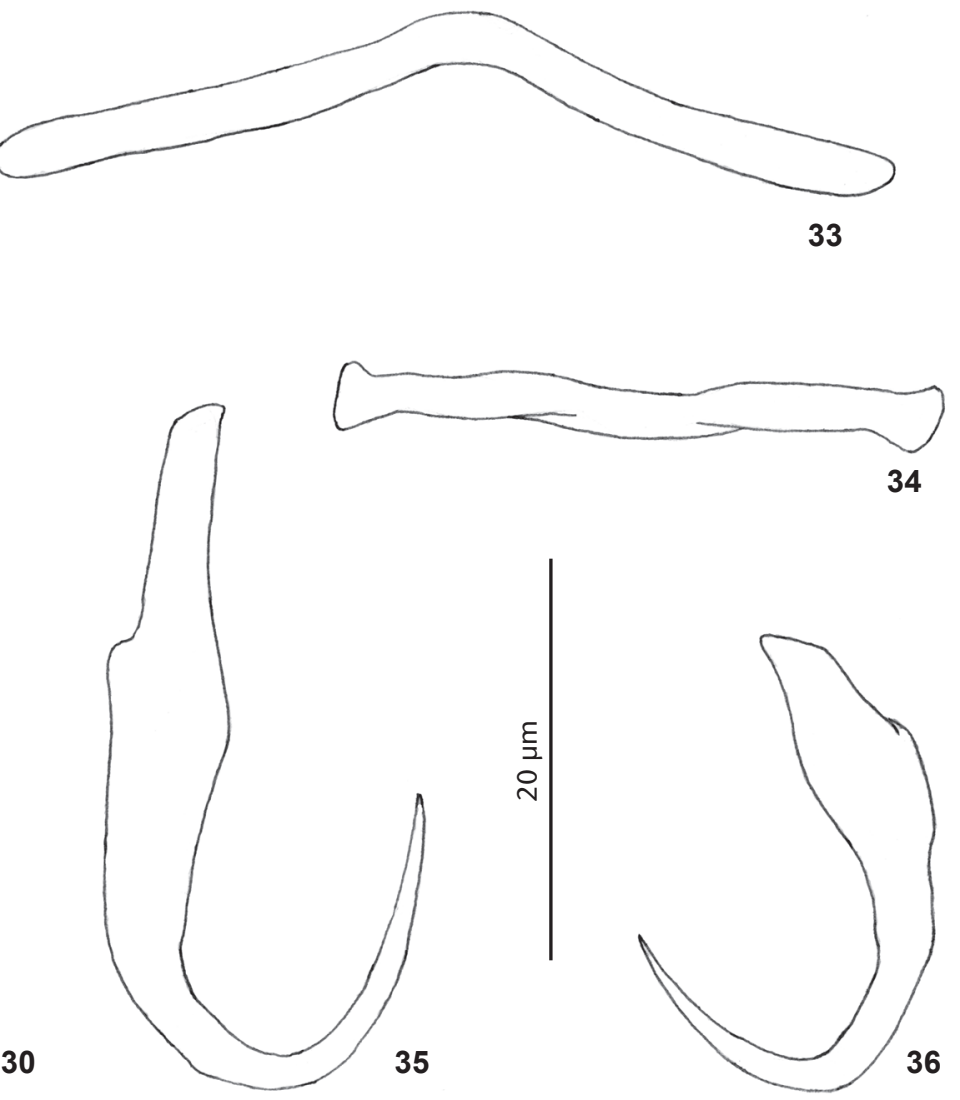

Figures 30-36. Euryhaliotrema longibaculum from the lane snapper, Lutjanus synagris, in the Gulf of Mexico. 30. Whole mount (composite, ventral view). 31. Hook. 32. Copulatory complex (ventral view). 33. Ventral bar. 34. Dorsal bar. 35. Dorsal anchor. 36. Ventral anchor. All figures are to the $20 \mu \mathrm{m}$ scale except Fig. 30 (100 $\mu \mathrm{m}$ scale).

cated that the base of the MCO is funnel shaped with a wide proximal opening, further supporting the present proposal for synonymy of Euryhaliotrema and Euryhaliotrematoides.

Euryhaliotrema longibaculum most closely resembles $E$. fatuum, a parasite of $L$. fulvus and L. fulviflamma from the western Pacific Ocean, by possessing dorsal anchors with an elon- gate superficial root, poorly developed deep root and elongate point extending anteriorly to near the level of the union of the anchor shaft and base. In addition, elongate narrow ventral bars, comparatively straight dorsal bars and similar ventral anchors are common to both species. Euryhaliotrema longibaculum differs from $E$. fatuum by possessing an articula- 
tion process in the copulatory complex connecting the accessory piece to the base of the MCO (articulation process absent, MCO and accessory piece non-articulated in E. fatuum).

The original description of this species (as Haliotrema longibaculum) by Zнuкоv (1976) was based on ten specimens from the lane snapper, L. synagris, while the original figures were made of a specimen obtained from the mahogony snapper, L. mahogoni, both fishes of which were collected off Cuba. Although Zhukov (1976) designated a "type specimen" and deposited it as No. 5505 in the helminth collection of the Zoological Institute, Russian Academy of Sciences, St. Petersburg, Russia, he did not specifically designate or mention the type host when he proposed the species. According to Dr. Pavel Gerasev of the Zoological Institute in St. Petersburg, the host of the holotype (ZIS 5505) was the mahogany snapper, which is therefore considered the type host of the species.

\section{Euryhaliotrema mehen (Soler-Jiménez, García- Gasca \& Fajer-Ávila, 2012) comb. nov.} Figs $37-42$

Syn. Euryhaliotrematoides mehen Soler-Jiménez, García-Gasca \& Fajer-Ávila, 2012

Type host and locality: Spotted rose snapper, Lutjanus guttatus (Steindachner), Lutjanidae: Cerritos, Mazatlán, Sinaloa, Mexico $\left(23^{\circ} 18^{\prime} 44^{\prime \prime} \mathrm{N}, 106^{\circ} 29^{\prime} 37^{\prime \prime} \mathrm{W}\right)$.

Source of current specimens: Spotted rose snapper, Lutjanus guttatus, Lutjanidae: off Taboga Island, Panama $\left(8^{\circ} 49^{\prime} \mathrm{N}, 79^{\circ} 34^{\prime} \mathrm{W}\right), 24$ May 2007; Perlas Archipelago, Panama $\left(8^{\circ} 22^{\prime} \mathrm{N}, 79^{\circ} 01^{\prime} \mathrm{W}\right), 24$ May 2007.

Site of infection: Gills.

Specimens studied: 10 voucher specimens, USNPC 105498, 105499; 4 paratypes of Euryhaliotrematoides mehen, USNPC 104737, 104738, 104739, 104740.

Previous records: Lutjanus guttatus: Cerritos, Mazatlán, Sinaloa, Mexico $\left(23^{\circ} 18^{\prime} 44^{\prime \prime} \mathrm{N}, 106^{\circ} 29^{\prime} 37^{\prime \prime} \mathrm{W}\right)$ (as Euryhaliotrematoides mehen) (Soler-Jiménez et al. 2012); Mazatlan Bay, Sinaloa, Mexico $\left(23^{\circ} 14^{\prime} 29^{\prime \prime} \mathrm{N}, 106^{\circ} 24^{\prime} 35^{\prime \prime} \mathrm{W}\right.$ ) (as Euryhaliotrematoides sp.) (SOler-Jiménez \& Fajer-Ávila 2012).

Measurements: Body 277 (269-286; $\mathrm{n}=3$ ) long; greatest width (excluding haptor) $64(52-73 ; \mathrm{n}=3)$. Haptor 43 (36-51; $\mathrm{n}=3)$ long, $72(60-79 ; \mathrm{n}=3)$ wide. Pharynx 21-22 ( $=3)$ wide. MCO 27 (25-29; $\mathrm{n}=5)$ long. Ventral anchor $34(30-35 ; \mathrm{n}=7)$ long; dorsal anchor $46(43-48 ; \mathrm{n}=7)$ long. Ventral bar 55 (50$60 ; n=7)$ long; dorsal bar $40(37-45 ; n=6)$ long. Hook $16(15-$ $17 ; \mathrm{n}=13)$ long. Germarium 37-38 ( $\mathrm{n}=1)$ long, 20-21 ( $\mathrm{n}=1)$ wide; testis $34(20-38 ; \mathrm{n}=2)$ long, $22(19-25 ; \mathrm{n}=2)$ wide.

Remarks: The specimens assigned to this species and collected from spotted rose snapper off Panama were initially identified as Euryhaliotrema longibaculum. Recently, SOLER-JIMÉNEZ et al. (2012) described Euryhaliotrematoides mehen for specimens collected from spotted rose snapper off the Pacific coast of Mexico. These authors recognized the morphological simila- rity of the two species, stating that $E$. mehen differed from $E$. longibaculum by differences in the morphology of the copulatory complex, anchors and bars. Most significantly, SOLER-JiméneZ et al. (2012) reported the copulatory complex of E. mehen to have a tubular MCO with a thickened fleshy edge of the base and a membranous accessory piece enveloping the distal portion of the MCO like a scarf. However, examination of four paratypes deposited in the USNPC (194737-740) by SOLER-JIMÉNEZ et al. (2012) (2 specimens stained in Gomori's trichrome \& 2 specimens mounted unstained in Gray \& Wess medium) suggested that the "scarf" represents the interior wall of the genital atrium into which portions of the accessory piece are incorporated; the accessory pieces of the two unstained specimens are morphologically identical to those of present specimens from Panama (see Fig. 38). The base of the MCO possesses a small inner cavity that may impart what appears to be a thickened, low density wall of the base; the cavity is not apparent in all specimens, suggesting that the character is not sufficient to differentiate the two species. Finally, differences observed in the anchors and bars of the two species were minimal and easily fall within expected intraspecific variation among dactylogyrids. The only remaining criterion for separating $E$. mehen from E. longibaculum is the respective geographic and host ranges. In order to prevent unwarranted synonyms, $E$. mehen is provisionally accepted as a valid species until the impact of the Panamanian Isthmus on speciation within this group of parasites is determined. Because Euryhaliotrema and Euryhaliotrematoides are herein considered synonyms, it remains necessary, however, to transfer Euryhaliotrematoides mehen to Euryhaliotrema as a new combination.

\section{Euryhaliotrema fajeravilae Kritsky \& Mendoza-Franco sp. nov.} Figs 43-48

Description: Body proper gently tapering anteriorly from peduncle; greatest width along peduncle. Tegument smooth. Cephalic region broad; cephalic lobes poorly to moderately developed. Four eyespots; one member of anterior pair frequently dissociated; members of posterior pair with lenses, subequal and equidistant compared to members of anterior pair; accessory chromatic granules few or absent in cephalic and anterior trunk regions. Pharynx spherical. Peduncle broad; haptor globose. Ventral anchor with moderately long superficial root, short deep root, curved shaft, elongate point extending past level of tip of superficial root. Dorsal anchor with elongate uplifted superficial root, small deep root, curved shaft, elongate point extending past level of tip of superficial root. Ventral bar broadly $\mathrm{V}$ shaped, with expanded ends; dorsal bar a slightly curved or straight rod with small terminal enlargements. Hook with uniform shank, upright acute thumb; FH loop about shank length. MCO a U-shaped tube with enlarged funnelshaped base. Accessory piece variable; articulation process con- 

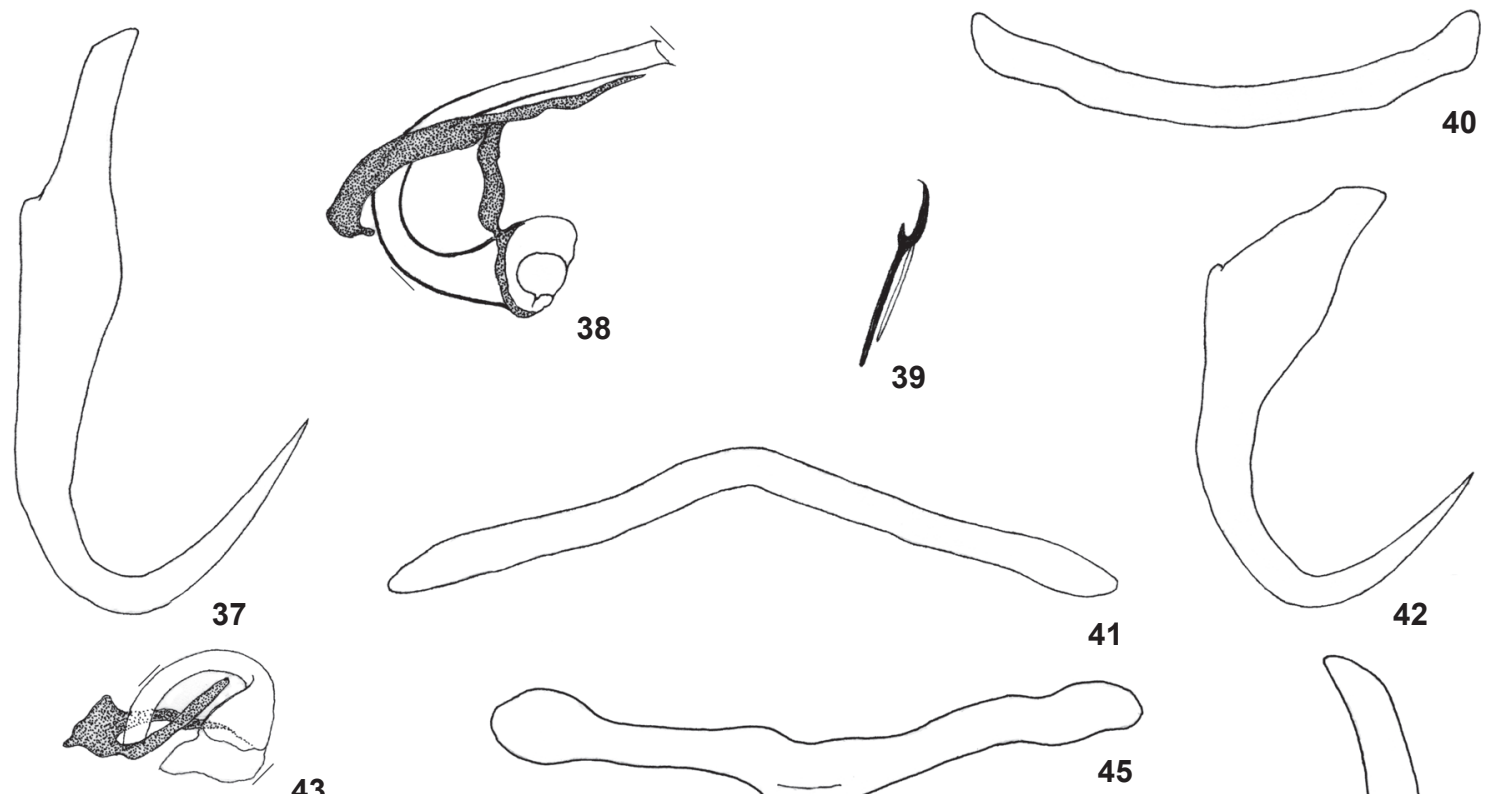

43

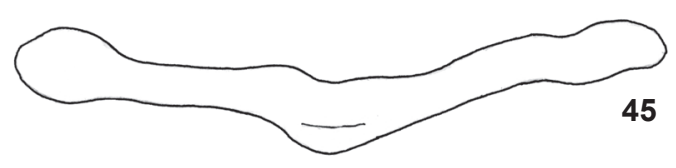

41
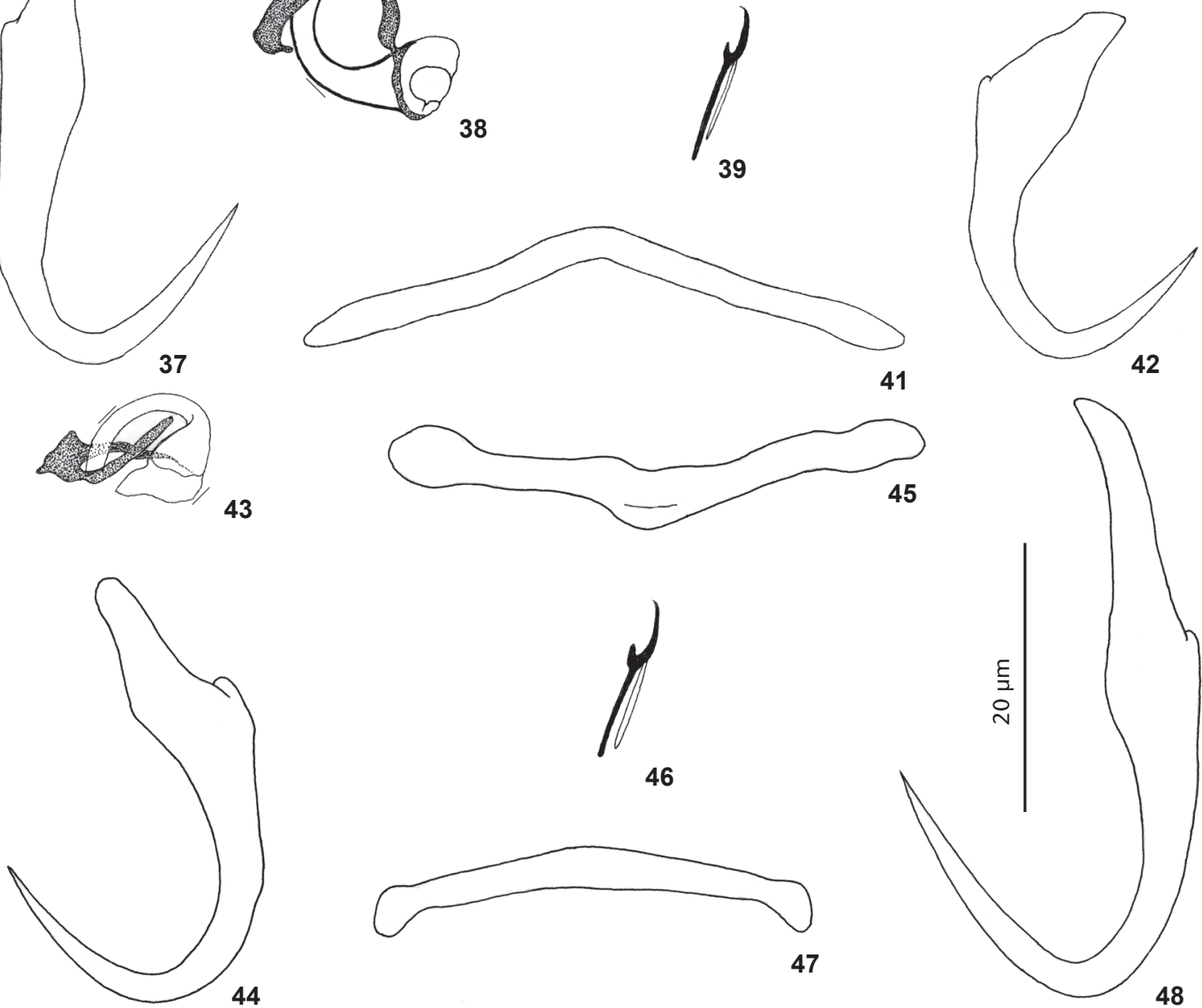

Figures 37-48. Haptoral and copulatory sclerites of two species of Euryhaliotrema from snappers in Panama. 37-42. Euryhaliotrema mehen comb. nov. from the spotted rose snapper, Lutjanus guttatus. 37. Dorsal anchor. 38. Copulatory complex (dorsal view). 39. Hook. 40. Dorsal bar. 41. Ventral bar. 42. Ventral anchor. 43-48. Euryhaliotrema fajeravilae sp. nov. from the yellow snapper, Lutjanus argentiventris. 43. Copulatory complex (ventral view). 44. Ventral anchor. 45. Ventral bar. 46. Hook. 47. Dorsal bar. 48. Dorsal anchor. All figures are drawn to the $20 \mu \mathrm{m}$ scale.

necting accessory piece with base of MCO. Testis ovate; seminal vesicle large, fusiform; prostatic reservoir not observed. Germarium pyriform; oviduct, ootype, uterus not observed; vaginal pore marginal at small indentation of tegument; vaginal canal inconspicuous; seminal receptacle not observed. Vitellaria dense, coextensive with gut; transverse vitelline duct anterior to germarium. Egg not observed.

Type host and locality: Yellow snapper, Lutjanus argentiventris (Peters), Lutjanidae: Perlas Archipelago, Panama $\left(8^{\circ} 22^{\prime} \mathrm{N}, 79^{\circ} 01^{\prime} \mathrm{W}\right), 24$ May 2007.
Site of infection: Gills.

Specimens studied: Holotype, USNPC 105502; 3 paratypes, USNPC 105503.

Etymology: This species is named in honor of our friend and colleague, Dr. Emma J. Fajer-Ávila, Unidad Mazatlán en Acuicultura y Manejo Ambiental, Mazatlán, Sinaloa, Mexico, in recognition of her contributions on the monogenoidean parasites of lutjanids in Mexico.

Measurements: Body $328(295-362 ; \mathrm{n}=2)$ long; greatest width (excluding haptor) $58(48-67 ; \mathrm{n}=2)$. Haptor $52(47-57 ; \mathrm{n}$ 
=2) long, 80 (70-89; $\mathrm{n}=2)$ wide. Pharynx $22(21-23 ; \mathrm{n}=2)$ wide. MCO 15-16 ( $\mathrm{n}=2)$ long. Ventral anchor $41(40-43 ; \mathrm{n}=2)$ long; dorsal anchor $58(56-60 ; \mathrm{n}=2)$ long. Ventral bar $54(51-57 ; \mathrm{n}=$ 2) long; dorsal bar $45(43-48 ; n=2)$ long. Hook $16(15-17 ; n=6)$ long. Germarium 33 (26-40; $\mathrm{n}=2)$ long, $20(19-21 ; \mathrm{n}=2)$ wide; testis $44(38-50 ; n=2)$ long, $26(24-28 ; n=2)$ wide.

Remarks: This species is one of a complex of Euryhaliotrema species infecting lutjanids and distributed on either side of southern North America. It differs from the other two members of the complex, E. longibaculum and E. mehen, by having larger anchors and a noticeably smaller copulatory complex.

\section{Euryhaliotrema perezponcei García-Vargas, Fajer- Ávila \& Lamothe-Argumedo, 2008}

Figs 49-56

Redescription: Body proper fusiform, usually with elongate tapered peduncle; greatest width in posterior trunk at level of gonads. Tegument smooth. Cephalic region narrow; cephalic lobes poorly to moderately developed. Four eyespots; members of posterior pair slightly larger, closer together than those of anterior pair; one member of anterior pair infrequently dissociated; accessory chromatic granules in cephalic region. Pharynx spherical. Haptor subrectangular to subhexagonal in dorsoventral view. Anchors similar; each with well-developed superficial root, short deep root, short nearly straight shaft, elongate point extending just past level of tip of superficial root; dorsal anchor slightly more delicate than ventral anchor. Ventral bar a rod with wavy medioventral surface imparting a broad $\mathrm{W}$ shape. Dorsal bar generally broadly V shaped, with variably developed medioposterior shield; shield frequently with exterior ornamentation. Hook with uniform shank, upright acute thumb; FH loop about shank length. MCO having a bulbous base and a coiled tubular shaft of about three counterclockwise rings. Accessory piece comprising complex sheath and distal rod; sheath proximally bifid with posterior rounded branch and anterior spatulate branch; articulation process absent. Gonads tandem to slightly overlapping. Testis ovate; seminal vesicle elongate, may be constricted near midlength; prostatic reservoir small, lying near bulbous base of MCO. Germarium variable; oviduct, ootype, uterus not observed; vaginal pore marginal, vaginal vestibule apparently absent; vaginal canal tubular, originating from kidney-shaped mass and directed to medial seminal receptacle. Vitellaria dense, coextensive with gut; transverse vitelline duct at level of or posterior to seminal receptacle. Egg usually deformed (an artifact of specimen preparation), with moderately long proximal filament.

Type host and locality: Spotted rose snapper, Lutjanus guttatus (Steindachner), Lutjanidae: Pacific Coast, Mazatlán, Sinaloa, Mexico $\left(23^{\circ} 29^{\prime} \mathrm{N}, 106^{\circ} 36^{\prime} \mathrm{W}\right)$.

Source of current specimens: Spotted rose snapper, Lutjanus guttatus, Lutjanidae: off Taboga Island, Panama $\left(8^{\circ} 49^{\prime} \mathrm{N}, 7^{\circ} 34^{\prime} \mathrm{W}\right), 24$ May 2007; Perlas Archipelago, Panama $\left(8^{\circ} 22^{\prime} \mathrm{N}, 79^{\circ} 01^{\prime} \mathrm{W}\right), 24$ May 2007.
Site of infection: Gills.

Specimens studied: 13 voucher specimens, USNPC 105500, 105501.

Previous records: Lutjanus guttatus: Pacific Coast, Mazatlán, Sinaloa, Mexico $\left(23^{\circ} 29^{\prime} \mathrm{N}, 106^{\circ} 36^{\prime} \mathrm{W}\right)$ (GARCía-VARGAs et al. 2008); Cruz de Huanacaxtle, Nayarit, Mexico $\left(20^{\circ} 44^{\prime} \mathrm{N}, 105^{\circ} 22^{\prime} \mathrm{W}\right)$ (García-Vargas et al. 2008); Mazatlan Bay, Sinaloa, Mexico $\left(23^{\circ} 14^{\prime} 29^{\prime \prime} \mathrm{N}, 106^{\circ} 24^{\prime} 35^{\prime \prime} \mathrm{W}\right)$ (SOLER-Jiménez \& Fajer-Ávila 2012).

Measurements: Body 578 (571-585; $\mathrm{n}=2)$ long; greatest width (excluding haptor) $98(89-106 ; \mathrm{n}=2)$. Haptor $72(66-79$; $\mathrm{n}=2)$ long, 85 (77-92; $\mathrm{n}=2)$ wide. Pharynx $30(29-31 ; \mathrm{n}=2)$ wide. MCO (proximal ring diameter) $33(29-38 ; \mathrm{n}=7)$. Ventral anchor 31 (28-32; $\mathrm{n}=10)$ long; dorsal anchor $31(28-33 ; \mathrm{n}=10)$ long. Ventral bar $44(37-47 ; n=9)$ long; dorsal bar 35 (31-39; $n$ $=10)$ long. Hook $14(13-15 ; \mathrm{n}=19)$ long. Germarium 52 (45-59; $\mathrm{n}=2)$ long, $27(26-29 ; \mathrm{n}=2)$ wide; testis $62(56-69 ; \mathrm{n}=2)$ long, $28(24-32 ; \mathrm{n}=2)$ wide.

Remarks: Euryhaliotrema perezponcei could be confused with E. torquecirrus by having similar anchors and dorsal bars. It differs from the latter species by having one component of the accessory piece of the copulatory complex with a proximal rounded branch (absent in E. torquecirrus), a shorter MCO, and a broadly W-shaped ventral bar (ventral bar comparatively straight in E. torquecirrus). The two species may represent sister species or a geminate species pair, each member of which is separated from the other by the Panamanian Isthmus.

\section{Euryhaliotrema anecorhizion Kritsky \& Mendoza-Franco sp. nov.} Figs $57-63$

Description: Body proper fusiform; greatest width at various levels along trunk. Tegument smooth. Cephalic region broad; cephalic lobes poorly to moderately developed. Four eyespots frequently dissociated; members of posterior pair with lenses, larger and closer together than members of anterior pair; accumulations and single accessory chromatic granules common in cephalic, anterior trunk regions. Pharynx spherical. Peduncle broad; haptor globose. Ventral anchor with moderately long superficial root, short deep root, slightly curved shaft, elongate point extending past level of tip of superficial root; point and shaft with longitudinal superficial grooves. Dorsal anchor similar to ventral anchor except with superficial root uplifted toward dorsal haptoral surface. Ventral and dorsal bars slightly curved rods with minimally enlarged ends; dorsal bar with rectangular enlargement of anteromedial margin. Hook with uniform shank, upright acute thumb; FH loop about shank length. MCO having a bulbous base and a delicately coiled shaft of about two and a half counterclockwise rings. Accessory piece comprising variable sheath along distal shaft of MCO; articulation process connecting accessory piece with base of MCO. Testis ovate; seminal vesicle fusiform; prostatic reservoir lying to right of base of MCO. Germarium subovate to bacilliform; oviduct, ootype, uterus not observed; vaginal pore marginal at 

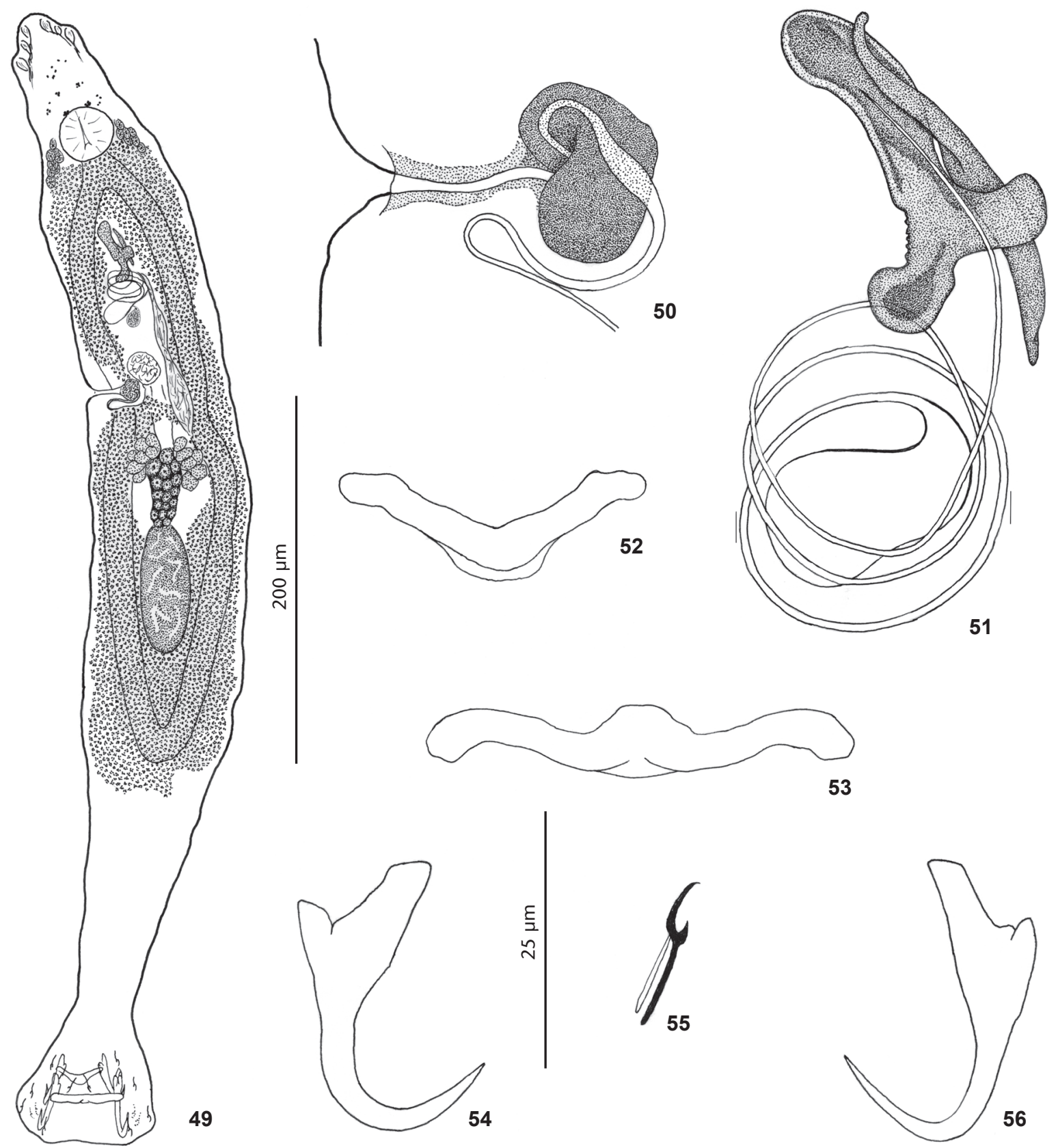

Figures 49-56. Euryhaliotrema perezponcei from the spotted rose snapper, Lutjanus guttatus, from the eastern Pacific Ocean, Panama. 49. Whole mount (composite, ventral view). 50. Vagina. 51. Copulatory complex (ventral view). 52. Dorsal bar. 53. Ventral bar. 54. Ventral anchor. 55. Hook. 56. Dorsal anchor. All figures are to the $25 \mathrm{~mm}$ scale except Fig. 49 (200 $\mu \mathrm{m}$ scale).

indistinct indentation of tegument; vaginal canal with distal posterior loop, extending medially to spherical seminal receptacle; seminal receptacle medial, pregermarial. Vitellaria dense, coextensive with gut; transverse vitelline duct anterior to seminal receptacle. Egg not observed.
Type host and locality: Yellow snapper, Lutjanus argentiventris (Peters), Lutjanidae: Perlas Archipelago, Panama $\left(8^{\circ} 22^{\prime} \mathrm{N}, 79^{\circ} 01^{\prime} \mathrm{W}\right), 24$ May 2007.

Other record: $L$. argentiventris: off Taboga Island, Panama $\left(8^{\circ} 49^{\prime} \mathrm{N}, 79^{\circ} 34^{\prime} \mathrm{W}\right), 24$ May 2007. 

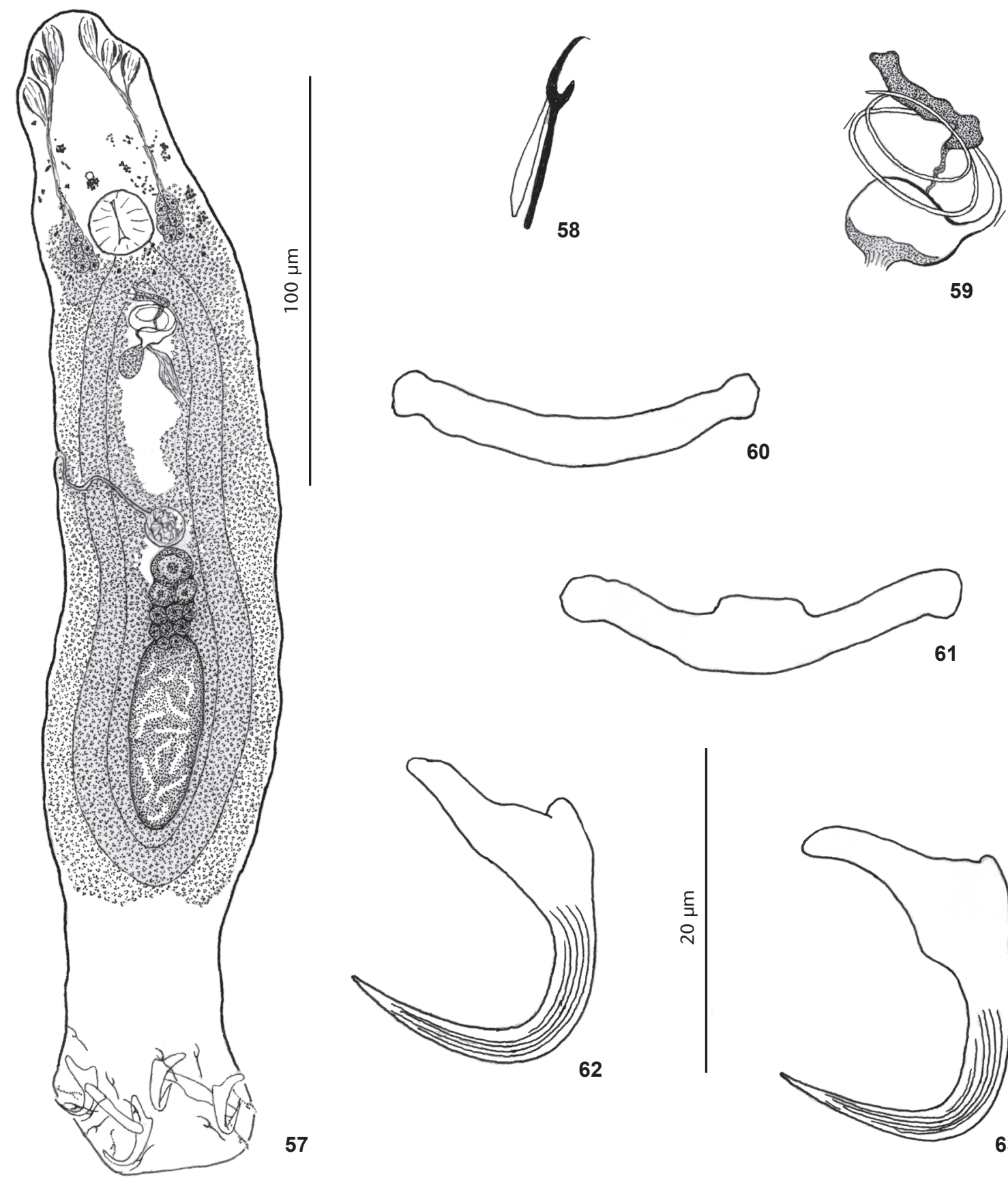

59
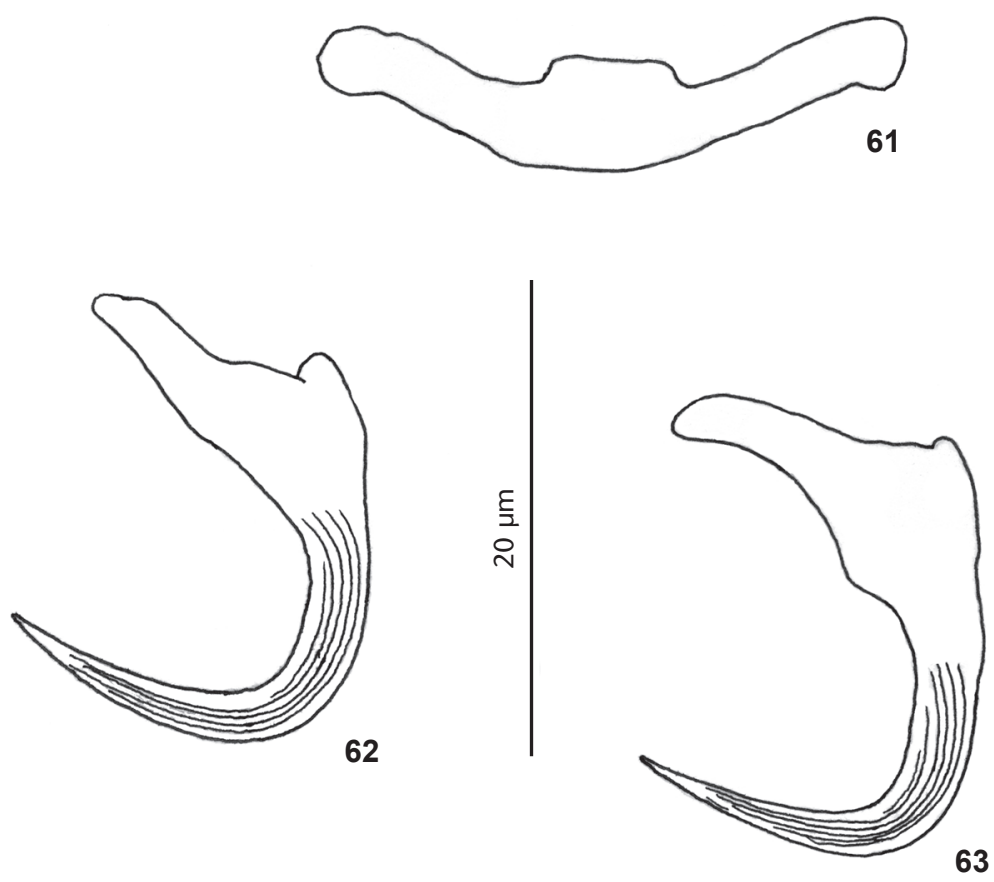

Figures 57-63. Euryhaliotrema anecorhizion sp. nov. from the yellow snapper, Lutjanus argentiventris, in Panama. 57. Whole mount (composite, ventral view). 58. Hook. 59. Copulatory complex (ventral view). 60. Ventral bar. 61. Dorsal bar. 62. Ventral anchor. 63. Dorsal anchor. All figures are to the $20 \mu \mathrm{m}$ scale except Fig. 57 (100 $\mu \mathrm{m}$ scale).

Site of infection: Gills.

Specimens studied: Holotype, USNPC 105504; 13 paratypes, USNPC 105505; 4 voucher specimens USNPC 105506.
Etymology: The specific name (a noun) is from Greek (aneckos $=$ to reach up/uplifted + rhiza $=$ root) appended to the diminutive ending -ion and refers to the upturned superficial root of the dorsal anchor. 
Measurements: Body $278(263-295 ; \mathrm{n}=4)$ long; greatest width (excluding haptor) $56(45-66 ; \mathrm{n}=4)$. Haptor $41(30-49$; $\mathrm{n}=4)$ long, $55(50-58 ; \mathrm{n}=4)$ wide. Pharynx $20(19-21 ; \mathrm{n}=4)$ wide. MCO (proximal ring diameter) $14(12-15 ; n=4)$. Ventral anchor $26(25-29 ; \mathrm{n}=9)$ long; dorsal anchor $28(26-30 ; \mathrm{n}=9)$ long. Ventral bar 30 (27-32; n = 7) long; dorsal bar 31 (29-34; =9) long. Hook $15(14-16 ; \mathrm{n}=14)$ long. Germarium 31 (25-36; $\mathrm{n}=2)$ long, $20(19-21 ; \mathrm{n}=2)$ wide; testis $45(38-57 ; \mathrm{n}=3)$ long, $20(18-22 ; \mathrm{n}=3)$ wide.

Remarks: Euryhaliotrema anecorhizion was collected from the gills of the yellow snapper in association with six other species of Euryhaliotrema, including E. cf. fastigatum, E. cf. longibaculum, E. cf. paracanthi, E. fajeravilae and 2 undescribed species (USNPC 105463, 105464). It is closest morphologically to E. fastigatum in the general morphology of the MCO and by having the points and shafts of the dorsal and ventral anchors with longitudinal superficial grooves. It differs from $E$. fastigatum by having an articulation process in the copulatory complex that attaches the accessory piece to the base of the $\mathrm{MCO}$ and from all other congeneric species by having a comparatively short upturned superficial root of the dorsal anchor.

\section{Euryhaliotrema diplops Kritsky, Yang \& Justine sp. nov. Figs 64-71}

Description: Body proper fusiform, gently tapered anteriorly from level of gonads; greatest width at level of gonads. Tegument smooth. Cephalic region broad; cephalic lobes poorly to moderately developed. Eyespots two (anterior pair absent), each with lenses; random accumulations of accessory chromatic granules common in cephalic, anterior trunk regions. Pharynx subspherical. Peduncle short, broad; haptor globose. Ventral anchor with depressed superficial root terminating acutely, short to nonexistent deep root, short curved shaft, elongate strongly recurved point extending past level of tip of superficial root. Dorsal anchor with delicate base (frequently folded) having inconspicuous fracture line, elongate superficial root, and short to nonexistent deep root; shaft short; elongate recurved point extending past level of tip of superficial root. Shafts and points of both anchors with longitudinal superficial grooves. Ventral bar a straight rod with knobbed ends and slender spine-like posteromedial projection; dorsal bar a slightly curved rod usually with small anteromedial and posteromedial pustules (anterior pustule more frequently lacking). Hook delicate, with uniform shank, upright acute thumb; FH loop nearly shank length. MCO having a bulbous base and a coiled flattened tubular shaft of about three counterclockwise rings. Accessory piece comprising variable terminal structure with articulation process extending within rings to bulbous base of MCO. Testis elongate ovate; seminal vesicle elongate, fusiform; prostatic reservoir subspherical, lying immediately posterior and dextral to base of MCO. Germarium ovate; oviduct, ootype, uterus not observed; Mehlis' gland large, dorsal and lateral to seminal receptacle. Vaginal pore marginal at inconspicuous indentation of tegument, unsclerotized; vaginal canal indistinct; subspherical seminal receptacle medial, immediately pregermarial. Vitellaria dense; transverse vitelline duct anterior to seminal receptacle. Egg not observed.

Type host and locality: Mangrove red snapper, Lutjanus argentimaculatus (Forsskål), Lutjanidae: Gulf of Tonkin (South China Sea) near Lingao, Hainan Province, China $\left(20^{\circ} 00^{\prime} \mathrm{N}\right.$, $\left.109^{\circ} 05^{\prime} \mathrm{E}\right), 20,23$ September 2003.

Other records: Lutjanus argentimaculatus: Dapeng Bay near Nanao, South China Sea, Guangdong Province, China $\left(23^{\circ} 25^{\prime} \mathrm{N}, 117^{\circ} 02^{\prime} \mathrm{E}\right), 24$ July 2007; Grande Rade, Nouméa, New Caledonia, 23 October 2007; Récif de Crouy, New Caledonia $\left(22^{\circ} 21.825^{\prime} \mathrm{S}, 166^{\circ} 21.961^{\prime} \mathrm{E}\right), 31$ October 2008 .

Site of infection: Gills.

Specimens studied: Holotype, USNPC 105507; 20 paratypes, USNPC 105508, 105509; 14 voucher specimens (from New Caledonia), USNPC 105510, 105511, MNHN JNC2735K1-K6.

Etymology: The specific name (a noun) is from Greek $($ diploos $=$ two + ops $=$ eye $)$ and refers to the presence of two (one pair) eyespots.

Measurements: Body $257(197-344 ; \mathrm{n}=8)$ long; greatest width (excluding haptor) $53(44-61 ; \mathrm{n}=8)$. Haptor 51 (42-57; $\mathrm{n}=8)$ long, $66(56-82 ; \mathrm{n}=8)$ wide. Pharynx $16(14-18 ; \mathrm{n}=7)$ wide. MCO (proximal ring diameter) $17(15-20 ; \mathrm{n}=19)$. Ventral anchor $33(31-35 ; \mathrm{n}=12)$ long; dorsal anchor $46(42-50 ; \mathrm{n}$ = 11) long. Ventral bar $34(31-38 ; \mathrm{n}=12)$ long; dorsal bar 38 $(35-46 ; \mathrm{n}=11)$ long. Hook $13(12-14 ; \mathrm{n}=15)$ long. Germarium $37(31-44 ; \mathrm{n}=5)$ long, $19(14-23 ; \mathrm{n}=5)$ wide; testis $44(41-48$; $\mathrm{n}=5)$ long, $18(13-22 ; \mathrm{n}=5)$ wide.

Remarks: Based on the comparative morphology of the haptoral sclerites, E. diplops is most similar to E. fastigatum from lutjanids of the western hemisphere. It differs from $E$. fastigatum by possessing a single pair of eyespots (two pairs in E. fastigatum), an articulation process attaching the accessory piece to the base of the MCO (accessory piece and MCO unarticulated in E. fastigatum) and a coiled MCO with about three counterclockwise rings (about two counterclockwise rings in E. fastigatum). Euryhaliotrema diplops also resembles several other species infecting the mangrove red snapper in China, including $E$. hainanense, E. xinyingense, E. guangdongense and E. lutjani. Of the four species, E. diplops is most similar to E. xinyingense, from which it differs by having a more robust MCO and a short straight ventral bar (bar broadly W shaped in E. xinyingense). It differs from all four of the species by having a single pair of eyespots and a hinge-like fracture line in the base of the dorsal anchor.

\section{Euryhaliotrema xinyingense Pan \& Zhang, 2006 Figs $72-77$}

Type host and locality: Mangrove red snapper, Lutjanus argentimaculatus (Forsskål), Lutjanidae: off Lingao, Hainan Island, China $\left(19^{\circ} 54^{\prime} \mathrm{N}, 109^{\circ} 30^{\prime} \mathrm{E}\right)$.

Source of current specimens: Mangrove red snapper, Lutjanus argentimaculatus, Lutjanidae: Récif de Crouy, New 

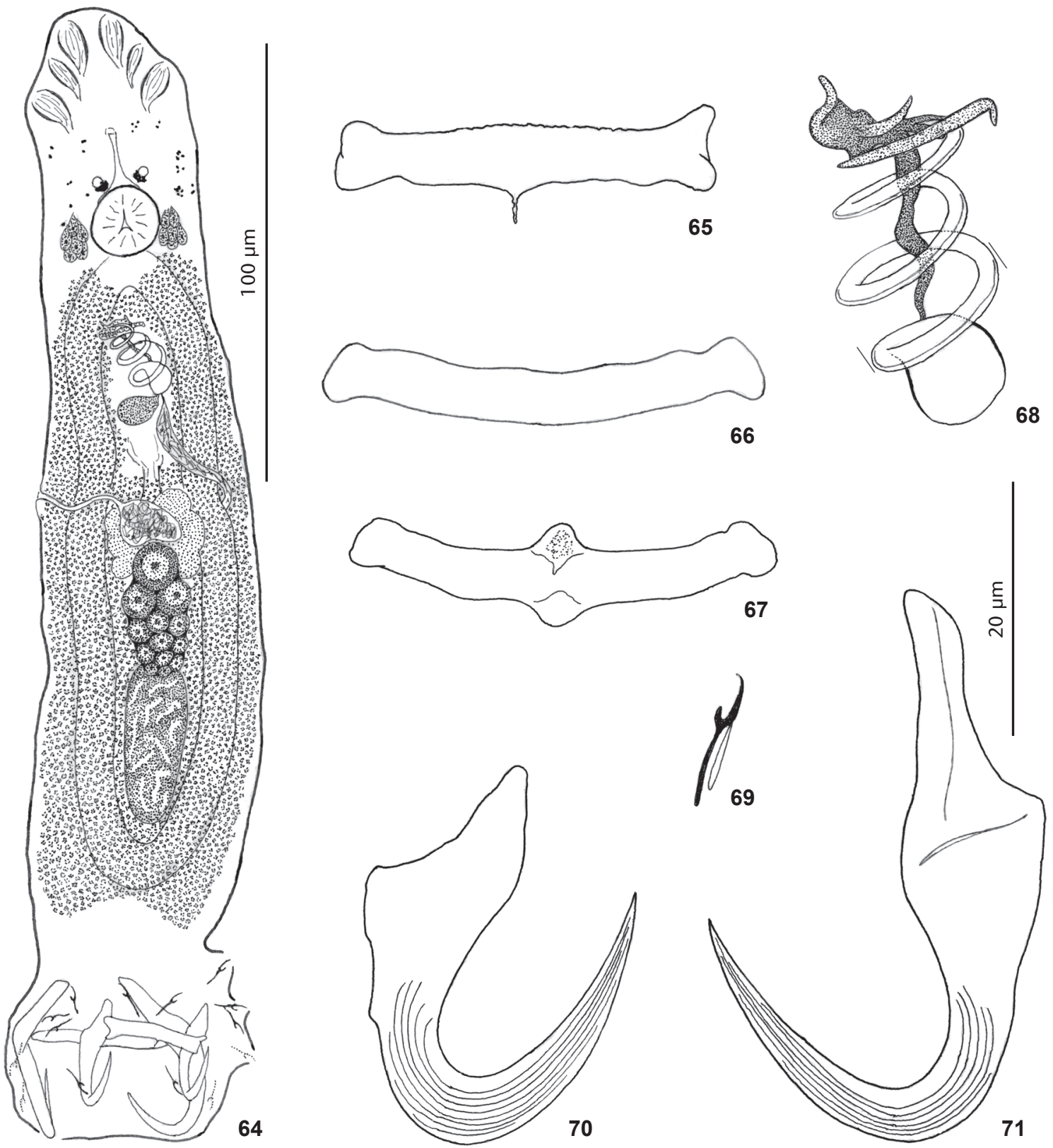

68

Figures 64-71. Euryhaliotrema diplops sp. nov. from the mangrove red snapper, Lutjanus argentimaculatus, in the Gulf of Tonkin, China. 64. Whole mount (composite, ventral view). 65. Ventral bar. 66, 67. Dorsal bars. 68. Copulatory complex (ventral view). 69. Hook. 70. Ventral anchor. 71. Dorsal anchor. All figures are to the $20 \mu \mathrm{m}$ scale except Fig. 64 (100 $\mu \mathrm{m}$ scale).

Caledonia $\left(22^{\circ} 21.825^{\prime} \mathrm{S}, 166^{\circ} 21.961^{\prime} \mathrm{E}\right), 31$ October 2008 ; Gulf of Tonkin (South China Sea) near Lingao, Hainan Province, China $\left(20^{\circ} 00^{\prime} \mathrm{N}, 109^{\circ} 05^{\prime} \mathrm{E}\right), 20,23$ September 2003.

Site of infection: Gills.

Specimens studied: Paratype, BMNH 2005.10.18.3-4; voucher specimen on slide containing a paratype of $E$. hainanense, BMNH 2005.10.18.1-2; voucher specimen (from
China), USNPC 105513; voucher specimen (from New Caledonia), USNPC 105512.

Previous record: No previous records, except that of the original description by PAN \& ZHANG (2006).

Measurements [original measurements from PAN \& ZHANG (2006) follow those of the present study (all available specimens including paratype and the specimen on the slide with a 
paratype of $E$. hainanense) in brackets, respectively]: MCO (proximal ring diameter) $20(17-22 ; \mathrm{n}=5)$ [18 (16-19)]. Ventral anchor 31 (29-33; n = 5) [30 (28-35)] long; dorsal anchor 36 $(34-39 ; \mathrm{n}=5)$ [33 (30-35)] long. Ventral bar $56(47-60 ; \mathrm{n}=4)$ [55 (50-65)] long; dorsal bar $33(29-40 ; \mathrm{n}=4)$ [33 (25-40] long. Hook $18(17-19 ; \mathrm{n}=15)$ [16 (10-20)] long.

Remarks: One specimen of E. xinyingense was found on the gills of a mangrove red snapper collected from each of China and New Caledonia. Both specimens were indistinguishable from the available paratype of $E$. xinyingense deposited in the Natural History Museum, London (BMNH 2005.10.18.3-4) and from a specimen present on the slide containing a paratype of $E$. hainanense (BMNH 205.10.18.1-2). Morphological differences between $E$. xinyingense and $E$. hainanense are minimal, and in absence of comparative material, differentiation of the two species may be difficult. However, comparative morphology of the dorsal anchors, the ventral bars and hooks apparently are the best means for separating specimens and provide sufficient evidence that the two species are valid. In E. xinyingense, the larger dorsal anchor is more delicate and possesses a noticeably longer superficial root, the ventral bar is longer, and the hooks are larger and more robust than the respective structures of $E$. hainanense (compare Figs 72-83). Finally, the dorsal anchor is longer than the ventral anchor in E. xinyingense (the opposite occurring in $E$. hainanense). Unfortunately, available specimens of both species are unsatisfactory to provide detailed redescriptions.

\section{Euryhaliotrema hainanense Pan \& Zhang, 2006 Figs 78-83}

Type host and locality: Mangrove red snapper, Lutjanus argentimaculatus (Forsskål), Lutjanidae: off Lingao, Hainan Island, China $\left(19^{\circ} 54^{\prime} \mathrm{N}, 109^{\circ} 30^{\prime} \mathrm{E}\right)$.

Source of current specimens: Mangrove red snapper, Lutjanus argentimaculatus, Lutjanidae: Récif de Crouy, New Caledonia $\left(22^{\circ} 21.825^{\prime} \mathrm{S}, 166^{\circ} 21.961^{\prime} \mathrm{E}\right), 31$ October 2008 ; Gulf of Tonkin near Lingao, China $\left(20^{\circ} 00^{\prime} \mathrm{N}, 109^{\circ} 05 \mathrm{E}\right), 23$ September 2003 .

Site of infection: Gills.

Specimens studied: Paratype, BMNH 2005.10.18.1-2; 2 voucher specimens (from New Caledonia), USNPC 105514; 2 voucher specimens (from China), USNPC 105515.

Previous records: No previous records, except that of the original description by PAN \& ZHANG (2006).

Measurements [original measurements from PAN \& ZHANG (2006) follow those of the present study (all available specimens including the paratype) in brackets, respectively]: Body $274(267-281 ; \mathrm{n}=2)$ [339 (300-390)] long; greatest width (excluding haptor) $75(70-79 ; \mathrm{n}=2)$ [123 (80-160)]. Haptor 50 $(44-56 ; \mathrm{n}=2)$ [43 (30-50)] long, $79(74-84 ; \mathrm{n}=2)$ [76 (65-100)] wide. Pharynx 19-20 $(\mathrm{n}=2)$ [23 $(18-28)]$ wide. MCO (proximal ring diameter) $21(18-24 ; \mathrm{n}=5)$. Ventral anchor $29(28-31 ; \mathrm{n}=$ 5) $[27$ (25-28)] long; dorsal anchor $27(26-29 ; n=5)$ [23 (2325)] long. Ventral bar $46(43-48 ; n=4)$ [45 (40-48)] long; dorsal bar $29(27-30 ; \mathrm{n}=4)$ [25 (20-30)] long. Hook $15(14-16 ; \mathrm{n}=6)$ [13 (10-15)] long. Germarium 39-40 ( $\mathrm{n}=1)$ [50] long, 26-27 (n = 1) [32 (25-38)] wide; testis 33-34 $(\mathrm{n}=1)$ [45 (50-63), sic] long, 20-21 ( $=1)$ [29 (25-33)] wide.

Remarks: Euryhaliotrema hainanense closely resembles $E$. xinyingense, both species of which parasitize the gills of mangrove red snapper. Differentiation of the two species, based on available specimens, is provided in the Remarks for E. xinyingense.

\section{Euryhaliotrema anguiformis (Zhang, 2001) comb. nov.}

Syns Haliotrema anguiformis Zhang, 2001; Aliatrema anguiformis (Zhang, 2001) Wu, Zhu, Xie \& Li, 2007

Type host and locality: The type host and locality were undetermined (see Remarks).

Site of infection: Gills.

Previous records: Lutjanus vaigiensis (now L. fulvus) and Lutjanus russellii: Yangjiang, Guangdong Province, China $\left(21^{\circ} 34^{\prime} \mathrm{N}, 111^{\circ} 49^{\prime} \mathrm{E}\right)$; Sanya, Hainan Province, China $\left(18^{\circ} 02^{\prime} \mathrm{N}\right.$, $109^{\circ} 05^{\prime} \mathrm{E}$ ) (both as Haliotrema anguiformis) (ZHANG 2001). Lutjanus fulvus: Moorea Island, Society Archipelago, French Polynesia $\left(17^{\circ} 30^{\prime} \mathrm{S}, 149^{\circ} 50^{\prime} \mathrm{W}\right)$; Marquesas Islands near Ua Huka, French Polynesia $\left(8^{\circ} 57^{\prime} \mathrm{S}, 139^{\circ} 35^{\prime} \mathrm{W}\right)$; south coast of $\mathrm{O}^{\prime} \mathrm{ahu}$, Hawaiian Islands $\left(21^{\circ} 17^{\prime} \mathrm{N}, 157^{\circ} 53^{\prime} \mathrm{W}\right.$ ) (all as Haliotrema sp. conf. anguiformis) (VIGNON et al. 2009). Lutjanus kasmira: Moorea Is-

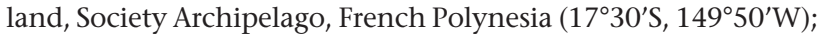
Marquesas Islands near Ua Huka, French Polynesia ( $8^{\circ} 57^{\prime} \mathrm{S}$, $139^{\circ} 35^{\prime} \mathrm{W}$ ) (both as Haliotrema sp. conf. anguiformis) (VIGNON et al. 2009). Lutjanus monostigma: Guangdong, China (as both Haliotrema anguiformis and Aliatrema anguiformis) (Wu et al. 2007).

Remarks: Zhang (2001) described this species as Haliotrema anguiformis based on six specimens collected from the gill filaments of $L$. vaigiensis (now L. fulvus) and $L$. russellii from Guangdong and Hainan Provinces in China. His drawings of the haptoral and particularly the copulatory sclerites (figs 10-5A-B in ZHANG 2001) suggest that he was dealing with a minimum of two different dactylogyrid species, both of which clearly belong in Euryhaliotrema. Later, Wu et al. (2007) reported collecting the species from L. monostigma from Guangdong Province in China for their investigation on the monophyly of the Ancyrocephalinae using rDNA sequence data; based on the results of their phylogenetic analyses, Wu et al. (2007) transferred the species to Aliatrema Plaisance \& Kritsky, 2004. Because of Zhang's apparent clumping of specimens apparently representing more than one putative species, all published host and locality records as well as the identity of the species remain uncertain. Examination of the type specimens, particularly the holotype, will be necessary to determine which form represents the species and whether or not all paratypes are conspecific. Confirmation of the record of WU et al. (2007) will require examination of new material from L. monostigma from the environs of Guangdong, China, as these authors appar- 


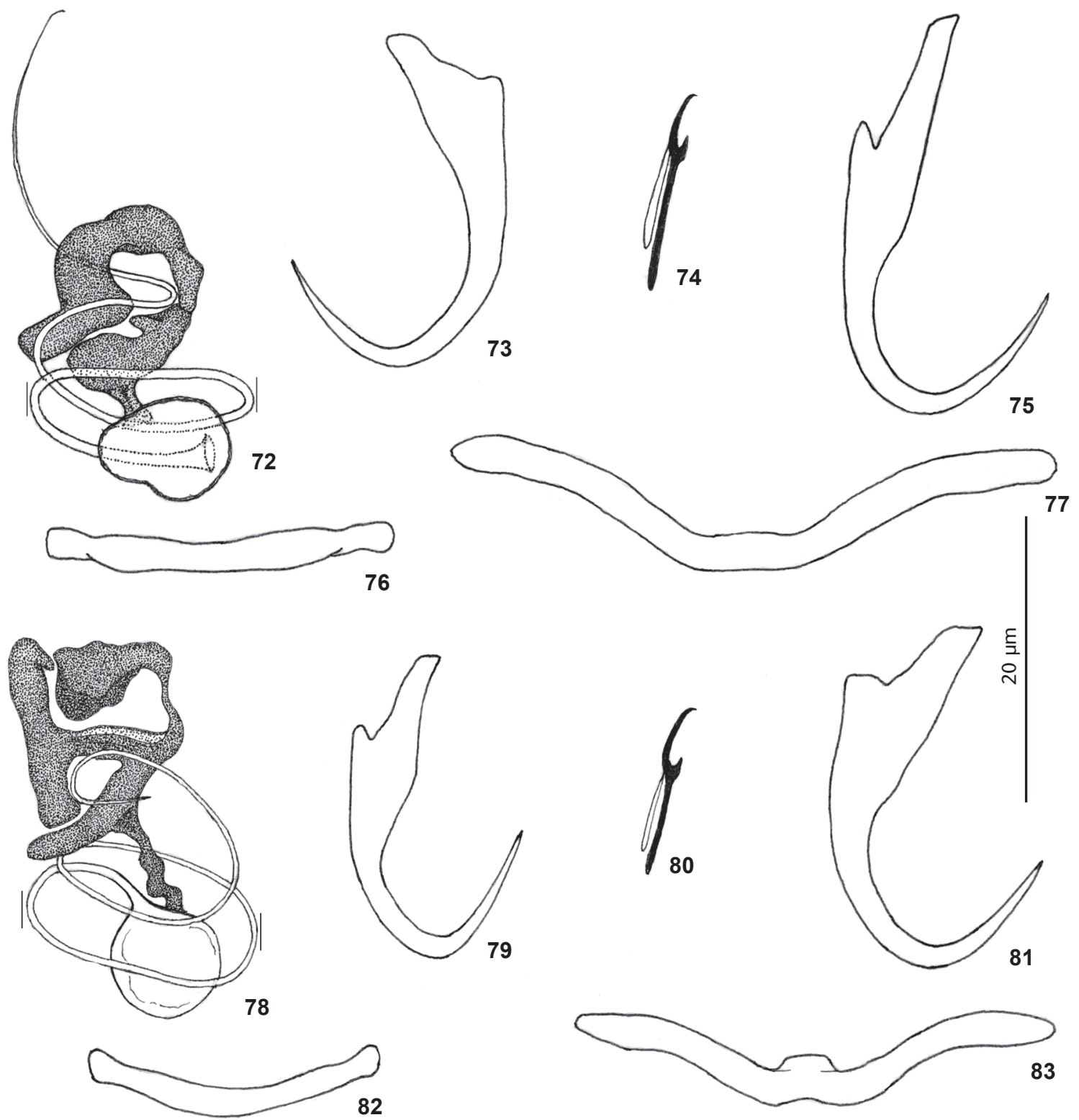

Figures 72-83. Haptoral and copulatory sclerites of two species of Euryhaliotrema from the mangrove red snapper, Lutjanus argentimaculatus in the Indo-Pacific Ocean. 72-77. Euryhaliotrema xinyingense. 72. Copulatory complex (ventral view). 73. Ventral anchor. 74. Hook. 75. Dorsal anchor. 76. Dorsal bar. 77. Ventral bar. 78-83. Euryhaliotrema hainanense. 78. Copulatory complex (ventral view). 79. Dorsal anchor. 80. Hook. 81. Ventral anchor. 82. Dorsal bar. 83. Ventral bar. All figures are to the $20 \mu \mathrm{m}$ scale.

ently failed to preserve voucher specimens of their form in a museum collection. No specimens of this species, including the type specimens, were available for the present study. Nonetheless, the species is transferred to Euryhaliotrema as Euryhaliotrema anguiformis (Zhang, 2001) comb. nov., based on the drawings provided in fig. 10-5 of ZHANG (2001) and on the proposed synonymy of Aliatrema with Euryhaliotrema.

\section{Euryhaliotrema nanaoense}

(Li, Yan, Yul, Lan \& Huang, 2005) comb. nov. Syn. Haliotrema nanaoensis Li, Yan, Yul, Lan \& Huang, 2005

Type host and locality: Mangrove red snapper, Lutjanus argentimaculatus (Forsskål), Lutjanidae: South China Sea, Guangdong Province, China $\left(22^{\circ} 05^{\prime} \mathrm{N}, 114^{\circ} 03^{\prime} \mathrm{E}\right)$. 
Site of infection: Gills.

Previous records: Lutjanus argentimaculatus: South China Sea, Guangdong Province, China $\left(22^{\circ} 05^{\prime} \mathrm{N}, 114^{\circ} 03^{\prime} \mathrm{E}\right.$ ) (as Haliotrema nanaoensis) (Li et al. 2005); Guangdong Province, China (as Haliotrema nanaoensis) (Wu et al. 2007).

Remarks: Li et al. (2005) placed this species in Haliotrema when they described it from the gills of the mangrove red snapper from the South China Sea. Although museum specimens were not available and the species was not collected during the present study, it clearly is a valid species having a copulatory complex lacking an accessory piece associated with the elongate proximally straight MCO. The species is transferred to Euryhaliotrema as E. nanaoense (Li, Yan, Yul, Lan \& Huang, 2005) comb. nov. based on the general morphology of the reproductive system and haptoral sclerites as depicted by Li et al. (2005). Euryhaliotrema nanaoense belongs to the group of congenerics that lack an accessory piece and whose species include $E$. spirotubiforum, E. adelpha, E. paululum and E. youngi, all parasites of lutjanids from the eastern hemisphere. Based on haptoral morphology, it is most similar to E. youngi, from which it differs primarily in the morphology of the MCO (MCO comprising a loose coil of slightly more than one ring in E. youngi).

\section{Euryhaliotrema cryptophallus Kritsky \& Yang sp. nov.}

Figs $84-90$

Description: Body proper fusiform; greatest width at level of gonads. Tegument smooth. Cephalic region slightly tapered anteriorly, broad; cephalic lobes well developed. Eyespots four; members of posterior pair with lenses, larger, closer together than those of anterior pair; accessory chromatic granules few (or absent) in cephalic, anterior trunk regions. Pharynx subspherical. Peduncle broad; haptor globose, usually directed ventrally from plane of trunk. Anchors similar, members of anterior pair slightly more robust than those of posterior pair; each with depressed moderately long superficial root, short to nonexistent deep root, short slightly curved shaft, elongate strongly recurved point extending past level of tip of superficial root; distal shafts and points of both anchors with longitudinal superficial grooves. Bars similar; each a broadly V-shaped rod with knobbed ends. Hook delicate, with uniform shank, upright acute thumb; FH loop nearly shank length. MCO weakly sclerotized, delicate, a coiled tubular shaft arising from bulbous base; coil comprising about one counterclockwise ring. Accessory piece a variable terminal sleeve enclosing distal half of shaft of MCO; articulation process absent. Gonads elongate ovate, slightly overlapping; testis dorsoposterior to germarium. Seminal vesicle fusiform; prostatic reservoir not observed. Oviduct, ootype, uterus not observed; Mehlis' gland large, dorsal and lateral to seminal receptacle. Vaginal pore dextromarginal, inconspicuous, unsclerotized; vaginal canal an indistinct straight tube leading to seminal receptacle; seminal receptacle subspherical, medial, immediately pregermarial. Vitellaria dense; transverse vitelline duct anterior to Mehlis' gland. Egg not observed.

Type host and locality: Mangrove red snapper, Lutjanus argentimaculatus (Forsskål), Lutjanidae: Gulf of Tonkin (South China Sea) near Lingao, Hainan Province, China $\left(20^{\circ} 00^{\prime} \mathrm{N}\right.$, $\left.109^{\circ} 05^{\prime} \mathrm{E}\right), 20,23$ September 2003.

Site of infection: Gills.

Specimens studied: Holotype, USNPC 105516; 44 paratypes, USNPC 105517.

Etymology: The specific name (a noun) is from Greek $($ kryptos $=$ hidden + phallos $=$ penis $)$ and refers to the cryptic copulatory complex.

Measurements: Body 303 (259-345; $\mathrm{n}=26)$ long; greatest width (excluding haptor) $67(51-87 ; \mathrm{n}=27)$. Haptor $44(34-51 ; \mathrm{n}=$ 25) long, $62(54-71 ; \mathrm{n}=26)$ wide. Pharynx $20(17-24 ; \mathrm{n}=27)$ wide. MCO 19 (15-27; $\mathrm{n}=13)$ long. Ventral anchor $27(25-28 ; \mathrm{n}=16)$ long; dorsal anchor $25(24-26 ; \mathrm{n}=16)$ long. Ventral bar 35 (31-38; $\mathrm{n}=13)$ long; dorsal bar $32(30-35 ; \mathrm{n}=14)$ long. Hook 15 (14-16; $\mathrm{n}$ = 19) long. Germarium $49(40-62 ; \mathrm{n}=17)$ long, $21(17-28 ; \mathrm{n}=17)$ wide; testis $63(49-85 ; \mathrm{n}=17)$ long, $25(20-33 ; \mathrm{n}=17)$ wide.

Remarks: Euryhaliotrema cryptophallus may be somewhat difficult to identify because of its dense vitelline follicles that usually mask the delicate and lightly sclerotized copulatory complex. It most closely resembles E. anecorhizion in the general morphology of the haptoral sclerites and copulatory complex. It differs from this species by having superficial roots of both anchors noticeably depressed (superficial anchor roots, especially those of the dorsal anchors, upturned in E. anecorhizion) and by having only one ring in the copulatory complex (about two rings in E. anecorhizion). In addition, E. cryptophallus lacks an articulation process connecting the accessory piece to the base of the MCO (articulation process present in E. anecorhizion).

\section{Euryhaliotrema lutjani Li, 2006}

Type host and locality: Presumed to be the mangrove red snapper, Lutjanus argentimaculatus (Forsskål), Lutjanidae: Vicinity of Shenzhen (obtained from the market in Guangzhou), China $\left(23.2^{\circ} \mathrm{N}, 113.3^{\circ} \mathrm{E}-22.5^{\circ} \mathrm{N}, 114.3^{\circ} \mathrm{E}\right.$ ) (see Remarks).

Site of infection: Gills.

Previous records: Lutjanus argentimaculatus: Vicinity of Shenzhen (obtained from the market in Guangzhou), China $\left(23.2^{\circ} \mathrm{N}, 113.3^{\circ} \mathrm{E}-22.5^{\circ} \mathrm{N}, 114.3^{\circ} \mathrm{E}\right)(\mathrm{Li} 2006)$. Sparus macrocephalus (now Acanthopagrus s. schlegelii): Vicinity of Shenzhen (obtained from the market in Guangzhou), China $\left(23.2^{\circ} \mathrm{N}, 113.3^{\circ} \mathrm{E}\right.$ $-22.5^{\circ} \mathrm{N}, 114.3^{\circ} \mathrm{E}$ ) (Li 2006).

Remarks: Type specimens of E. lutjani were not available and the species was not collected during the present investigation. The original description lacks morphological detail (see Li 2006) that would allow its separation from some of the other species described from lutjanids from the western Pacific Ocean. The species requires redescription based on the type specimens and perhaps freshly collected material from the western Pacific region (see below). 

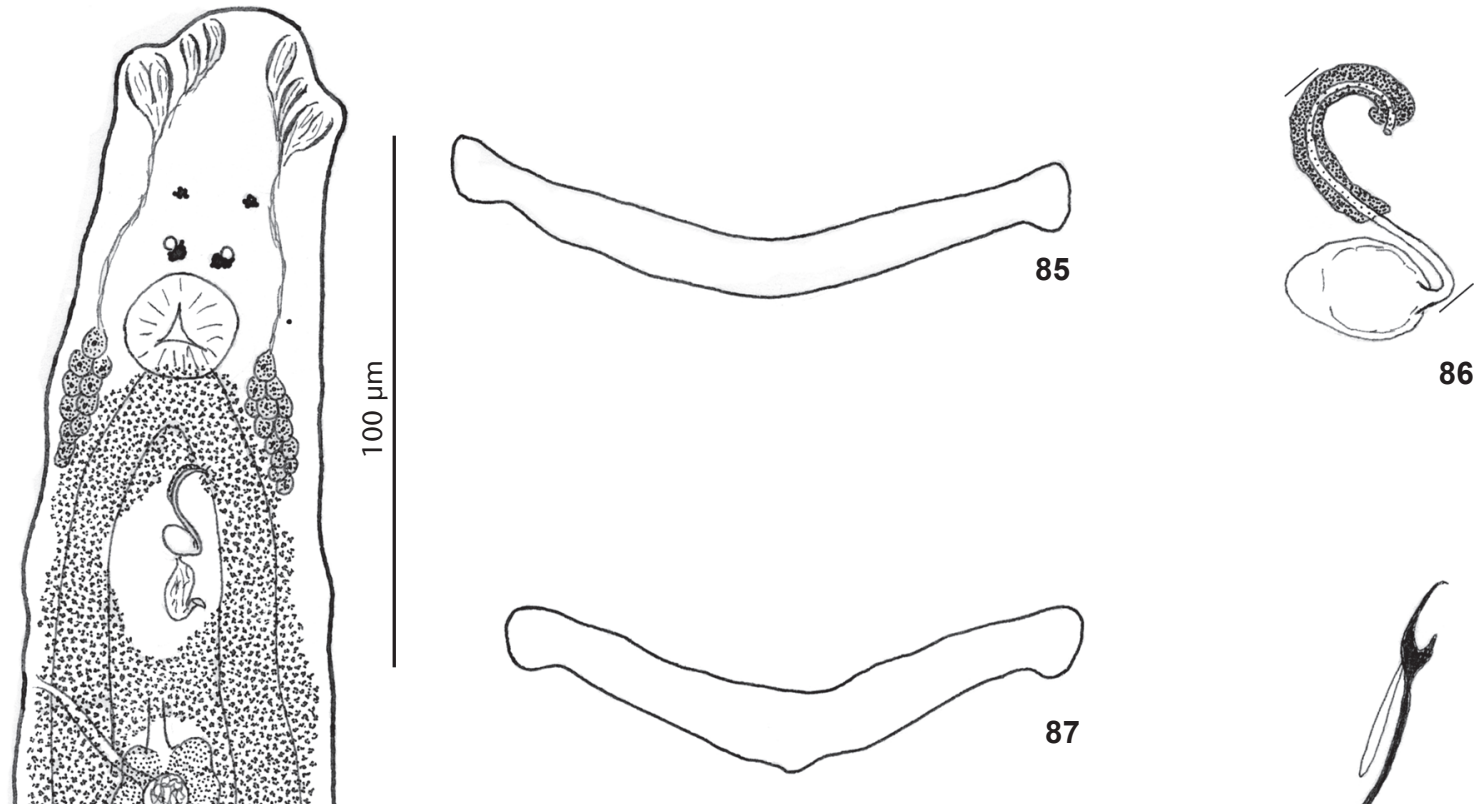

86
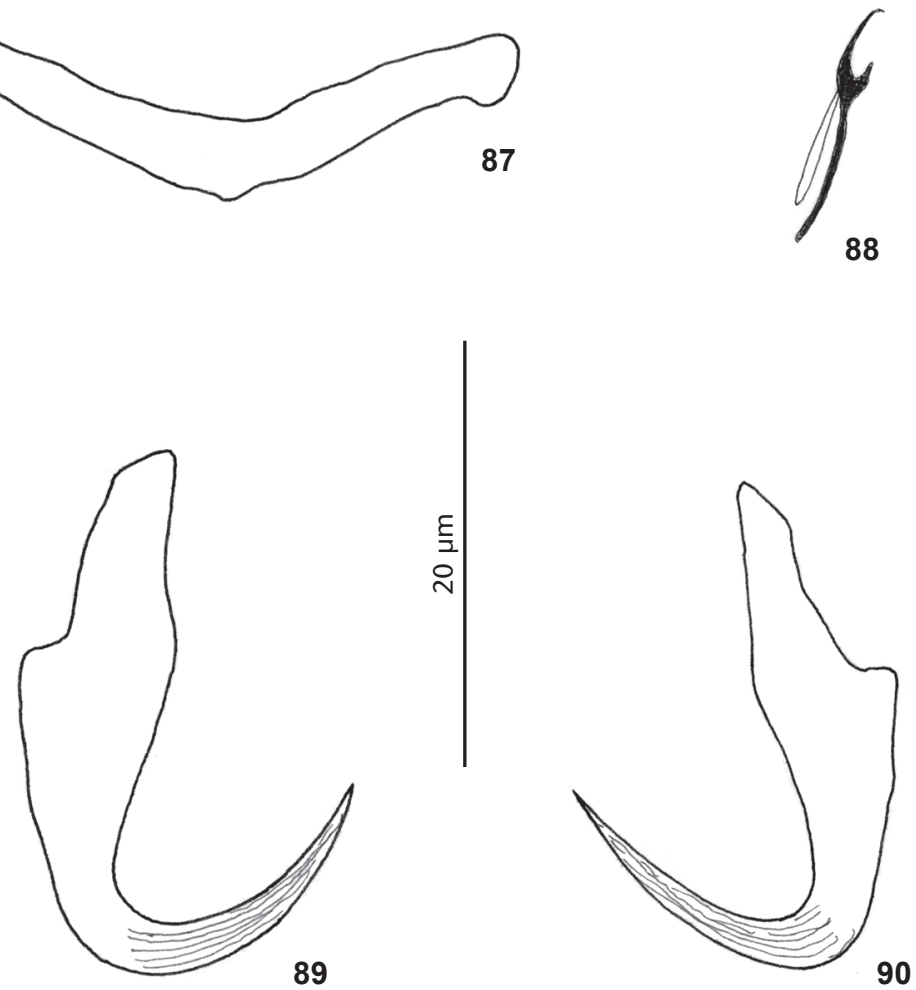

Figures 84-90. Euryhaliotrema cryptophallus sp. nov. from the mangrove red snapper, Lutjanus argentimaculatus, in the Gulf of Tonkin, China. 84. Whole mount (composite, ventral view). 85. Ventral bar. 86. Copulatory complex (ventral view). 87. Dorsal bar. 88. Hook. 89. Ventral anchor. 90. Dorsal anchor. All figures are to the $20 \mu \mathrm{m}$ scale except Fig. 84 (100 $\mu \mathrm{m}$ scale).

LI (2006) described E. lutjani from the mangrove red snapper Lutjanus argentimaculatus (Lutjanidae) and the blackhead seabream Sparus macrocephalus (now Acanthopagrus s. schlegelii) (Sparidae) without identifying the host of the holotype. The mangrove red snapper, however, is presumed to be the type host of E. lutjani based on the specific name of the parasite and the fact that the fish was mentioned first in Li's list of hosts for the species. Li (2006) also provided two sets of coordinates from which the parasites were collected, both of which suggest that the type locality of the species is apparently the environs near Shenzhen, China. The presumed type host and type locality for E. lutjani are provisional pending determination of the host and place of origin of the holotype.

Species of Euryhaliotrema have been reported from the 
gills of fishes representing six perciform families worldwide: the Ambassidae, Chaetodontidae, Haemulidae, Lutjanidae, Sciaenidae and Sparidae. While the level of host specificity appears to vary among individual species of Euryhaliotrema, all species of the genus, other than E. lutjani and E. johni, are currently restricted to hosts representing a single family of fishes. Because of the pattern of host specificity displayed among the other species of Euryhaliotrema, it appears likely that Li (2006) had specimens representing at least two different species when E. lutjani was originally described. Although specimens of $E$. kurodai (USNPC 105466) were encountered upon examination of A. s. schlegelii from the South China Sea (Kritsky \& YANG, unpublished), none of the dactylogyrid specimens collected from this sparid host could be assigned to E. lutjani based on LI's (2006) original description and figures of the species.

\section{Euryhaliotrema guangdongense$$
\text { Li, Yan, Yul, Lan \& Huang, } 2005
$$

Type host and locality: Mangrove red snapper, Lutjanus argentimaculatus (Forsskål), Lutjanidae: Vicinity of Shenzhen, China $\left(22.5^{\circ} \mathrm{N}, 114.3^{\circ} \mathrm{E}\right)$.

Site of infection: Gills.

Previous records: No previous records, except that of the original description (Li et al. 2005).

Remarks: Euryhaliotrema guangdongense differs from all known species of Euryhaliotrema by possessing a coiled MCO with 8-9 counterclockwise rings (all remaining congenerics possess six or fewer rings in the MCO). The species was not collected during the present study, and the type specimens were not available for study.

\section{Euryhaliotrema johni}

\section{(Tripathi, 1959) Kritsky \& Boeger, 2002}

Syns Ancyrocephalus johni Tripathi, 1959; Haliotrema johni (Tripathi, 1959) Young, 1968; Haliotrema johni (Tripathi, 1959) Young, 1968; Euryhaliotrema johnii (Tripathi, 1959) Kritsky \& Boeger, 2002.

Type host and locality: John's snapper, Lutjanus johnii (Bloch), Lutjanidae: River Hooghly, Diamond Harbour, India.

Site of infection: Gills.

Previous records: Lutjanus johnii: River Hooghly, Diamond Harbour, India (as Ancyrocephalus johni) (TRIPATHI 1959); Green Island, Queensland, Australia (as Haliotrema johnii) (Young 1968); Malaysia (as Haliotrema johni) (Anonymous 1991, LEONG \& Wong 1987a, b, 1989, 1992, Liang \& LEONG 1991, 1992); no locality provided (as Haliotrema johni) (Lin \& YI 1993). Lutjanus fulviflamma: Heron Island, Queensland, Australia (as Haliotrema johnii) (Young 1968); no locality provided (as Haliotrema johni) (LiN \& Yi 1993). Lutjanus vaigiensis (now L. fulvus): Guangzhou, Guangdong Province, China $\left(23.2^{\circ} \mathrm{N}\right.$, $113^{\circ} \mathrm{E}$ ) (as Euryhaliotrema johnii) (Li 2005); South China Sea, China (as Haliotrema johnii) (Li et al. 1995). Lutjanus russellii:
South China Sea, China (as Haliotrema johnii) (Li et al. 1995). Lutjanus rhodopterus $^{1}$ : Yangjiang, Guangdong Province, China (as Euryhaliotrema johnii) (Wu et al. 2006). Sparus macrocephalus (now Acanthopagrus s. schlegelii): Zapo, Yangjiang, Guangdong Province, China (as Haliotrema johni) (LIN \& YI 1993); South China Sea, China (as Haliotrema johnii) (Li et al. 1995).

Remarks: The original description of this species as Ancyrocephalus johni from Lutjanus johnii in India by TRIPATHI (1959) is inadequate, and the species requires redescription. While it was not collected during the present study and redescription is not currently possible, illustrations of the haptoral and copulatory sclerites obtained from four of YounG's (1968) voucher specimens of the species deposited in the USNPC (61273) were presented by KRITSKY \& Boeger (2002). Based on these drawings, Euryhaliotrema johni most closely resembles $E$. lutiani. Both species have an MCO with an elongate bananashaped base and short coiled tubular shaft of approximately one ring. Euryhaliotrema johni differs from E. lutiani in the comparative morphology of the anchors, vagina and accessory piece. In E. johni, the bases of the ventral and dorsal anchors are elongate (bases of both anchors comparatively shorter in E. lutiani), the roots of the dorsal anchor are poorly defined (well defined in E. lutiani), the vagina is comparatively long (short in E. lutiani) and the accessory piece lacks a distal hook-like modification (present in E. lutiani).

\section{Euryhaliotrema lutiani \\ (Yamaguti, 1953) Kritsky \& Boeger, 2002}

Syn. Haliotrema lutiani Yamaguti, 1953

Type host and locality: Lutjanus sp., Lutjanidae: Macassar, Celebes.

Site of infection: Gills.

Previous records: Lutjanus sp.: Macassar, Celebes (as Haliotrema lutiani) (YAmagutr 1953); Lutjanus vitta: Guangxi Province, China (as Haliotrema lutiani) (Wang 1997).

Remarks: This species was not collected during the present study. The haptoral and copulatory sclerites of E.lutiani were illustrated by KRITSKY \& BOEGER (2002) based on the holotype and five paratypes deposited in the Meguro Parasitological Museum (MPM), Tokyo, Japan (MPM 22640). Differentiation of the species from its most similar congeneric, E. johni, is presented in the Remarks of the latter species. The record by WANG (1997) of E. lutiani on the gills of Lutjanus vitta requires confirmation; the ventral anchors depicted in fig. 3a of WANG (1997) suggest that this author had specimens of E. johni (see Remarks for E. johni).

\section{Euryhaliotrema fatuum Kritsky \& Justine sp. nov. Figs 91-98}

Description: Body proper subtriangular, tapered anteriorly from level of testis in posterior trunk; greatest width at level of testis. Tegument smooth. Cephalic region broad; cephalic lobes poorly to moderately developed. Four eyespots; mem- 

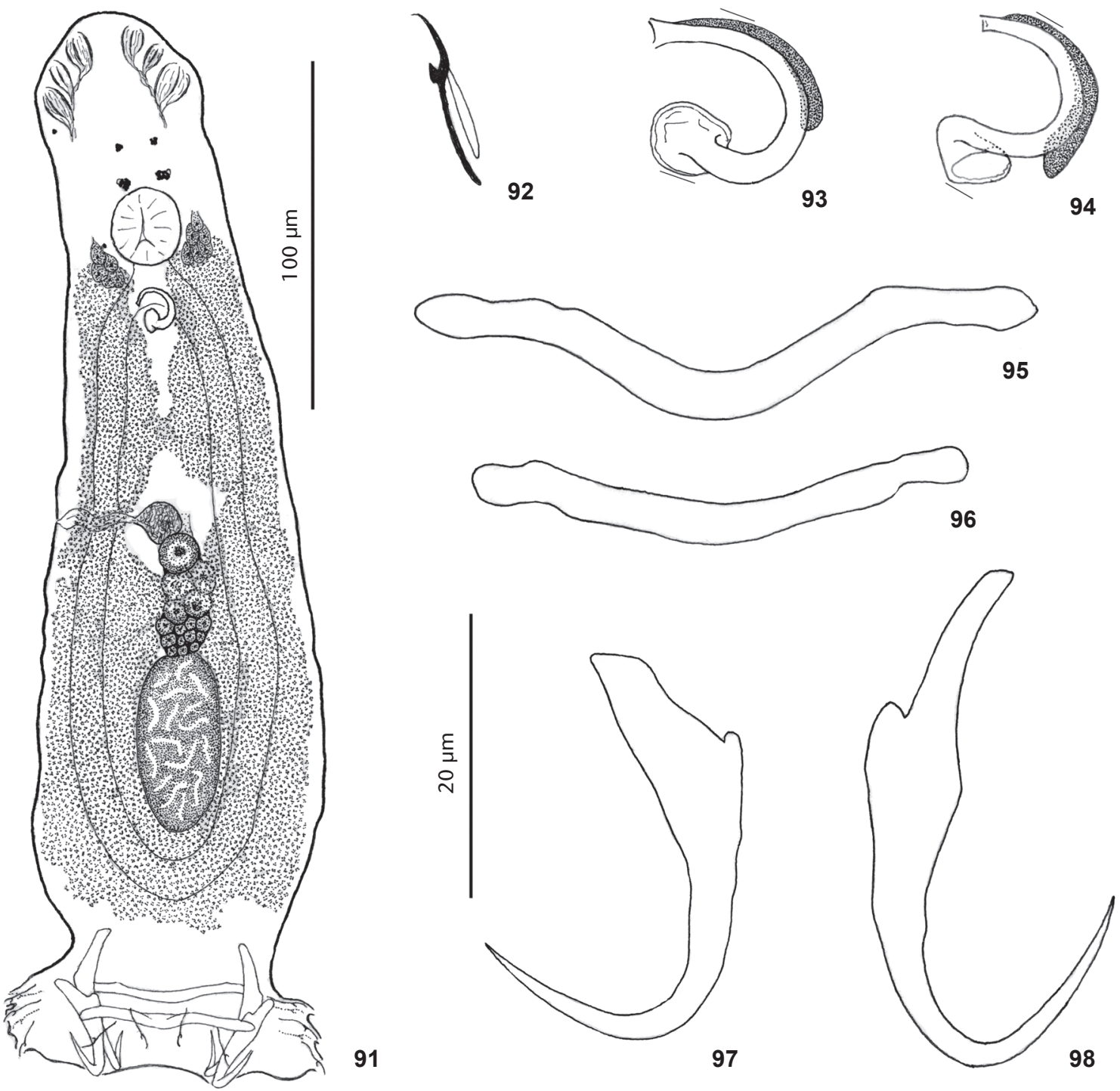

Figures 91-98. Euryhaliotrema fatuum sp. nov. from the dory snapper, Lutjanus fulviflamma, from off Heron Island, Australia. 91. Whole mount (composite, ventral view). 92. Hook. 93, 94. Copulatory complexes (ventral views). 95. Ventral bar. 96. Dorsal bar. 97. Ventral anchor. 98. Dorsal anchor. All figures are to the $20 \mathrm{~mm}$ scale except Fig. 91 (100 $\mu \mathrm{m}$ scale).

bers of posterior pair with lenses, equidistant to those of anterior pair; members of anterior pair infrequently absent or composed of as few as two granules each; accessory chromatic granules uncommon in cephalic region. Pharynx spherical. Peduncle broad; haptor with bilateral lobes containing hook pairs 2-4, 6, 7. Ventral anchor with well-developed superficial root, small deep root, straight shaft, long recurved point extending past level of tip of superficial root. Dorsal anchor with elongate uplifted and delicate superficial root, small deep root, slightly arced shaft, elongate recurved point extending past level of tip of superficial root. Bars similar, broadly U shaped; ven- tral bar with ends directed laterally. Hook with uniform shank, upright acute thumb; FH loop about 3/4 shank length. MCO with funnel-shaped base and tubular coiled shaft of less than one counterclockwise ring, frequently appearing $\mathrm{C}$ shaped. Accessory piece a simple sheath along distal shaft of MCO; articulation process absent. Testis ovate; seminal vesicle, prostatic reservoir not observed. Germarium bacilliform; oviduct, ootype, uterus not observed; vaginal pore marginal, obscure; vaginal canal a delicate broad tube; seminal receptacle medial, pregermarial. Vitellaria dense; bilateral vitelline ducts confluent anterior to seminal receptacle. Egg not observed. 
Type host and locality: Dory snapper, Lutjanus fulviflamma (Forsskål), Lutjanidae: off Heron Island, Great Barrier Reef, Australia $\left(23^{\circ} 27^{\prime}\right.$ S, $\left.151^{\circ} 55^{\prime} \mathrm{E}\right), 18$ July 2001.

Other records: Lutjanus fulviflamma: Récif de Crouy, off Nouméa, New Caledonia $\left(22^{\circ} 21.825^{\prime} \mathrm{S}, 166^{\circ} 21.961^{\prime} \mathrm{E}\right), 13$ May 2008. Lutjanus fulvus: La Régnière, off Nouméa, New Caledonia $\left(22^{\circ} 19.804^{\prime} \mathrm{S}, 166^{\circ} 20.229^{\prime} \mathrm{E}\right), 8$ September 2005.

Site of infection: Gills.

Specimens studied: Holotype, QM G233848; 22 paratypes, QM G233849-856, USNPC 105518; 31 voucher specimens (from L. fulviflamma), USNPC 105519, MNHN JNC2531K1-K10; 23 voucher specimens (from L. fulvus), USNPC 105520, MNHN JNC1591K1-K6, JNC1592K1-K2.

Etymology: The specific name (an adjective) is from Latin (fatuus $=$ simple) and refers to the haptoral and copulatory sclerites.

Measurements (dimensions of specimens from L. fulvus follow those of the type specimens in brackets, respectively): Body $280(252-321 ; \mathrm{n}=14)$ [272 $(226-340 ; \mathrm{n}=6)]$ long; greatest width (excluding haptor) $72(64-81 ; \mathrm{n}=13)$ [74 $(60-92 ; \mathrm{n}=6)]$. Haptor $39(26-49 ; \mathrm{n}=14)$ [48 (41-52; $\mathrm{n}=5)]$ long, $87(75-97 ; \mathrm{n}=$ 13) $[84(62-100 ; \mathrm{n}=5)]$ wide. Pharynx $20(17-24 ; \mathrm{n}=14)[21(16-$ $24 ; \mathrm{n}=6)]$ wide. MCO (proximal ring diameter) $16(14-17 ; \mathrm{n}=6)$ [18 (14-22; n = 3)]. Ventral anchor $33(32-35 ; n=8)$ [31 (29-33; $\mathrm{n}=16)]$ long; dorsal anchor $41(39-43 ; \mathrm{n}=8)$ [38 (35-40; $\mathrm{n}=15)]$ long. Ventral bar $53(51-56 ; \mathrm{n}=8)$ [56 (50-60; $\mathrm{n}=13)]$ long; dorsal bar $40(37-42 ; \mathrm{n}=8)$ [41 $(37-45 ; \mathrm{n}=14)]$ long. Hook 15 $(14-16 ; \mathrm{n}=18)$ [16 (15-17; $\mathrm{n}=28)]$ long. Germarium 38 (27-50; $\mathrm{n}=9)[31(28-35 ; \mathrm{n}=2)]$ long, $17(15-20 ; \mathrm{n}=9)$ [16 (15-17; $\mathrm{n}=$ 2)] wide; testis $54(48-65 ; \mathrm{n}=10)$ [34 $(31-38 ; \mathrm{n}=3)]$ long, 23 (1929; $\mathrm{n}=10)$ [16 $(13-20 ; \mathrm{n}=3)]$ wide.

Remarks: This species resembles E. mehen, E. fajeravilae and $E$. longibaculum, all parasites of lutjanids from the western hemisphere, by the comparative morphology of the haptoral anchors and bars. It differs from the three species by lacking an articulation process connecting the accessory piece to the base of the MCO and by having a sharp recurve of the shaft at its origin from the base in the MCO.

\section{Euryhaliotrema cardinale Kritsky \& Justine sp. nov. Figs 99-104}

Description: Body proper fusiform, tapering anteriorly from level of testis; greatest width in posterior trunk at level of testis. Tegument smooth. Cephalic region narrow; cephalic lobes well developed. Two pairs of eyespots; members of posterior pair with lenses, larger and closer together than members of anterior pair; anterior pair occasionally absent or represented by few small ovate granules; few accessory chromatic granules in cephalic, anterior trunk regions. Pharynx spherical. Peduncle broad, tapered posteriorly; haptor subhexagonal to subtrapezoidal, with lateral lobes. Ventral anchor robust, with poorly differentiated deep root, depressed superficial root, slightly curved shaft, point extending slightly past level of tip of superficial root. Dorsal anchor delicate, with knob-like deep root, elongate superficial root, curved shaft, point extending to level of tip of superficial root; base with diagonal hinge (thinning). Dorsal and ventral bars similar, each appearing as broad U or V shapes with slightly enlarged ends. Hook with uniform shank, upright acute thumb; FH loop about shank length. MCO with funnel-shaped base and delicate tubular shaft arranged as a counterclockwise coil of about one and a half rings. Accessory piece comprising variable distal sheath with articulation process extending within rings to base of MCO. Testis elongate ovate; vas deferens, seminal vesicle not observed; single prostatic reservoir large, lying to left of MCO. Germarium bacilliform; Mehlis' gland poorly developed; uterus delicate, midventral. Vaginal pore marginal; vaginal canal short, lightly sclerotized, with distal loop; seminal receptacle pregermarial, pyriform, with neck extending to ventral side of right intestinal cecum to unite with vaginal canal. Vitellaria dense; bilateral vitelline ducts extending from lateral bands toward midline anterior to seminal receptacle, joining to form common vitelline duct. Egg not observed.

Type host and locality: Dory snapper, Lutjanus fulviflamma (Forsskål), Lutjanidae: Récif de Crouy, off Nouméa, New Caledonia $\left(22^{\circ} 21.825^{\prime}\right.$ S, $\left.166^{\circ} 21.961^{\prime} \mathrm{E}\right), 13$ May 2008.

Other records: Lutjanus fulviflamma: off Heron Island, Great Barrier Reef, Australia $\left(23^{\circ} 27^{\prime} \mathrm{S}, 151^{\circ} 55^{\prime} \mathrm{E}\right), 18$ July 2001 . Lutjanus ehrenbergii: Nabq Bay, Ras Mohammed National Park (South Sinai, Red Sea), (28 $\left.02^{\prime} 52^{\prime \prime} \mathrm{N}, 34^{\circ} 26^{\prime} 21^{\prime \prime} \mathrm{E}\right), 23$ October 2005.

Site of infection: Gills.

Specimens studied: Holotype, MNHN JNC2531K11; 5 paratypes, MNHN JNC2531K12, USNPC 105521; 10 voucher specimens (from L. fulviflamma, Australia), QM G233857-860, USNPC 105523; 8 voucher specimens (from L. ehrenbergii), USNPC 105522.

Etymology: The specific name (an adjective) is from Latin (cardinis $=$ a hinge +- alis $=$ pertaining to $)$ and refers to the diagonal thin of the base that allows dorsoflexion of the dorsal anchor.

Measurements (dimensions of specimens from $L$. ehrenbergii follow those of the type specimens in brackets, respectively): Body $289(282-296 ; n=2)$ [417-418 ( $n=1)]$ long; greatest width (excluding haptor) $63(60-66 ; \mathrm{n}=2)$ [73-74 $(\mathrm{n}=$ 1)]. Haptor 54-55 $(n=1)$ [63-64 $(n=1)]$ long, 74-75 $(n=1)$ [77-78 $(\mathrm{n}=1)]$ wide. Pharynx 19-20 $(\mathrm{n}=2)[20-21(\mathrm{n}=1)]$ wide. MCO (proximal ring diameter) $20(15-24 ; \mathrm{n}=4)$ [20 (17-23; $\mathrm{n}=4)]$. Ventral anchor $44(42-45 ; \mathrm{n}=4)$ [43 $(38-45 ; \mathrm{n}=6)]$ long; dorsal anchor $47(44-49 ; \mathrm{n}=4)$ [47 (44-48; n = 6)] long. Ventral bar 37 $(35-39 ; \mathrm{n}=2)$ [39 (37-40; $\mathrm{n}=6)]$ long; dorsal bar $34(32-37 ; \mathrm{n}=2)$ [35 (33-36; $\mathrm{n}=6)]$ long. Hook $12(11-13 ; \mathrm{n}=11)$ [13 (12-14; $\mathrm{n}=$ 14)] long. Germarium $29(20-37 ; \mathrm{n}=2)$ long, $17(15-19 ; \mathrm{n}=2)$ wide; testis $40(29-52 ; \mathrm{n}=2)$ long, $21(19-23 ; \mathrm{n}=2)$ wide.

Remarks: Euryhaliotrema cardinale resembles the following species by having a thinning of the base of the dorsal anchor that allows dorsoflexion of the anchor shaft and point toward the tip of the superficial root: E. fastigatum, E. distinctum, E. tormocleithrum, E. ramulum, E. cognatus and E. diplops, all of which are parasites of lutjanid hosts. It differs from $E$. fastigatum 

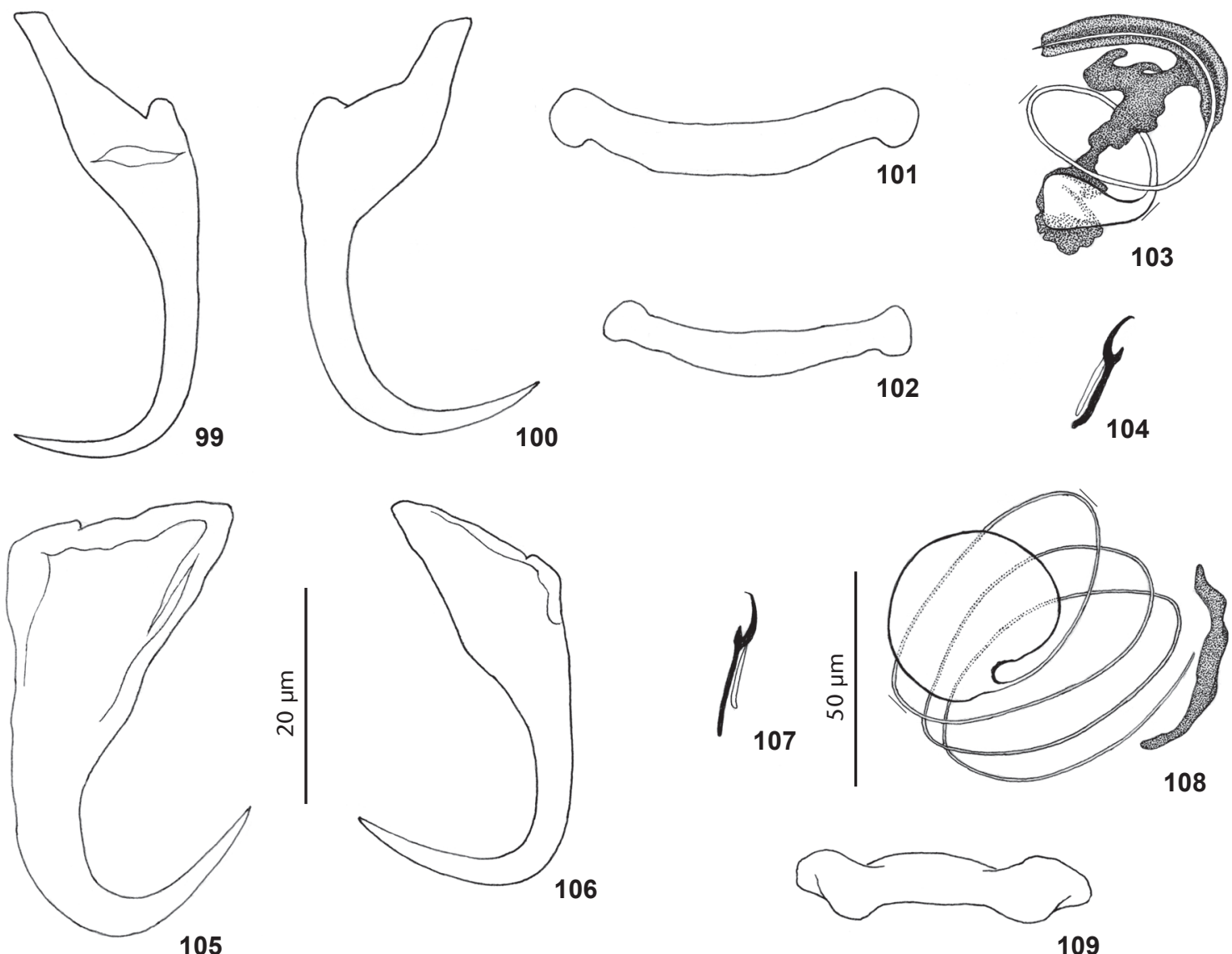

106
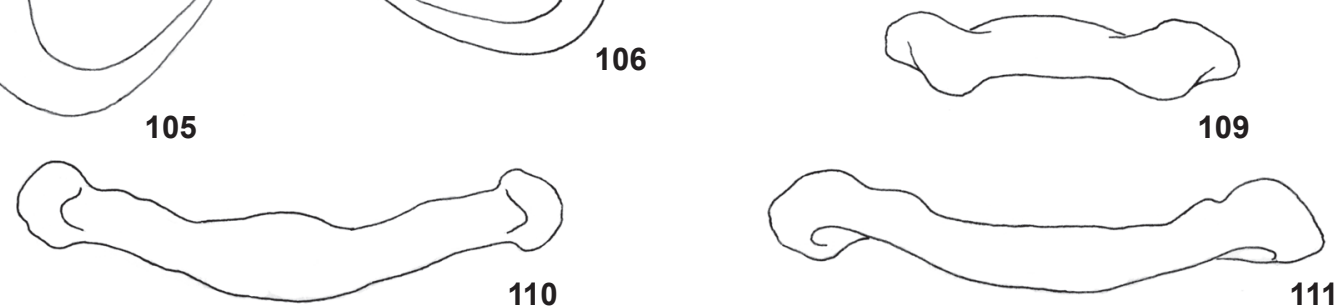

Figures 99-111. Haptoral and copulatory sclerites of Euryhaliotrema spp. from snappers of the Indo-Pacific Ocean. 99-104. Euryhaliotrema cardinale sp. nov. from the dory snapper, Lutjanus fulviflamma, from New Caledonia. 99. Dorsal anchor. 100. Ventral anchor. 101. Ventral bar. 102. Dorsal bar. 103. Copulatory complex (ventral view). 104. Hook. 105-111. Euryhaliotrema chrysotaeniae from Russell's snapper, Lutjanus russellii, from New Caledonia. 105. Ventral anchor. 106. Dorsal anchor. 107. Hook. 108. Copulatory complex (dorsal view). 109. Ventral bar. 110, 111. Dorsal bars. All figures are drawn to the $20 \mu \mathrm{m}$ scale except Fig. 108 (50 $\mu \mathrm{m}$ scale).

by possessing an articulation process connecting the accessory piece to the base of the MCO, and is easily differentiated from E. distinctum and E. tormocleithrum by lacking modifications of the superficial root of the ventral anchor (Figs 124, 126), from E. diplops by having two pairs of eyespots and fewer rings in the coiled male copulatory organ (approximately one and a half rings in E. cardinale and about three rings in E. diplops) and from E. ramulum by lacking bifurcated ends of the ventral bar. It most closely resembles E. cognatus in the general morphology of the haptoral sclerites but differs from it by having a greater diameter of the basal ring of the more delicate tubular shaft of the MCO (Fig. 115).

\section{Euryhaliotrema chrysotaeniae} (Young, 1968) Kritsky \& Boeger, 2002

Figs 105-111

Syn. Haliotrema chrysotaeniae Young, 1968

Type host and locality: Spanish flag snapper, Lutjanus chrysotaenia (Bleeker) (now L. carponotatus), Lutjanidae: Heron Island, Queensland, Australia.

Source of current specimens: Spanish flag snapper, Lutjanus carponotatus, Lutjanidae: off Heron Island, Great Barrier Reef, Australia (23⒉'S, $\left.151^{\circ} 55^{\prime} \mathrm{E}\right), 21$, 22 July 2001. Russell's snapper, Lutjanus russellii, Lutjanidae: La Régnière, off Nouméa, 
New Caledonia $\left(22^{\circ} 19.804^{\prime} \mathrm{S}, 166^{\circ} 20.229^{\prime} \mathrm{E}\right), 8$ September 2005 ; fish market, Nouméa, New Caledonia (20 June 2007). Five-lined snapper, Lutjanus quinquelineatus, Lutjanidae (new host record): La Régnière, off Nouméa, New Caledonia $\left(22^{\circ} 19.804^{\prime} S\right.$, $\left.166^{\circ} 20.229^{\prime} \mathrm{E}\right), 19$ March 2007. Dory snapper, Lutjanus fulviflamma, Lutjanidae (new host record): Récif de Crouy, off Nouméa, New Caledonia $\left(22^{\circ} 21.825^{\prime}\right.$ S, $\left.166^{\circ} 21.961^{\prime} \mathrm{E}\right), 13$ May 2008 (this record requires confirmation, see Remarks). Blacktail snapper, Lutjanus fulvus, Lutjanidae: La Régnière, off Nouméa, New Caledonia $\left(22^{\circ} 19.804^{\prime}\right.$ S, $166^{\circ} 20.229^{\prime}$ E), 8 September 2005.

Site of infection: Gills.

Specimens studied: 14 voucher specimens (from $L$. carponotatus), USNPC 105527, QM G233861-865; 26 voucher specimens (from L. russellii), USNPC 105524, 105525, MNHN JNC1582K1-K2, JNC1583K1, JNC1584K1, JNC1585K1-K3, JNC1586K1-K3; 15 voucher specimens (from L. quinquelineatus), USNPC 105529, MNHN JNC2143K1, JNC2145K1-K3, JNC2147K1; voucher specimen (from L. fulviflamma), USNPC 105526; 10 voucher specimens (from L. fulvus), USNPC 105528, MNHN JNC1591K7-K10.

Previous records: Lutjanus chrysotaenia (now $L$. carponotatus): Heron Island, Queensland, Australia (as Haliotrema chrysotaeniae) (Young 1968). Lutjanus fulvus: Moorea Island, Society Archipelago, French Polynesia (17³0'S, $\left.149^{\circ} 50^{\prime} \mathrm{W}\right)$; Marquesas Islands near Ua Huka, French Polynesia $\left(8^{\circ} 57^{\prime} \mathrm{S}, 139^{\circ} 35^{\prime} \mathrm{W}\right)$; south coast of $\mathrm{O}^{\prime} \mathrm{ahu}$, Hawaiian Islands $\left(21^{\circ} 17^{\prime} \mathrm{N}, 157^{\circ} 53^{\prime} \mathrm{W}\right.$ ) (all as Euryhaliotrema chrysotaeniae) (VIGNON et al. 2009). Lutjanus kasmira: Moorea Island, Society Archipelago, French Polynesia $\left(17^{\circ} 30^{\prime} \mathrm{S}, 149^{\circ} 50^{\prime} \mathrm{W}\right)$; Marquesas Islands near Ua Huka, French Polynesia ( $\left.8^{\circ} 57^{\prime} \mathrm{S}, 139^{\circ} 35^{\prime} \mathrm{W}\right)$; south coast of $\mathrm{O}^{\prime} \mathrm{ahu}$, Hawaiian Islands $\left(21^{\circ} 17^{\prime} \mathrm{N}, 157^{\circ} 53^{\prime} \mathrm{W}\right.$ ) (all as Euryhaliotrema chrysotaeniae) (VIGNon et al. 2009). Lutjanus russellii: Guangdong Province, China $\left(23^{\circ} 08^{\prime} \mathrm{N}, 113^{\circ} 15^{\prime} \mathrm{E}\right)$ (as Euryhaliotrema chrysotaeniae) (LI \& YAN 2007).

Measurements: Table V.

Remarks: This species was originally described by YounG (1968) as Haliotrema chrysotaeniae and subsequently transferred

Table V. Measurements of Euryhaliotrema chrysotaeniae from four species of Lutjanus.

\begin{tabular}{|c|c|c|c|c|}
\hline & L. russellii & L. quinquelineatus & L. carponotatus & L. fulvus \\
\hline \multicolumn{5}{|l|}{ Body } \\
\hline Length & $662(632-689 ; \mathrm{n}=3)$ & - & $570(542-598 ; \mathrm{n}=2)$ & $482(472-492 ; n=2)$ \\
\hline Width $^{1}$ & $116(113-120 ; n=3)$ & - & $97(90-105 ; n=2)$ & $121(110-132 ; \mathrm{n}=2)$ \\
\hline \multicolumn{5}{|l|}{ Haptor } \\
\hline Length & $76(66-84 ; n=3)$ & - & - & $72(58-85 ; n=2)$ \\
\hline Width & $95(90-104 ; n=3)$ & - & - & $93(90-95 ; n=2)$ \\
\hline \multicolumn{5}{|l|}{ Pharynx } \\
\hline Width & $34(32-36 ; n=3)$ & - & $32(30-34 ; \mathrm{n}=2)$ & $33(32-34 ; n=2)$ \\
\hline \multicolumn{5}{|l|}{$\mathrm{MCO}$} \\
\hline Ring diameter & $50(43-58 ; n=16)$ & $48(46-49 ; n=2)$ & $53(48-58 ; n=11)$ & $44(36-48 ; n=7)$ \\
\hline \multicolumn{5}{|l|}{ Testis } \\
\hline Length & $69(58-75 ; \mathrm{n}=3)$ & - & $69(63-74 ; n=2)$ & - \\
\hline Width & $49(45-54 ; n=3)$ & - & $52(51-53 ; \mathrm{n}=2)$ & - \\
\hline \multicolumn{5}{|l|}{ Germarium } \\
\hline Length & $52(41-59 ; \mathrm{n}=3)$ & - & $51(49-52 ; \mathrm{n}=2)$ & - \\
\hline Width & $33(31-35 ; \mathrm{n}=3)$ & - & $29(23-34 ; n=2)$ & - \\
\hline \multicolumn{5}{|l|}{ Ventral anchor } \\
\hline Length & $39(37-41 ; \mathrm{n}=16)$ & $38(34-41 ; n=5)$ & $39(37-41 ; n=9)$ & $41(38-42 ; n=8)$ \\
\hline \multicolumn{5}{|l|}{ Dorsal anchor } \\
\hline Length & $36(34-39 ; \mathrm{n}=16)$ & $36(33-39 ; n=6)$ & $36(34-38 ; n=10)$ & $37(35-40 ; n=8)$ \\
\hline \multicolumn{5}{|l|}{ Ventral bar } \\
\hline Length & $25(22-28 ; n=13)$ & $25(22-30 ; n=7)$ & $26(22-31 ; n=9)$ & $26(23-29 ; n=9)$ \\
\hline \multicolumn{5}{|l|}{ Dorsal bar } \\
\hline Length & $42(38-46 ; n=13)$ & $41(39-46 ; n=6)$ & $39(36-40 ; n=10)$ & $41(38-42 ; n=9)$ \\
\hline \multicolumn{5}{|l|}{ Hook } \\
\hline Length & $16(15-17 ; \mathrm{n}=27)$ & $16(15-17 ; n=7)$ & $16(15-17 ; \mathrm{n}=17)$ & $16(15-17 ; \mathrm{n}=8)$ \\
\hline
\end{tabular}

${ }^{1}$ Excluding haptor. 
to Euryhaliotrema by Kritsky \& Boeger (2002), who based the transfer on their examination of the two type specimens (USNPC 61274, 61275). The original description is adequate except that Young (1968) indicated that only 12 hooks were observed in the haptor of the two preserved type specimens. Based on his drawing of the holotype [fig. 7(a)], Young (1968) apparently missed the members of hook pair 5 which lie near the level of the shafts and points of the ventral anchors. Examination of the unstained specimens collected during the present study demonstrated that the species possesses the full complement of 14 hooks (7 pairs) normally present in dactylogyrid species (Mizelle \& Price 1963), although hook pair 5 is often difficult to find in some specimens depending on the position and orientation of the ventral anchors.

Euryhaliotrema chrysotaeniae differs from all other congenerics by possessing a coiled MCO with three to four clockwise rings; in all other congenerics, the coiled MCO is counterclockwise. The direction of the coil is correctly shown in the drawings of the MCO (ventral views) of both Young (1968) and Kritsky \& Boeger (2002) and is verified in the present collection of specimens (Fig. 108, dorsal view).

The present record of E. chrysotaeniae on the gills of $L$. fulviflamma from New Caledonia requires confirmation, as it is based on a single damaged specimen with the haptor torn away. Verification of the record will involve collection and examination of complete specimens from the dory snapper from New Caledonia, in order to verify haptoral morphology.

\section{Euryhaliotrema cognatus Kritsky \& Galli sp. nov. Figs 112-118}

Description: Body proper fusiform; greatest width usually in posterior trunk at level of testis. Tegument smooth. Cephalic region broad; cephalic lobes moderately developed. Four eyespots; members of posterior pair with lenses, equidistant and larger than members of anterior pair; few accessory chromatic granules in cephalic region. Pharynx spherical. Peduncle broad, slightly tapered posteriorly; haptor subhexagonal, with lateral lobes. Ventral anchor with short superficial root, knob-like deep root, curved moderately long shaft, point extending past level of tip of superficial root. Dorsal anchor with elongate superficial root, poorly developed deep root, curved shaft, point extending past level of tip of superficial root; base with diagonal hinge, proximal portion frequently bent toward midline of haptor at hinge. Ventral bar a slightly curved rod with enlarged ends; dorsal bar straight, with ends directed posterolaterally. Hook with uniform shank, upright acute thumb; FH loop about shank length. Tubular coiled shaft of MCO having about two counterclockwise rings originating from bulbous base. Accessory piece comprising variable sheath along distal shaft of MCO; articulation process within rings of male copulatory complex. Testis ovate; proximal vas deferens not observed; seminal vesicle subspherical, lying immediately posterior to MCO; ejaculatory duct looping anteriorly from semi- nal vesicle before entering base of $\mathrm{MCO}$; prostatic reservoir small, lying to left of base of MCO. Germarium pyriform; oviduct, ootype, uterus not observed. Vaginal pore marginal; vaginal vestibule with wall having variably sclerotized regions; vaginal canal funnel shaped, narrowing to fine duct before entering medial seminal receptacle. Vitellaria dense; transverse vitelline duct anterior to seminal receptacle. Egg not observed.

Type host and locality: Two-spot red snapper, Lutjanus bohar (Forsskål), Lutjanidae: off Malé, Republic of Maldives, 5 April 2007.

Other record: Lutjanus gibbus: off Malé, Republic of Maldives, 5 April 2007.

Site of infection: Gills.

Specimens studied: Holotype, USNPC 105530; 33 paratypes, USNPC 105531. 5 voucher specimens (from L. gibbus), USNPC 105532.

Etymology: The specific name (a noun) is from Latin (cognatus $=$ a relative) and refers to the species relationship with other members of Euryhaliotrema.

Measurements (dimensions of specimens from L. gibbus follow those of the type specimens in brackets, respectively): Body $290(251-330 ; \mathrm{n}=17)$ [305-306 $(\mathrm{n}=1)]$ long; greatest width (excluding haptor) $63(43-87 ; \mathrm{n}=17)$ [72-73 $(\mathrm{n}=1)]$. Haptor $51(45-63 ; \mathrm{n}=16)$ [72-73 $(\mathrm{n}=1)]$ long, $65(56-76 ; \mathrm{n}=$ 16) $[62-63(\mathrm{n}=1)]$ wide. Pharynx $20(17-22 ; \mathrm{n}=16)[21-22(\mathrm{n}=$ 1)] wide. MCO (proximal ring diameter) $10(8-12 ; \mathrm{n}=12)[11$ $(10-12 ; \mathrm{n}=2)]$. Ventral anchor $39(37-42 ; \mathrm{n}=16)$ [39 (37-40; $\mathrm{n}$ = 3)] long; dorsal anchor $39(36-42 ; n=8)$ [37-38 $(n=1)]$ long. Ventral bar $34(31-37 ; \mathrm{n}=12)$ [35-36 $(\mathrm{n}=2)]$ long; dorsal bar $34(32-40 ; \mathrm{n}=12)$ [32 (31-33; $\mathrm{n}=2)]$ long. Hook $13(12-14 ; \mathrm{n}=$ 30) $[13(12-14 ; \mathrm{n}=5)]$ long. Germarium $42(32-50 ; \mathrm{n}=5)$ long, $22(20-25 ; \mathrm{n}=5)$ wide; testis $54(43-63 ; \mathrm{n}=12)$ [57-58 $(\mathrm{n}=1)]$ long, $31(24-39 ; \mathrm{n}=12)$ [35-36 ( $\mathrm{n}=1)]$ wide.

Remarks: The copulatory complex of E. cognatus resembles those of E. monacanthus and E. thatcheri, both parasites of freshwater sciaenids, Plagioscion spp., in South America. It differs from these species by possessing an articulation process connecting the accessory piece to the bulbous base of the MCO (accessory piece and MCO unarticulated in E. monacanthus and $E$. thatcheri). It differs further from E. monacanthus by having ventral and dorsal anchor/bar complexes in the haptor (dorsal anchor/bar complex absent, apparently representing a secondary loss, in E. monacanthus).

\section{Euryhaliotrema distinctum Kritsky \& Galli sp. nov.} Figs 119-124

Description: Body proper fusiform; greatest width in anterior trunk at level of copulatory complex. Tegument smooth. Cephalic region broad; cephalic lobes well developed. Single pair of eyespots, each with conspicuous lens; accessory chromatic granules small, ovate, uncommon in cephalic region. Pharynx subspherical to subovate. Peduncle broad; haptor subhexagonal, with lateral lobes. Ventral anchor robust, lacking deep root, with 

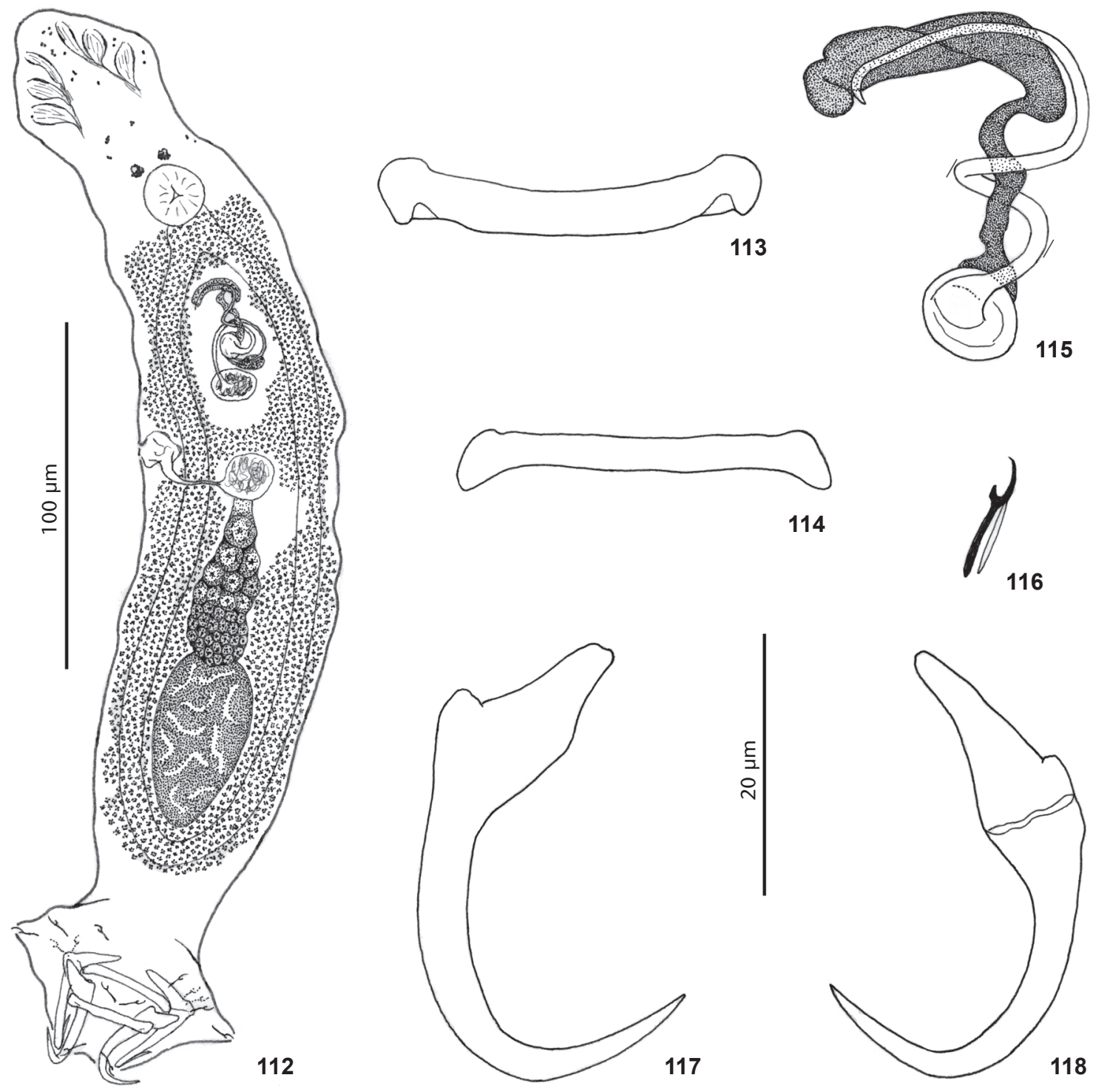

114
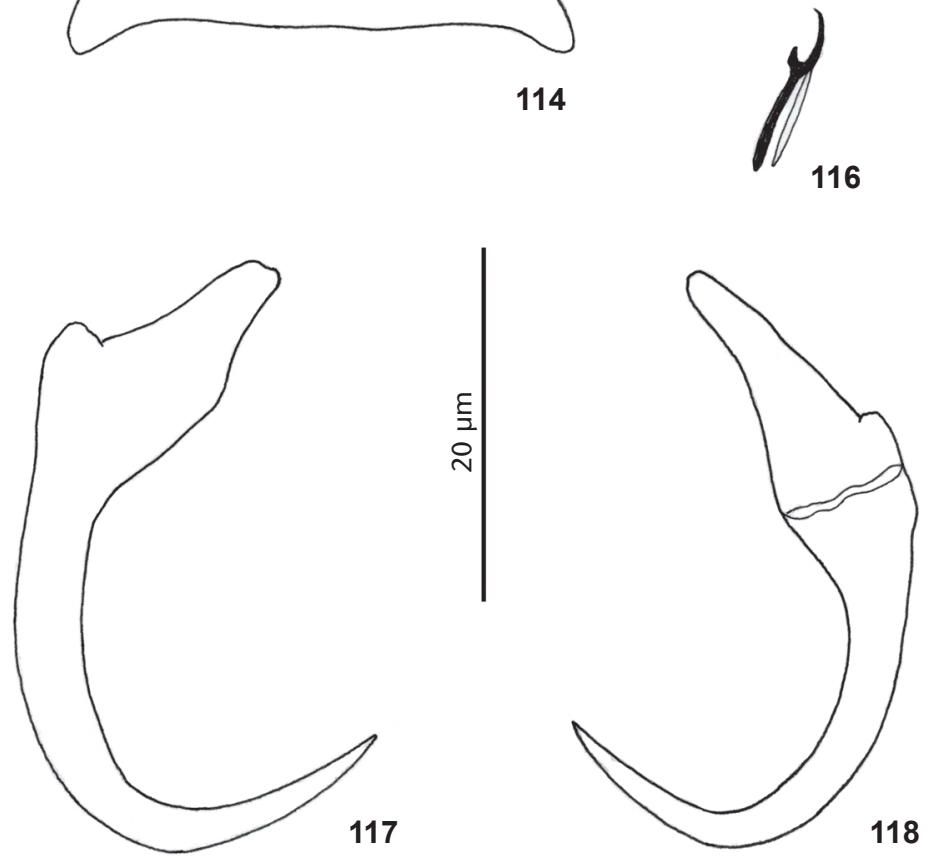

Figures 112-118. Euryhaliotrema cognatus sp. nov. from the two-spot red snapper, Lutjanus bohar, from the Republic of Maldives. 112. Whole mount (composite, ventral view). 113. Ventral bar. 114. Dorsal bar. 115. Copulatory complex (ventral view). 116. Hook. 117. Ventral anchor. 118. Dorsal anchor. All figures are to the $20 \mathrm{~mm}$ scale except Fig. $112(100 \mu \mathrm{m}$ scale).

short depressed superficial root, heavy shaft constricted distally, elongate point extending past level of tip of superficial root; point with longitudinal superficial ridges. Dorsal anchor with elongate superficial root, poorly developed deep root, robust straight irregular shaft; point extending slightly past level of tip of superficial root; base with diagonal hinge, proximal portion may be bent toward body midline at hinge; point with longitudinal superficial ridges. Ventral bar rod shaped, with bifurcated ends and anteromedial rectangular ridge; dorsal bar straight, subtrapezoidal, anterior margin shorter than posterior margin.
Hook with uniform shank, upright acute thumb; FH loop about shank length. MCO a coil of about one counterclockwise ring originating from broad cone-shaped base. Accessory piece comprising variable distal sheath; articulation process present within ring of shaft of MCO. Testis elongate ovate; proximal vas deferens not observed; indistinct seminal vesicle lying sinistroposterior to base of MCO; prostatic reservoir not observed. Germarium bacilliform; oviduct, ootype, uterus not observed. Vaginal pore marginal; vagina, seminal receptacle not observed. Vitellaria dense. Egg not observed. 
Type host and locality: Two-spot red snapper, Lutjanus bohar (Forsskål), Lutjanidae: off Malé, Republic of Maldives, 5 April 2007.

Site of infection: Gills.

Specimens studied: Holotype, USNPC 105533; paratype, USNPC 105534.

Etymology: The specific name (an adjective) is from the Latin distinctus (separate, different) and refers to the unique copulatory complex and anchors.

Measurements: Body 364-365 ( $\mathrm{n}=1)$ long; greatest width (excluding haptor) 65-66 $(\mathrm{n}=1)$. Haptor 58-59 $(\mathrm{n}=1)$ long, 74-75 ( $\mathrm{n}=1)$ wide. Pharynx 23-24 $(\mathrm{n}=1)$ wide. MCO (proximal ring diameter) $17(15-20 ; n=2)$. Ventral anchor 43-44 $(\mathrm{n}=$ 1) long; dorsal anchor 53-54 $(\mathrm{n}=1)$ long. Ventral bar 34 (33$36 ; \mathrm{n}=2)$ long; dorsal bar $34(32-36 ; \mathrm{n}=2)$ long. Hook 12-13 ( = 3) long. Germarium 49-50 ( $n=1)$ long, 19-20 ( $n=1)$ wide; testis 45-46 ( $\mathrm{n}=1)$ long, 20-21 ( $\mathrm{n}=1)$ wide.

Remarks: Euryhaliotrema distinctum differs from all congeneric species by its unique anchors and large cone-shaped base of the MCO. Although only two specimens of this species were collected from the two-spot red snapper off the Maldive Islands, the unique features of the anchors and copulatory complex justify proposal of the form as a new species of Euryhaliotrema.

\section{Euryhaliotrema tormocleithrum Kritsky \& Galli sp. nov.}

Figs 125-131

Description: Body proper fusiform; greatest width usually in posterior trunk at level of testis. Tegument smooth. Cephalic region broad; cephalic lobes moderately to poorly developed; anterior trunk narrowed. Four eyespots; members of respective pairs equidistant; posterior eyespots with lenses, larger than members of anterior pair; accessory chromatic granules ovate, variable in size, scattered throughout cephalic and anterior trunk regions. Pharynx ovate. Peduncle short, broad, tapered posteriorly; haptor subhexagonal, with bilateral lobes. Ventral anchor with short depressed superficial root, small knob-like deep root, evenly curved shaft and point; point extending well past level of tip of superficial root; anchor base with medial depression receiving ends of ventral bar. Dorsal anchor with elongate superficial root, poorly developed deep root, long curved shaft, point extending slightly past level of tip of superficial root; base with diagonal hinge, proximal portion of base occasionally bent at hinge toward midline of haptor. Ventral bar robust, with posteromedial triangular protuberance with medial perforation; dorsal bar a straight rod, frequently with medial constriction. Hook with uniform shank, upright acute thumb; FH loop about shank length. MCO with funnelshaped base, coiled tubular shaft having about one and one half counterclockwise rings. Accessory piece comprising variable sheath along distal portion of shaft of MCO; articulation process united with proximal end of accessory piece. Testis ovate; vas deferens, seminal vesicle, prostatic reservoir not ob- served. Germarium bacilliform; oviduct, ootype, uterus not observed; Mehlis' gland well developed. Vaginal pore marginal at level of germarium; vaginal canal not observed. Vitellaria dense; bilateral vitelline ducts confluent anterior to germarium. Egg not observed.

Type host and locality: Humpback red snapper, Lutjanus gibbus (Forsskål), Lutjanidae: off Malé, Republic of Maldives, 5 April 2007.

Site of infection: Gills.

Specimens studied: Holotype, USNPC 105535; 12 paratypes, USNPC 105536.

Etymology: The specific name (a noun) is from Greek (tormos $=$ a hole + kleithron $=\mathrm{a}$ bar) and refers to the ventral bar.

Measurements: Body $413(366-486 ; \mathrm{n}=3)$ long; greatest width (excluding haptor) $74(63-82 ; \mathrm{n}=3)$. Haptor $63(58-69$; $\mathrm{n}=4)$ long, $75(70-77 ; \mathrm{n}=4)$ wide. Pharynx $22(20-25 ; \mathrm{n}=3)$ wide. MCO (proximal ring diameter) $24(22-27 ; \mathrm{n}=5)$. Ventral anchor 40 (38-41; $\mathrm{n}=8)$ long; dorsal anchor $50(46-54 ; \mathrm{n}=7)$ long. Ventral bar 49 (45-51; $\mathrm{n}=7)$ long; dorsal bar 37 (35-38; $\mathrm{n}$ = 7) long. Hook $14(12-15 ; \mathrm{n}=15)$ long. Germarium 44-45 ( $\mathrm{n}=$ 1) long, 22-23 ( $\mathrm{n}=1)$ wide; testis $56(54-58 ; \mathrm{n}=2)$ long, 32 (2638; $\mathrm{n}=2$ ) wide.

Remarks: Available specimens of E. tormocleithrum were in generally poor condition. Nonetheless, the species is easily separated from all congeners except $E$. monoporosum by having a ventral bar with a perforated posteromedial protuberance and a ventral anchor with a reduced superficial root and a medial cavity in the base receiving the ends of the ventral bar. The new species is differentiated from E. monoporosum, a parasite of chaetodontid fishes, by possessing haptoral anchors with elongate shafts and points. In addition, the superficial root of the dorsal anchor is long and delicate in E. tormocleithrum, while the corresponding root in E. monoporosum is comparatively short and thickset.

\section{Euryhaliotrema ramulum Kritsky \& Galli sp. nov.} Figs 132-137

Description: Body proper fusiform, tapering anteriorly from level of testis; greatest width usually in posterior trunk at level of testis. Tegument smooth. Cephalic region broad; cephalic lobes poorly differentiated. Usually single pair of eyespots present; one or both members of anterior pair usually absent, poorly developed (if present); each member of posterior pair with conspicuous lens; accessory chromatic granules small, ovate to subspherical, scattered in cephalic and trunk regions (infrequently absent). Pharynx spherical. Peduncle broad, tapered posteriorly; haptor subhexagonal, with bilateral lobes. Ventral anchor with moderately long superficial root, poorly developed deep root, short shaft, point extending slightly past level of tip of superficial root. Dorsal anchor with elongate superficial root, poorly developed deep root, evenly curved shaft and point; point extending slightly past level of tip of superficial root; base with diagonal hinge, proximal portion of base 

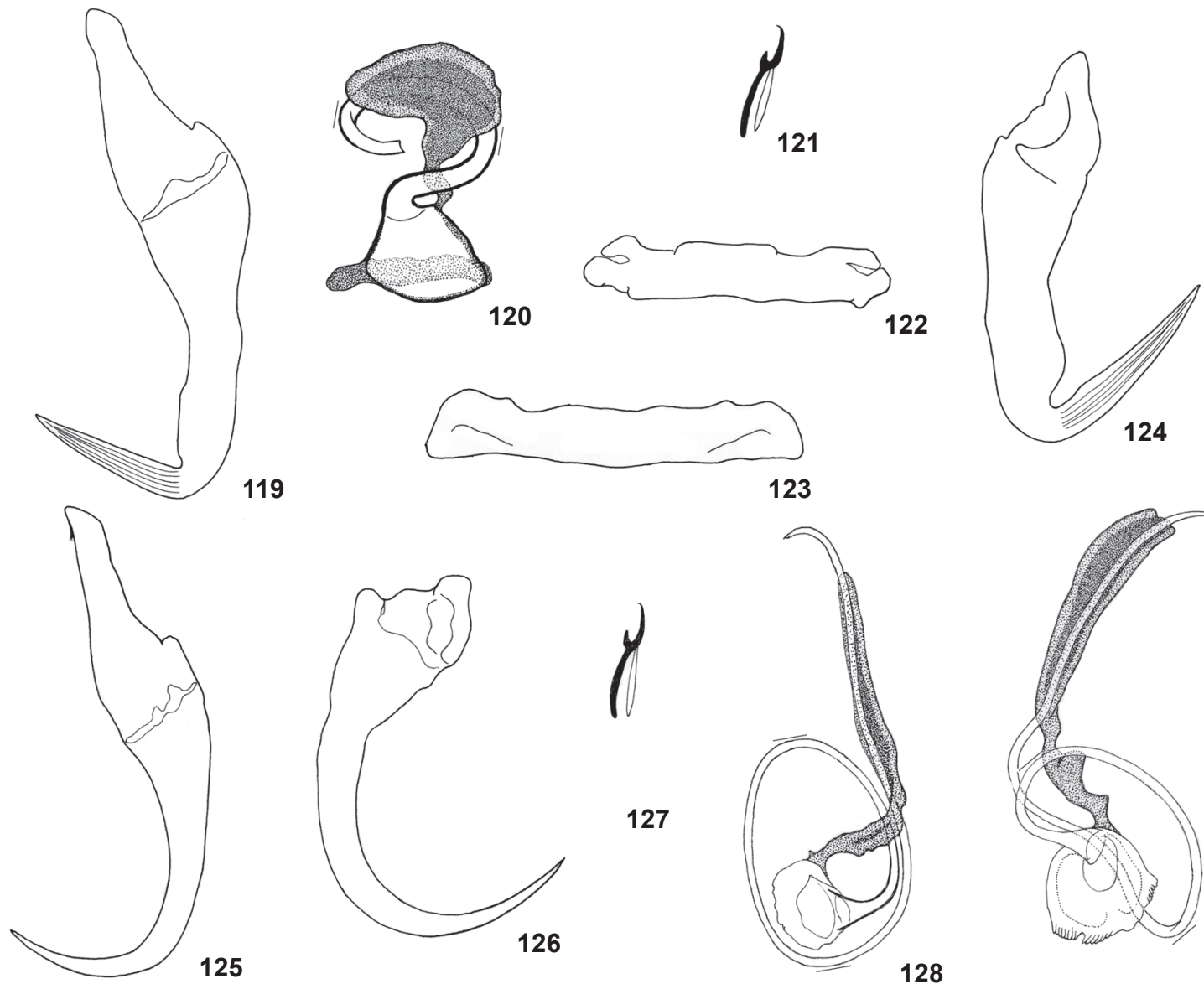

123

127


128

29


Figures 119-137. Haptoral and copulatory sclerites of Euryhaliotrema spp. from the gills of snappers, Lutjanus spp., from the Republic of Maldives. 119-124. Euryhaliotrema distinctum sp. nov. from the two-spot red snapper, Lutjanus bohar. 119. Dorsal anchor. 120. Copulatory complex (ventral view). 121. Hook. 122. Ventral bar. 123. Dorsal bar. 124. Ventral anchor. 125-131. Euryhaliotrema tormocleithrum sp. nov. from humpback red snapper, Lutjanus gibbus. 125. Dorsal anchor. 126. Ventral anchor. 127. Hook. 128. Copulatory complex (ventral view). 129. Copulatory complex (dorsal view). 130. Dorsal bar. 131. Ventral bar. 132-137. Euryhaliotrema ramulum sp. nov. from humpback red snapper, Lutjanus gibbus. 132. Copulatory complex (ventral view). 133. Ventral bar. 134. Dorsal bar. 135. Ventral anchor. 136. Hook. 137. Dorsal anchor. All figures are to the $20 \mu \mathrm{m}$ scale. 
frequently bent at hinge toward midline of haptor. Ventral bar rod shaped, with bifurcated ends; dorsal bar straight, with slightly enlarged ends directed posterolaterally. Hook with uniform shank, upright acute thumb; FH loop about shank length. MCO with bulbous base, coiled tubular shaft of nearly two counterclockwise rings. Accessory piece comprising variable sheath along distal shaft of MCO; articulation process present within rings of male copulatory complex. Testis ovate; proximal vas deferens not observed; seminal vesicle tear-drop shaped, lying sinistroposterior to base of MCO; prostatic reservoir not observed. Germarium bacilliform; oviduct, ootype, uterus not observed. Vaginal pore dextromarginal; vaginal canal a narrow duct leading to seminal receptacle immediately anterior to germarium. Vitellaria dense; bilateral vitelline ducts confluent slightly anterior to seminal receptacle. Egg not observed.

Type host and locality: Humpback red snapper, Lutjanus gibbus (Forsskål), Lutjanidae: off Malé, Republic of Maldives, 5 April 2007.

Site of infection: Gills.

Specimens studied: Holotype, USNPC 105537; 25 paratypes, USNPC 105538.

Etymology: The specific name (a noun) is from the Latin ramus (a branch) appended to the diminutive suffix (-ulus) and refers to the ends of the ventral bar.

Measurements: Body $295(274-336 ; n=4)$ long; greatest width (excluding haptor) $63(55-73 ; \mathrm{n}=5)$. Haptor 53 (44-61; $\mathrm{n}=5)$ long, 63 (60-65; $\mathrm{n}=4)$ wide. Pharynx $20(19-23 ; \mathrm{n}=5)$ wide. MCO (proximal ring diameter) $11(9-13 ; \mathrm{n}=7)$. Ventral anchor 29 (27-31; $\mathrm{n}=19)$ long; dorsal anchor 40 (37-43; $\mathrm{n}=$ 14) long. Ventral bar $35(33-38 ; n=16)$ long; dorsal bar 35 (32$36 ; \mathrm{n}=14)$ long. Hook $12(11-13 ; \mathrm{n}=37)$ long. Germarium 39 $(38-40 ; \mathrm{n}=2)$ long, $20(15-24 ; \mathrm{n}=2)$ wide; testis $47(39-55 ; \mathrm{n}=$ 4) long, $27(20-34 ; \mathrm{n}=4)$ wide.

Remarks: Although fairly abundant on the gills of the humpback red snapper examined during the present study, available specimens of $E$. ramulum were in generally poor condition. The species is easily differentiated from all other congenerics by having a ventral bar with bifurcated ends.

\section{Euryhaliotrema simplicis Kritsky \& Justine sp. nov. Figs 138-144}

Description: Body proper fusiform, usually tapering anteriorly from level of testis; greatest width usually in posterior trunk at level of gonads. Tegument smooth. Cephalic region broad; cephalic lobes poorly differentiated. Two pairs of eyespots lacking lenses; members of anterior pair absent or frequently dissociated, comprised of comparatively few granules (when present); one or both members of posterior pair infrequently absent. Accessory chromatic granules small, ovate, scattered in cephalic and anterior trunk regions. Pharynx spherical. Peduncle broad; haptor subhexagonal, with rounded bilateral lobes. Ventral anchor with moderately long superficial root, short broadly truncate deep root, arcing shaft, point extending slightly past level of tip of superficial root. Dorsal anchor delicate, with elongate superficial and deep roots, slightly curved shaft and elongate point extending past level of tip of superficial root. Ventral bar broadly V shaped, with spatulate ends; dorsal bar a slender arcing rod. Hook with uniform shank, upright acute thumb; FH loop about shank length. MCO lightly sclerotized, with bulbous base, short tubular coiled shaft of less than one counterclockwise ring. Accessory piece variable, poorly developed, lying along distal shaft of MCO; articulation process absent. Testis elongate ovate; proximal vas deferens not observed; seminal vesicle lying to left of body midline posterior to $\mathrm{MCO}$; prostatic reservoir juxtaposed to seminal vesicle to right of body midline. Germarium bacilliform to subovate; oviduct, ootype, uterus not observed; Mehlis' gland well developed. Vaginal pore dextromarginal; vaginal canal a narrow duct; seminal receptacle immediately anterior to germarium. Vitellaria dense; bilateral vitelline ducts confluent anterior to seminal receptacle. Egg not observed.

Type host and locality: Five-lined snapper, Lutjanus quinquelineatus (Bloch), Lutjanidae: La Régnière, off Nouméa, New Caledonia $\left(22^{\circ} 19.804^{\prime}\right.$ S, $\left.166^{\circ} 20.229^{\prime} \mathrm{E}\right), 8$ September 2005 , 19 March 2007.

Site of infection: Gills.

Specimens studied: Holotype, MNHN JNC1589K1; 13 paratypes, USNPC 105539, 105540, MNHN JNC2145K4-K7.

Etymology: The specific name (an adjective) is from Latin $($ simplex $=$ simple $)$ and refers to the comparatively common and unmodified haptoral and copulatory sclerites.

Measurements: Body $286(268-330 ; \mathrm{n}=6)$ long; greatest width (excluding haptor) $72(58-81 ; \mathrm{n}=6)$. Haptor 45 (37-55; $\mathrm{n}=6)$ long, $83(64-93 ; \mathrm{n}=6)$ wide. Pharynx $22(18-24 ; \mathrm{n}=6)$ wide. MCO $20(17-21 ; \mathrm{n}=5)$ long. Ventral anchor $28(25-31 ; \mathrm{n}$ = 9) long; dorsal anchor $34(32-36 ; n=8)$ long. Ventral bar 49 $(44-54 ; \mathrm{n}=7)$ long; dorsal bar $37(33-41 ; \mathrm{n}=6)$ long. Hook 16 $(14-17 ; \mathrm{n}=18)$ long. Germarium 35 (31-40; $\mathrm{n}=3)$ long, 17 (14$20 ; \mathrm{n}=3)$ wide; testis $34(31-37 ; \mathrm{n}=3)$ long, $15(12-17 ; \mathrm{n}=3)$ wide.

Remarks: This species closely resembles E. fatuum, from which it differs by having well-developed deep roots of the dorsal anchors (deep roots poorly developed in E. fatuum), a Vshaped ventral bar (ventral bar broadly $U$ shaped with ends directed laterally in E. fatuum), and by lacking a proximal bend of the shaft of the MCO (present in E. fatuum). In addition, the haptoral anchors are measurably smaller in E. simplicis.

\section{Euryhaliotrema ferocis Kritsky \& Yang sp. nov. Figs $145-152$}

Description: Body proper robust, fusiform to subtriangular, tapered anteriorly from level of testis; greatest width usually in trunk slightly posterior to testis. Tegument smooth. Cephalic region narrow compared to anterior trunk; cephalic lobes well differentiated. Two pairs of eyespots equidistant; 

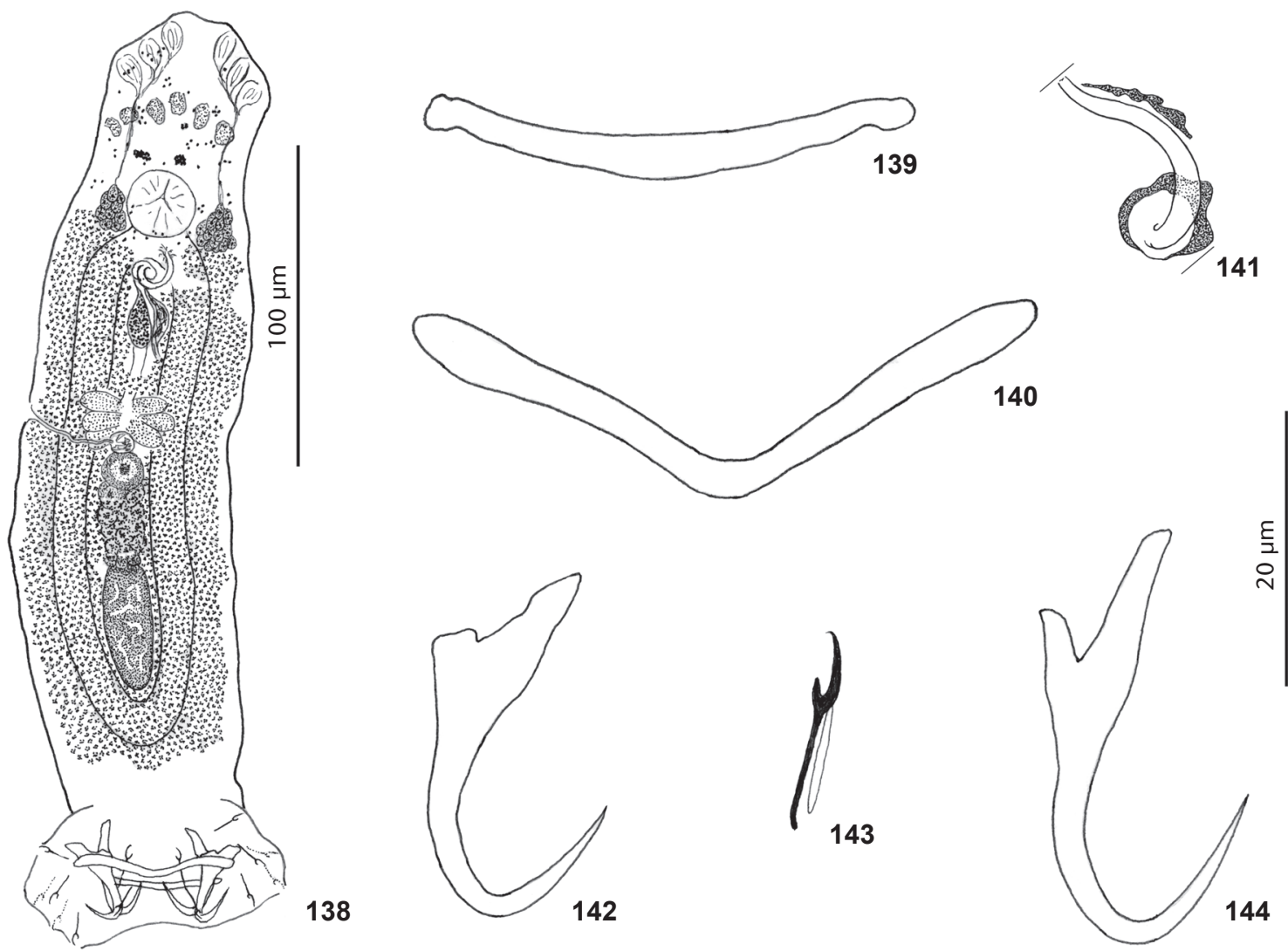

Figures 138-144. Euryhaliotrema simplicis sp. nov. from the five-lined snapper, Lutjanus quinquelineatus, from New Caledonia. 138. Whole mount (composite, ventral view). 139. Dorsal bar. 140. Ventral bar. 141. Copulatory complex (ventral view). 142. Ventral anchor. 143. Hook. 144. Dorsal anchor. All figures are to the $20 \mathrm{~mm}$ scale except Fig. 138 (100 $\mu \mathrm{m}$ scale).

posterior pair with lenses, slightly larger than members of anterior pair. Accessory chromatic granules small, ovate, few to many scattered in cephalic region. Pharynx subspherical to subovate. Peduncle short, broad to nonexistent; haptor frequently directed ventrally from plane of trunk, subrectangular, with rounded bilateral lobes. Ventral anchor robust, with short roots, forward leaning shaft, point extending past level of tip of superficial root. Dorsal anchor with superficial root varying in length from short to moderately long, knoblike deep root, short shaft and elongate point extending slightly past level of tip of superficial root. Ventral bar platelike, with rounded ends; dorsal bar a straight rod, with rounded ends. Hook with uniform shank, upright acute thumb; FH loop about shank length. MCO with funnel-shaped base, coiled tubular shaft having about two counterclockwise rings. Accessory piece a sleeve enclosing distal portion of shaft of MCO; articulation process absent. Testis ovate; vas deferens, seminal vesicle, prostatic reservoir not observed. Germarium ovate; oviduct not observed; Mehlis' gland well developed; uterus delicate. Vaginal pore dextromarginal; vaginal canal a narrow unsclerotized duct; seminal receptacle immediately anterior to Mehlis' gland. Vitellaria dense; transverse vitelline ducts confluent anterior to seminal receptacle. Egg ovate, with one side flattened; filament elongate, originating from proximal end of egg.

Type host and locality: Malabar blood snapper, Lutjanus malabaricus (Bloch \& Schneider), Lutjanidae: South China Sea off Nan'ao, Guangdong Province, China $\left(28^{\circ} 27^{\prime} \mathrm{N}, 116^{\circ} 43^{\prime} \mathrm{E}\right)$, 24, 25 July 2007.

Site of infection: Gills.

Specimens studied: Holotype, USNPC 105541; 33 paratypes, USNPC 105542.

Etymology: The specific name (an adjective) is from Latin (ferox $=$ bold) and refers to the robustness of the species.

Measurements: Body 450 (326-593; $\mathrm{n}=15)$ long; greatest width (excluding haptor) $129(109-166 ; \mathrm{n}=16)$. Haptor 52 $(42-67 ; \mathrm{n}=14)$ long, 97 (76-119; $\mathrm{n}=16)$ wide. Pharynx 36 (33$38 ; \mathrm{n}=16)$ wide. $\mathrm{MCO}$ (proximal ring diameter) $20(17-49 ; \mathrm{n}=$ 14). Ventral anchor $45(41-49 ; \mathrm{n}=14)$ long; dorsal anchor 38 $(32-42 ; \mathrm{n}=14)$ long. Ventral bar $41(36-46 ; \mathrm{n}=13)$ long; dorsal bar $51(47-58 ; \mathrm{n}=14)$ long. Hook $14(12-15 ; \mathrm{n}=21)$ long. 


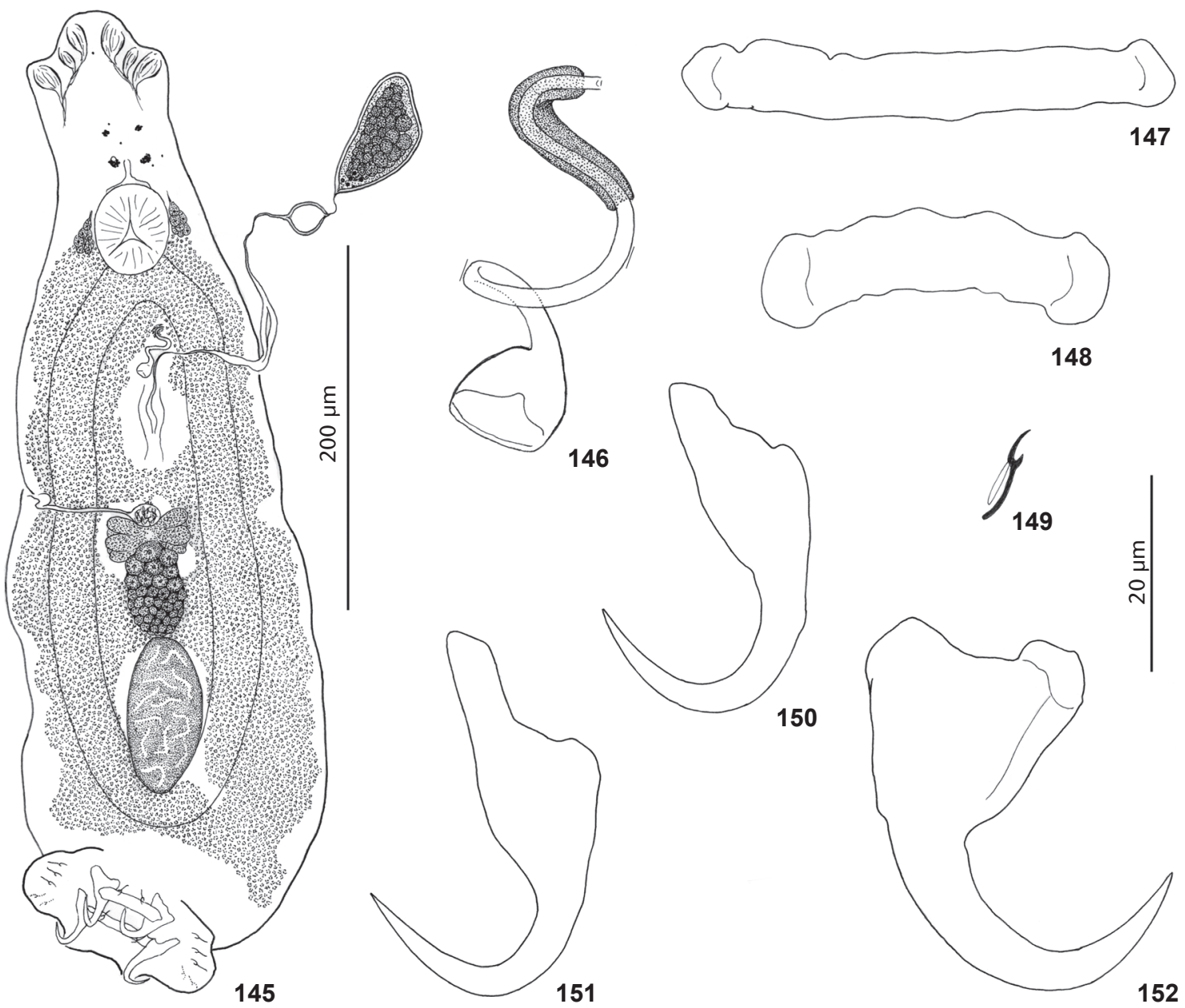

Figures 145-152. Euryhaliotrema ferocis sp. nov. from the Malabar blood snapper, Lutjanus malabaricus, from China. 145. Whole mount (composite, ventral view) showing recently released egg (distal portion of egg filament retained in uterus). 146. Copulatory complex (ventral view). 147. Dorsal bar. 148. Ventral bar. 149. Hook. 150, 151. Dorsal anchors showing variation in length of superficial root. 152. Ventral anchor. All figures are to the $20 \mu \mathrm{m}$ scale except Fig. 145 (200 $\mu \mathrm{m}$ scale).

Germarium 59 (45-76; $\mathrm{n}=9)$ long, $32(26-35 ; \mathrm{n}=9)$ wide; testis $79(63-115 ; \mathrm{n}=14)$ long, 43 (33-55; $\mathrm{n}=14)$ wide. Egg (excluding filament) $56-57(n=1)$ long, $28-29(n=1)$ wide.

Remarks: Most of the available specimens of this species were contracted in the posterior trunk and haptor. Euryhaliotrema ferocis most closely resembles $E$. dontykoleos in the general morphology of the MCO, haptoral bars, and anchors. It differs from E. dontykoleos by possessing hooks with upright acute thumbs (thumbs apparently protruding and knob-like in E. dontykoleos) and by lacking an articulation process in the copulatory complex (present in E. dontykoleos) (see Fehlauer \& Boeger 2005). Finally, E. dontykoleos parasitizes the gills of a freshwater sciaenid in South America, whereas E. ferocis is marine and occurs on the gills of a lutjanid from the western Pacific Ocean.

\section{Euryhaliotrema seyi sp. nov. \\ Figs $153-160$}

Description: Body proper fusiform; greatest width usually in posterior trunk at level of testis. Tegument smooth. Cephalic region broad; cephalic lobes poorly differentiated. Two pairs of eyespots; posterior pair with lenses, larger, slightly closer together than members of anterior pair; anterior pair infrequently absent or dissociated. Accessory chromatic granules small, ovate to subspherical, few to many scattered in cephalic region. Pharynx subspherical. Peduncle short, tapered posteriorly; haptor globose. Ventral anchor with moderately long depressed superficial root, short knob-like deep root, straight shaft, slightly recurved point extending to near level of tip of super- 

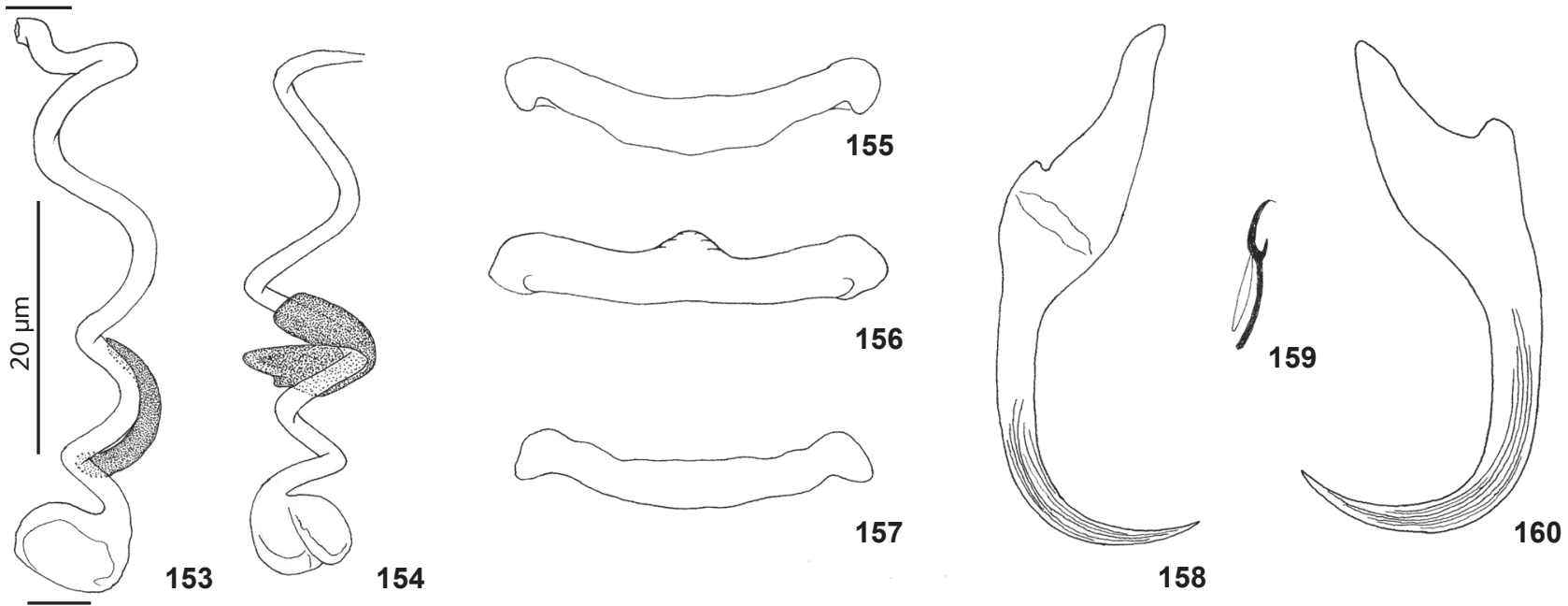

Figures 153-160. Euryhaliotrema seyi sp. nov. from the dory snapper, Lutjanus fulviflamma, from Egypt. 153, 154. Copulatory complexes (ventrolateral views). 155. Ventral bar. 156. Ventral bar (slightly rotated to show the dorsomedial protuberance. 157. Dorsal bar. 158. Dorsal anchor. 159. Hook. 160. Ventral anchor. All figures are drawn to the $20 \mu \mathrm{m}$ scale.

ficial root; point and shaft with superficial longitudinal grooves. Dorsal anchor with elongate delicate superficial root, small deep root, straight shaft, slightly recurved point extending to near level of tip of superficial root; point and shaft with superficial longitudinal grooves; anchor base with diagonal hinge; distal portion of base frequently bent at hinge toward haptoral midline. Bars similar; each rod like with slightly enlarged ends; ventral bar frequently showing dorsomedial protuberance. Hook with uniform shank, upright acute thumb; FH loop about shank length. MCO with bulbous base, loosely coiled shaft with between three and four counterclockwise rings. Accessory piece representing a sleeve enclosing medial portion of shaft of MCO, apparently unarticulated to shaft allowing movement along shaft; articulation process absent. Most structures of male and female reproductive systems indistinct or not observed. Vaginal pore dextromarginal; small vaginal vestibule present; vaginal canal unsclerotized, distally dilated, narrowing proximally. Bilateral vitelline fields variable, frequently not reaching posterior to gonads (possibly due to poor fixation of specimens); bilateral vitelline ducts fuse anterior to germarium. Egg not observed.

Type host and locality: Dory snapper, Lutjanus fulviflamma (Forsskål), Lutjanidae: Nabq Bay, Ras Mohammed National Park (South Sinai, Red Sea), Egypt $\left(28^{\circ} 02^{\prime} 52^{\prime \prime}\right.$, $\left.34^{\circ} 26^{\prime} 21^{\prime \prime} \mathrm{E}\right), 20$ October 2005.

Other record: Lutjanus russellii: Persian Gulf off Kuwait, 2 June 1995.

Site of infection: Gills.

Specimens studied: Holotype, USNPC 105543; 21 paratypes, USNPC 105544; 13 voucher specimens (from $L$. russellii), USNPC 105545,
Etymology: The specific name honors Dr. Otto Sey (retired), University of Pecs, Hungary, a friend and colleague, who collected the specimens of $E$. seyi from a Russell's snapper off Kuwait.

Measurements (dimensions of specimens from L. russellii follow those of the type specimens in brackets, respectively): Body $291(248-369 ; \mathrm{n}=6)$ [470 (423-515; $\mathrm{n}=6)$ ] long; greatest width (excluding haptor) $65(56-77 ; \mathrm{n}=5)$ [86 $(76-92 ; \mathrm{n}=6)]$. Haptor $65(57-79 ; \mathrm{n}=5)$ [81 $(76-87 ; \mathrm{n}=6)]$ long, $63(55-71 ; \mathrm{n}=$ 4) $[81(72-89 ; \mathrm{n}=5)]$ wide. Pharynx $17(16-19 ; \mathrm{n}=5)$ [23 (20$25 ; \mathrm{n}=6)]$ wide. MCO $48(42-59 ; \mathrm{n}=10)$ [45 (42-51; $\mathrm{n}=4)]$ long. Ventral anchor $42(38-45 ; \mathrm{n}=15)$ [45 $(42-47 ; \mathrm{n}=7)]$ long; dorsal anchor $46(42-48 ; n=15)$ [47 $(44-51 ; n=4)]$ long. Ventral bar $35(29-39 ; \mathrm{n}=14)$ [39 $(35-41 ; \mathrm{n}=4)$ ] long; dorsal bar 33 $(29-37 ; \mathrm{n}=12)$ [35 (30-38; $\mathrm{n}=5)]$ long. Hook $13(12-14 ; \mathrm{n}=44)$ [13 (12-14; $\mathrm{n}=19)]$ long. Germarium 32-33 $(\mathrm{n}=1)$ [55-56 $(\mathrm{n}=$ 1)] long, $17-18(\mathrm{n}=1)[27-28(\mathrm{n}=1)]$ wide; testis $37-38(\mathrm{n}=1)$ [99 (78-121; $\mathrm{n}=2)$ ] long, 22-23 ( $\mathrm{n}=1)$ [51 $(49-53 ; \mathrm{n}=2)]$ wide.

Remarks: Specimens of $E$. seyi from both L. fulviflamma and $L$. russellii were not optimally preserved, and as a result, information on some internal features could not be determined. Those from $L$. russellii were larger than the specimens from $L$. fulviflamma, the differences probably due, in part, to the former having undergone moderate decomposition prior to fixation.

This species belongs to the group of congenerics having a cork-screw shaped MCO and a hinge-like thinning in the base of the dorsal anchor. These include E. diplops, E. cognatus and $E$. ferocis, all parasites of lutjanids from the Indo-Pacific Ocean. It differs from E. diplops and E. cognatus by lacking an articulation process in the copulatory complex and is distinguished from $E$. ferocis by having approximately three rings in the coiled 
MCO (about two rings in E. ferocis) and more delicate and larger anchors (anchors with robust bases and short shafts in $E$. ferocis).

Although occurring on hosts with distributions throughout the Indian and western Pacific Oceans, E. seyi appears, at present, to be restricted to the western regions of its hosts' respective ranges, including the Persian Gulf and Red Sea. It was not collected from dory snapper and Russell's snapper examined from off the eastern coast of China, Heron Island off Australia, and the environs of New Caledonia. However, comparatively few specimens of both snappers were examined from the various collection sites during the present study, and the possibility exists that all of the species of Euryhaliotrema occurring on these hosts have a more extensive distribution than that suggested by the present survey.

\section{Euryhaliotrema spirotubiforum}

\section{(Zhang, 2001) Wu, Zhu, Xie \& Li, 2006 Figs 161-167}

Syns Haliotrema spirotubiforum Zhang, 2001; Aliatrema spirotubiforum (Zhang, 2001) Wu, Zhu, Xie \& Li, 2007.

Redescription (based on 32 voucher specimens from $L$. vitta): Body proper fusiform; greatest width usually near midlength of trunk or at level of gonads. Tegument smooth. Cephalic region narrow; cephalic lobes poorly to moderately developed. Two pairs of eyespots; members of posterior pair with conspicuous lenses, larger, closer together than members of anterior pair; anterior pair small, one member frequently dissociated or absent; accessory chromatic granules generally small, subovate, few to absent in cephalic and anterior trunk regions. Pharynx subspherical. Peduncle broad, short, tapering toward haptor; haptor globose. Ventral and dorsal anchors similar; each with moderately long superficial root, knob-like deep root, short shaft, elongate point extending well past level of tip of superficial root. Ventral bar rod shaped, slightly arced; dorsal bar a broad U or V shape, with ends directed laterally. Hook with uniform shank, upright acute thumb; FH loop about shank length. MCO a delicate coiled or meandering tube arising from bulbous base; coil comprising a counterclockwise ring. Accessory piece absent. Testis ovate; proximal vas deferens not observed; seminal vesicle subspherical, lying posterior to base of MCO; small prostatic reservoir to left of base of MCO. Germarium pyriform; oviduct, ootype, uterus not observed. Vaginal pore dextromarginal; vaginal canal a narrow duct reaching seminal receptacle immediately anterior to germarium. Vitellaria dense; transverse vitelline duct anterior to seminal receptacle. Egg not observed.

Type host and locality: Presumed to be the blacktail snapper, Lutjanus vaigiensis (Quoy \& Gaimard) (now L. fulvus), Lutjanidae: Yangjiang, Guangdong Province, China $\left(21^{\circ} 34^{\prime} \mathrm{N}\right.$, $\left.111^{\circ} 49^{\prime} \mathrm{E}\right)$ (see Remarks).

Source of current specimens: Brownstripe red snapper, Lutjanus vitta, Lutjanidae (new host record): Baie des Citrons, off Nouméa, New Caledonia $\left(22^{\circ} 17.441^{\prime} \mathrm{S}, 166^{\circ} 25.446^{\prime} \mathrm{E}\right), 16$ October 2007, 24 April 2008. Russell's snapper, Lutjanus russellii, Lutjanidae: La Régnière, off Nouméa, New Caledonia $\left(22^{\circ} 19.804^{\prime}\right.$ S, $\left.166^{\circ} 20.229^{\prime} \mathrm{E}\right), 8$ September 2005 . Dory snapper, Lutjanus fulviflamma, Lutjanidae (new host record): Nabq Bay, Ras Mohammed National Park (South Sinai, Red Sea), Egypt $\left(28^{\circ} 02^{\prime} 52^{\prime \prime} \mathrm{N}, 34^{\circ} 26^{\prime} 21^{\prime \prime} \mathrm{E}\right), 20,25$ October 2005; off Heron Is-

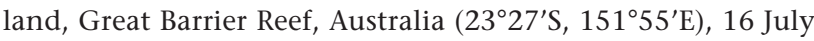
2001. Blackspot snapper, Lutjanus ehrenbergii, Lutjanidae (new host record): Nabq Bay, Ras Mohammed National Park (South Sinai, Red Sea), Egypt $\left(28^{\circ} 02^{\prime} 52^{\prime \prime} \mathrm{N}, 34^{\circ} 26^{\prime} 21^{\prime \prime} \mathrm{E}\right), 27$ October 2005. Spanish flag snapper, Lutjanus carponotatus, Lutjanidae (new host record): off Heron Island, Great Barrier Reef, Australia $\left(23^{\circ} 27^{\prime} \mathrm{S}, 151^{\circ} 55^{\prime} \mathrm{E}\right), 16$ July 2001 . Five-lined snapper, Lutjanus quinquelineatus, Lutjanidae (new host record): La Régnière, off Nouméa, New Caledonia $\left(22^{\circ} 19.804^{\prime}\right.$ S, $\left.166^{\circ} 20.229^{\prime} \mathrm{E}\right), 8$ September 2005, 19 March 2007. Blacktail snapper, Lutjanus fulvus, Lutjanidae: La Régnière, off Nouméa, New Caledonia $\left(22^{\circ} 19.804^{\prime} \mathrm{S}, 166^{\circ} 20.229^{\prime} \mathrm{E}\right), 8$ September 2005.

Site of infection: Gills.

Specimens studied: 32 voucher specimens (from $L$. vitta), USNPC 105553, 105554, MNHN JNC2306K1-K12; voucher specimen (from L. russellii), USNPC 105550; 12 voucher specimens (from L. fulviflamma), USNPC 105547, 105552; 8 voucher specimens (from L. ehrenbergii), USNPC 105549; voucher specimen (from L. carponotatus), USNPC 105546; 12 voucher specimens (from L. quinquelineatus), USNPC 105551, 105555, MNHN JNC2140K1, JNC2146K1, JNC1588K1-K3; 5 voucher specimens (from L. fulvus), USNPC 105548, MNHN JNC1591K11, JNC1592K3.

Previous records: Lutjanus vaigiensis (now L. fulvus): Yangjiang, Guangdong Province, China $\left(21^{\circ} 34^{\prime} \mathrm{N}, 111^{\circ} 49^{\prime} \mathrm{E}\right.$ ) (as Haliotrema spirotubiforum) (ZHANG 2001). Lutjanus fulvus: Moorea Island, Society Archipelago, French Polynesia (17³0'S, $149^{\circ} 50^{\prime} \mathrm{W}$ ); Marquesas Islands near Ua Huka, French Polynesia $\left(8^{\circ} 57^{\prime} \mathrm{S}, 139^{\circ} 35^{\prime} \mathrm{W}\right)$; south coast of $\mathrm{O}^{\prime} \mathrm{ahu}$, Hawaiian Islands $\left(21^{\circ} 17^{\prime} \mathrm{N}, 157^{\circ} 53^{\prime} \mathrm{W}\right.$ ) (all as Euryhaliotrema spirotubiforum) (Vignon et al. 2009). Lutjanus kasmira: Moorea Island, Society


Islands near Ua Huka, French Polynesia $\left(8^{\circ} 57^{\prime} \mathrm{S}, 139^{\circ} 35^{\prime} \mathrm{W}\right)$; south coast of $\mathrm{O}^{\prime} \mathrm{ahu}$, Hawaiian Islands $\left(21^{\circ} 17^{\prime} \mathrm{N}, 157^{\circ} 53^{\prime} \mathrm{W}\right)$ (all as Euryhaliotrema spirotubiforum) (VIGNON et al. 2009). Lutjanus russellii: Guangdong Province, China $\left(21^{\circ} 34^{\prime} \mathrm{N}\right.$, $111^{\circ} 49^{\prime} \mathrm{E}$ and $23^{\circ} 08^{\prime} \mathrm{N}, 113^{\circ} 15^{\prime} \mathrm{E}$ ) (as Haliotrema spirotubiforum) (ZhANG 2001, Li \& YAN 2007, respectively). Lutjanus stellatus: Yangjiang, Guangdong Province, China (Wu et al. 2006, 2007).

Measurements: Table VI.

Remarks: This species was originally described as Haliotrema spirotubiforum by ZHANG (2001) and was characterized, in part, by lacking an accessory piece in the copulatory complex. Wu et al. (2006) discounted the absence of an accessory piece when they transferred $H$. spirotubiforum to Euryhaliotrema based on its host occurrence (members of the 



Figures 161-167. Euryhaliotrema spirotubiforum from the brownstripe red snapper, Lutjanus vitta, from New Caledonia. 161. Whole mount (composite, ventral view). 162. Ventral bar. 163. Dorsal bar. 164. Copulatory complex (dorsal view). 165. Hook. 166. Ventral anchor. 167. Dorsal anchor. All figures are to the $20 \mu \mathrm{m}$ scale except Fig. 161 (100 $\mu \mathrm{m}$ scale).

Lutjanidae), molecular and other morphological evidence. The molecular evidence used by Wu et al. (2006) to transfer the species to Euryhaliotrema was based on the relationships of only three dactylogyrid species (H. spirotubiforum, $H$. johni and an unidentified species labeled Haliotrema ZHDDb). Later, these authors (2007) again transferred the species, along with Haliotrema kurodai and Haliotrema anguiformis, to Aliatrema, when additional dactylogyrid species were added to their molecular analysis. Wu et al. (2007) supported their transfers to Aliatrema by stating that the three related species lacked an accessory piece in their copulatory complex, even though ZHANG's (2001) drawings of $H$. anguiformis (Figs 10-5a, b) clearly show an accessory piece associated with the MCO in both forms figured for the original description. Because morphological evidence, particularly that of the copulatory complex, no longer supports separating Aliatrema from Euryhaliotrema (see Remarks under the diagnosis of Euryhaliotrema), the combination proposed by $\mathrm{Wu}$ et al. (2006) is accepted herein. 
Table VI. Measurements of Euryhaliotrema spirotubiforum from four species of Lutjanus.

\begin{tabular}{|c|c|c|c|c|}
\hline & L. vitta & L. fulviflamma & L. ehrenbergii & L. quinquelineatus \\
\hline \multicolumn{5}{|l|}{ Body } \\
\hline Length & $263(207-294 ; n=10)$ & - & - & - \\
\hline Width ${ }^{1}$ & $67(46-78 ; n=11)$ & - & - & - \\
\hline \multicolumn{5}{|l|}{ Haptor } \\
\hline Length & $51(45-61 ; \mathrm{n}=12)$ & - & - & - \\
\hline Width & $61(54-70 ; n=12)$ & - & - & - \\
\hline \multicolumn{5}{|l|}{ Pharynx } \\
\hline Width & $19(16-22 ; \mathrm{n}=12)$ & $17-18(n=1)$ & - & - \\
\hline \multicolumn{5}{|l|}{$\mathrm{MCO}$} \\
\hline Ring diameter & $13(10-16 ; n=11)$ & $12(9-15 ; n=4)$ & $11(10-13 ; n=4)$ & $10-11(n=1)$ \\
\hline \multicolumn{5}{|l|}{ Testis } \\
\hline Length & $44(33-54 ; n=11)$ & - & - & - \\
\hline Width & $25(17-33 ; n=11)$ & - & - & - \\
\hline \multicolumn{5}{|l|}{ Germarium } \\
\hline Length & $32(22-43 ; n=7)$ & - & - & - \\
\hline Width & $18(12-22 ; \mathrm{n}=8)$ & - & - & - \\
\hline \multicolumn{5}{|l|}{ Ventral anchor } \\
\hline Length & $38(35-40 ; n=18)$ & $37(35-39 ; n=5)$ & $37(35-39 ; \mathrm{n}=5)$ & $35(31-37 ; \mathrm{n}=10)$ \\
\hline \multicolumn{5}{|l|}{ Dorsal anchor } \\
\hline Length & $38(35-44 ; n=18)$ & $36(34-39 ; n=5)$ & $37(35-38 ; n=5)$ & $36(33-38 ; n=9)$ \\
\hline \multicolumn{5}{|l|}{ Ventral bar } \\
\hline Length & $39(34-45 ; n=13)$ & $42(37-45 ; n=5)$ & $41(36-44 ; n=5)$ & $40(36-43 ; n=5)$ \\
\hline \multicolumn{5}{|l|}{ Dorsal bar } \\
\hline Length & $39(33-44 ; n=15)$ & $42(39-44 ; n=5)$ & $40(38-43 ; n=5)$ & $37(31-43 ; n=5)$ \\
\hline \multicolumn{5}{|l|}{ Hook } \\
\hline Length & $13(12-15 ; \mathrm{n}=28)$ & $13(12-14 ; \mathrm{n}=9)$ & $14(13-15 ; n=13)$ & $13(12-14 ; n=14)$ \\
\hline
\end{tabular}

'Excluding haptor.

Euryhaliotrema spirotubiforum demonstrates a comparatively low level of host specificity, having been recorded from a total of nine species of Lutjanus from the Indo-Pacific Ocean. Respective specimens of E. spirotubiforum from the seven species of Lutjanus, collected and examined for the present study, showed only minimal morphological differences. Euryhaliotrema spirotubiforum most closely resembles E. adelpha, E. paululum and $E$. youngi, based on the absence of an accessory piece and morphology of the MCO. It differs from E. adelpha by having more robust dorsal and ventral anchors and by the ends of the comparatively robust U- or V-shaped dorsal bar directed laterally (delicate dorsal bar $\mathrm{V}$ shaped, with ends directed anterolaterally in E. adelpha). Euryhaliotrema spirotubiforum differs from $E$. paululum by lacking a posteromedial projection on the dorsal bar and from $E$. youngi by having a noticeably smaller ring diameter of the coil of the MCO.

The type host of E. spirotubiforum is presumed to be $L$. vaigensis (now L. fulvus), because this host was listed first in the list of hosts in the original description. However, ZHANG
(2001) did not specifically identify the type host of the species or the host of the holotype. Confirmation of the type host for E. spirotubiforum will require identification of the host of the holotype, which was not available for the present study.

\section{Euryhaliotrema adelpha Kritsky \& Justine sp. nov.}

Figs $168-174$

Description: Body proper fusiform, tapering anteriorly from level of testis; greatest width at level of testis. Tegument smooth. Cephalic region broad; cephalic lobes moderately developed. Two pairs of eyespots; members of posterior pair with lenses, larger, closer together than members of anterior pair; anterior pair occasionally absent or represented by few small ovate granules; accessory chromatic granules subspherical, few distributed in cephalic, anterior trunk regions. Pharynx subspherical. Peduncle broad, lacking noticeable taper posteriorly; haptor subhexagonal, with bilateral lobes. Ventral and dorsal anchors similar; each with poorly differentiated deep 
root, elongate slightly depressed superficial root, slightly curved shaft, point extending past level of tip of superficial root; anchor shaft and point with superficial longitudinal grooves. Ventral bar a wavy rod with knob-like ends directed posterolaterally. Dorsal bar delicate, V shaped. Hook with uniform shank, upright acute thumb; FH loop about shank length. MCO with funnel-shaped base and loosely coiled shaft having slightly more than one counterclockwise ring. Accessory piece absent. Testis ovate; vas deferens, seminal vesicle, prostatic reservoir not observed. Germarium subovate to bacilliform; Mehlis' gland poorly developed; uterus, seminal receptacle not observed. Vaginal pore submarginal, inconspicuous; vaginal canal short, non-sclerotized. Vitellaria dense; bilateral vitelline ducts extending from lateral bands toward midline anterior to Mehlis' gland. Egg not observed.

Type host and locality: Five-lined snapper, Lutjanus quinquelineatus (Bloch), Lutjanidae: La Régnière, off Nouméa, New Caledonia $\left(22^{\circ} 19.804^{\prime}\right.$ S, $\left.166^{\circ} 20.229^{\prime} \mathrm{E}\right), 8$ September 2005, 19 March 2007.

Site of infection: Gills.

Specimens studied: Holotype, MNHN JNC1589K2; 38 paratypes, MNHN JNC1587K1, JNC1588K4-K6, JNC1589K3-K4, JNC1590K1-K4, JNC2142K1, JNC2144K1, JNC2145K8-K9, JNC2147K2-K3, USNPC 105556, 105557.

Etymology: The specific name (a noun) is from Greek $($ adelpha $=$ sister $)$ and refers to the putative close relationship of this species to E. spirotubiforum and other congeneric species lacking an accessory piece.

Measurements: Body $207(167-245 ; \mathrm{n}=16)$ long; greatest width (excluding haptor) $51(39-61 ; \mathrm{n}=17)$. Haptor 50 (38$58 ; \mathrm{n}=18)$ long, $61(42-73 ; \mathrm{n}=17)$ wide. Pharynx $16(13-20 ; \mathrm{n}$ $=17)$ wide. MCO $34(26-41 ; n=9)$ long. Ventral anchor 37 (34$39 ; \mathrm{n}=12)$ long; dorsal anchor $33(31-35 ; \mathrm{n}=7)$ long. Ventral bar $43(38-45 ; n=9)$ long; dorsal bar $43(36-46 ; n=8)$ long. Hook $13(11-14 ; \mathrm{n}=25)$ long. Germarium $25(21-29 ; \mathrm{n}=9)$ long, $15(12-20 ; \mathrm{n}=8)$ wide; testis $32(27-42 ; \mathrm{n}=13)$ long, 18 $(11-24 ; \mathrm{n}=12)$ wide.

Remarks: Euryhaliotrema adelpha most closely resembles E. spirotubiforum in the general morphology of the MCO and haptoral anchors. It differs from this species by having a more elongate and delicate shaft of the ventral anchor (compare Figs $166,174)$ and by having a V-shaped dorsal bar with ends directed anterolaterally rather than laterally (compare Figs 163, 171).

\section{Euryhaliotrema paululum Kritsky \& Justine sp. nov. Figs $175-180$}

Description: Body proper fusiform; greatest width in posterior trunk at level of testis. Tegument smooth. Cephalic region broad; cephalic lobes poorly to moderately developed. Four eyespots; members of posterior pair with lenses, larger, slightly closer together than members of anterior pair; accessory chromatic granules subovate to irregular, uncommon in cephalic region. Pharynx spherical. Peduncle broad; haptor subhexagonal. Anchors similar; each with elongate superficial root, knob-like deep root, curved short shaft, elongate point extending slightly past level of tip of superficial root; anchor shafts and points with longitudinal superficial grooves; dorsal anchor more delicate than ventral anchor. Bars similar, broadly $\mathrm{U}$ or V shaped; dorsal bar with short posteromedial process. Hook with uniform shank, upright acute thumb; FH loop about shank length. MCO with funnel-shaped base, loosely coiled tubular shaft having slightly more than one counterclockwise ring. Accessory piece absent. Testis ovate; seminal vesicle pyriform, lying posterior to base of MCO; prostatic reservoir comparatively large, lying to left of shaft of MCO. Germarium subspherical to bacilliform, ventrally overlapping anterior end of testis; oviduct, ootype, uterus not observed. Vaginal pore marginal, inconspicuous; vaginal canal unsclerotized, straight, directed diagonally and posteriorly to unite with medial subspherical seminal receptacle. Vitellaria dense; transverse vitelline duct anterior to seminal receptacle. Egg not observed. Type host and locality: Common bluestripe snapper, Lutjanus kasmira (Forsskål), Lutjanidae: External slope of coral barrier facing the wreck Ever Prosperity, off Nouméa, New Caledonia $\left(22^{\circ} 27.588^{\prime} \mathrm{S}, 166^{\circ} 21.920^{\prime} \mathrm{E}\right), 22$ August 2006.

Site of infection: Gills.

Specimens studied: Holotype, MNHN JNC1923K1; 12 paratypes, MNHN JNC1923K2-K5, USNPC 105558.

Etymology: The specific name (an adjective) is from the Latin paulula (the diminutive of little) and refers to the small size of members of the species.

Measurements: Body $172(161-180 ; \mathrm{n}=3)$ long; greatest width (excluding haptor) $42(39-47 ; \mathrm{n}=3)$. Haptor $42(37-46 ; \mathrm{n}$ =3) long, $44(37-54 ; \mathrm{n}=3)$ wide. Pharynx $14(12-16 ; \mathrm{n}=3)$ wide. MCO (ring diameter) $8(6-12 ; \mathrm{n}=10)$. Ventral anchor 37 (35-39; $\mathrm{n}=10)$ long; dorsal anchor $36(33-39 ; \mathrm{n}=7)$ long. Ventral bar 31 $(27-34 ; \mathrm{n}=5)$ long; dorsal bar $31(29-33 ; \mathrm{n}=4)$ long. Hook 13 (12-14; $\mathrm{n}=18)$ long. Germarium 16-17 ( $\mathrm{n}=1)$ long, 14-15 ( $\mathrm{n}=$ 1) wide; testis $22(20-24 ; n=3)$ long, $12(10-15 ; n=3)$ wide.

Remarks: This species closely resembles E. spirotubiforum, from which it differs by being noticeably smaller and by having a dorsal bar with a posteromedial process. The process is delicate and difficult to observe in some specimens, especially those stained for study of internal organ systems.

Vignon et al. (2009) did not report this species from the common bluestripe snapper, L. kasmira, in the Hawaiian Islands and French Polynesia during their case study on parasite introduction and host management. They identified three dactylogyrid species infecting L. kasmira that are herein included in Euryhaliotrema: E. spirotubiforum, E. chrysotaeniae and a form identified as Haliotrema sp. conf. anguiformis. While $E$. paululum is recorded from common bluestripe snapper, the similar E. spirotubiforum was not collected from this host during the present study. In view of the primary differentiating feature separating the two species being the difficult to observe and easily missed posteromedial process on the dorsal bar, the 

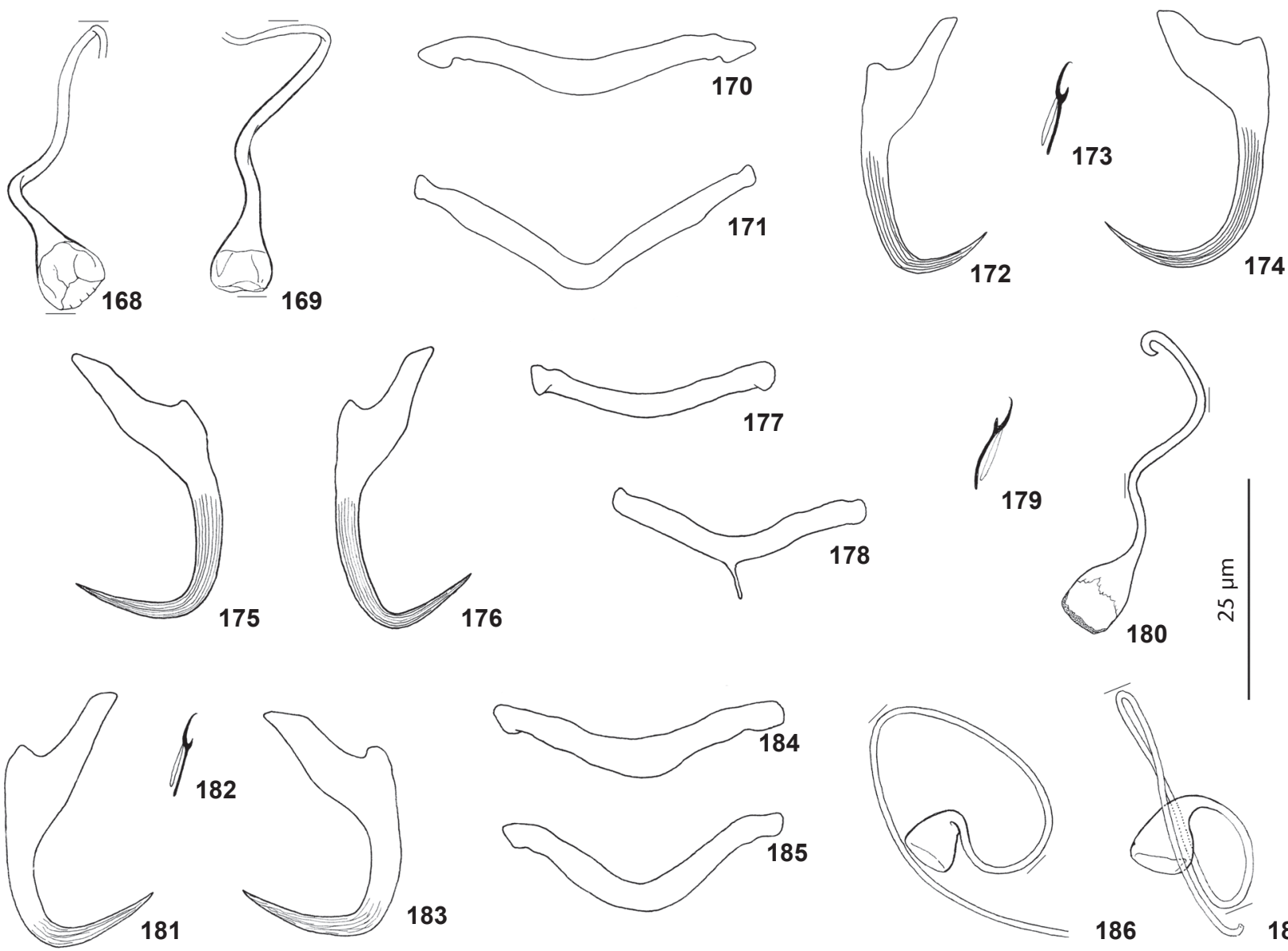

Figures 168-187. Haptoral and copulatory sclerites of Euryhaliotrema spp. from the gills of snappers, Lutjanus spp., from the western Pacific Ocean. 168-174. Euryhaliotrema adelpha sp. nov. from the five-lined snapper, Lutjanus quinquelineatus, from New Caledonia. 168. Copulatory complex (ventral view). 169. Copulatory complex (dorsal view). 170. Ventral bar. 171. Dorsal bar. 172. Dorsal anchor. 173. Hook. 174. Ventral anchor. 175-180. Euryhaliotrema paululum sp. nov. from common blue stripe snapper, Lutjanus kasmira, from New Caledonia. 175. Ventral anchor. 176. Dorsal anchor. 177. Ventral bar. 178. Dorsal bar. 179. Hook. 180. Copulatory complex (ventral view). 181-187. Euryhaliotrema youngi sp. nov. from Spanish flag snapper, Lutjanus carponotatus, from Australia. 181. Dorsal anchor. 182. Hook. 183. Ventral anchor. 184. Ventral bar. 185. Dorsal bar. 186. Copulatory complex (ventral view). 187. Copulatory complex (dorsal view). All figures are to the $25 \mu \mathrm{m}$ scale.

possibility exists that the form identified by VIGNON et al. (2009) as E. spirotubiforum from Hawaii and French Polynesia may represent E. paululum. Unfortunately, these authors failed to deposit reference material of their helminth species in a museum for species confirmation (J.-L. Justine, personal communication).

\section{Euryhaliotrema youngi sp. nov.} Figs 181-187

Description: Body proper fusiform, with nearly parallel sides; greatest width usually in posterior trunk at level of gonads. Tegument smooth. Cephalic region nearly as wide as trunk; cephalic lobes poorly to moderately developed. Four eyespots; members of posterior pair with lenses, slightly larger and closer together than members of anterior pair; accessory chromatic granules ovate, small, few or absent in cephalic region. Pharynx subspherical. Peduncle broad; haptor globose, with rounded bilateral margins. Anchors similar; each with elongate superficial root, knob-like deep root, slightly curved short shaft, elongate point extending slightly past level of tip of superficial root; point with superficial longitudinal grooves; dorsal anchor more delicate than ventral anchor. Bars similar, broadly U shaped. Hook with uniform shank, upright acute thumb; FH loop about shank length. MCO with funnel-shaped base, coiled tubular shaft comprising slightly more than one 
wide counterclockwise ring. Accessory piece absent. Testis ovate to bacilliform; seminal vesicle a sigmoid dilation of vas deferens, lying to left of base of MCO; prostatic reservoir tear-drop shaped, lying to left of base of MCO. Germarium elongate ovate, ventrally overlapping anterior end of testis; oviduct, seminal receptacle, uterus not observed. Vaginal pore, vagina not observed. Vitellaria dense; transverse vitelline duct anterior to Mehlis' gland. Egg not observed.

Type host and locality: Spanish flag snapper, Lutjanus carponotatus (Richardson), Lutjanidae: off Heron Island, Great



Other record: Lutjanus fulviflamma: off Heron Island,

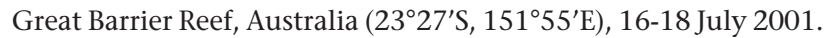

Site of infection: Gills.

Specimens studied: Holotype, QM G233866; 19 paratypes, QM G233867-871, USNPC 105559; 23 voucher specimens (from L. fulviflamma), QM G233872-876, USNPC 105560.

Etymology: This species is named in honor of Dr. P. C. Young, who conducted extensive surveys and described many new species of Monogenoidea from the Great Barrier Reef in Australia during the 1960s.

Measurements (dimensions of specimens from $L$. fulviflamma follow those of the type specimens in brackets, respectively): Body $232(152-356 ; n=9)$ [284 (246-307; $n=7)$ ] long; greatest width (excluding haptor) $47(41-55 ; \mathrm{n}=9)$ [60 $(44-75 ; \mathrm{n}=5)]$. Haptor $50(44-55 ; \mathrm{n}=8)$ [51 (46-57; $\mathrm{n}=7)$ ] long, $57(49-69 ; \mathrm{n}=8)$ [58 (54-63; $\mathrm{n}=6)]$ wide. Pharynx 18 (17 $22 ; \mathrm{n}=10)[20(17-24 ; \mathrm{n}=5)]$ wide. $\mathrm{MCO}$ (ring diameter) 30 $(27-33 ; \mathrm{n}=8)$ [31 (29-34; $\mathrm{n}=8)]$. Ventral anchor $34(32-36 ; \mathrm{n}=$ 9) $[35(33-38 ; \mathrm{n}=15)]$ long; dorsal anchor $33(30-35 ; \mathrm{n}=9)$ [34 (31-36; $\mathrm{n}=14)$ ] long. Ventral bar $37(31-40 ; \mathrm{n}=7)$ [38 (34-41; $\mathrm{n}=11)$ ] long; dorsal bar $39(33-42 ; \mathrm{n}=8)[36(31-42 ; \mathrm{n}=13)]$ long. Hook $13(12-14 ; \mathrm{n}=17)$ [13 (12-14; $\mathrm{n}=30)]$ long. Germarium $24(22-25 ; \mathrm{n}=4)$ [36 $(32-42 ; \mathrm{n}=3)]$ long, $14(11$ $15 ; \mathrm{n}=4)[18(14-21 ; \mathrm{n}=3)]$ wide; testis $28(25-33 ; \mathrm{n}=7)$ [40 $(35-43 ; \mathrm{n}=3)]$ long, $14(11-16 ; \mathrm{n}=7)$ [24 (15-30; $\mathrm{n}=3)]$ wide.

Remarks: Euryhaliotrema youngi appears closest to $E$. spirotubiforum, E. adelpha and E. paululum. It differs from all of these species by having a comparatively wider ring diameter in the shaft of the MCO.

\section{DISCUSSION}

Evidence continues to mount indicating that amphiamerican clades (= geminate species pairs) among monogenoids occur in the waters off southern North America. KRITSKY et al. (2009b) suggested such clades among species of Neotetraonchus BravoHollis, 1968, Aristocleidus Mueller, 1936 and Euryhaliotrema (all Dactylogyridae), Rhabdosynochus Mizelle \& Blatz, 1941 (Diplectanidae) and Heterobothrium Cerfontaine, 1895 (Diclidophoridae) (see also Mendoza-Franco et al. 2009). These putative clades were thought to have developed through a vicariant coevolutionary model when the Panamanian Isthmus divided historical host and parasite distributions into eastern Pacific and western Atlantic populations about 3.2 mya. Based on morphometrics, additional amphiamerican pairs apparently occur among the Euryhaliotrema species infecting lutjanid hosts. These include the respective specimens currently assigned to $E$. fastigatum and E. paracanthi from the eastern Pacific Ocean and the Gulf of Mexico and Caribbean Sea and the putative amphiamerican pair represented by the Atlantic species $E$. longibaculum and the Pacific species E. mehen (see Remarks for the respective species). While confirmation of geminate species pairs of Monogenoidea off North America requires objective phylogenetic analyses, perhaps involving both morphological and molecular data, the occurrence of putative pairs suggests that differentiation of morphological features in the Monogenoidea is a comparatively long process, which in the amphiamerican clades resulted in only slight to insignificant morphological changes developing over the extended period of 3.2 mya.

Isolation of Euryhaliotrema species of the Indo-Pacific regions from those of the western hemisphere is presumably much older than 3.2 mya, and morphological divergence between the species of the two regions is generally greater than that observed within amphiamerican clades. Nonetheless, geminate relationships apparently also exist among the species occurring in the two regions. Based on comparative morphology of haptoral sclerites, for example, E. diplops and E. cryptophallus from the Indo-Pacific Ocean more closely resemble $E$. fastigatum from the western Atlantic than they do other congenerics occurring in their regional waters. While convergence cannot be discounted, the resemblance of these three species suggests that morphological divergence and speciation within the genus requires an extended period of time that may extend into several millions of years.

While examination of 30 ( 8 of which were uninfected with Euryhaliotrema spp.) of the 108 extant species of the Lutjanidae resulted in the identification of 27 species of Euryhaliotrema, the small sample sizes and the limited geographic distributions of the hosts that were surveyed suggests that the 33 species of Euryhaliotrema currently known to parasitize lutjanid hosts is far from representing the total diversity of species infecting members of the family worldwide. This is supported, in part, by the finding that the parasite species found to infect examined hosts differed in the various sites surveyed within the respective host's geographic distribution. For example, the mangrove red snapper L. argentimaculatus, Russell's snapper L. russellii, and the dory snapper L. fulviflamma enjoy wide geographic distributions in the western Pacific and Indian Oceans (Froese \& Pauly 2011). Present collections of $L$. argentimaculatus included sites off eastern China and New Caledonia, while those for L. fulviflamma included Australia, China, New Caledonia and the Red Sea, and for L. russellii, the Persian Gulf and New Caledonia. In none of these localities were identical parasite communities observed, with many of 
the sites having unique species of Euryhaliotrema on the respective hosts. KRITSKY et al. (2009a) observed similar differences in parasite communities comprising species of Haliotrematoides parasitizing these hosts, especially among those parasitizing red mangrove and dory snappers. This family of fishes requires considerable more investigation of their parasites in order to determine total diversity, not only of Euryhaliotrema species, but of other groups of monogenoidean flatworms as well.

While not within the scope of the present study or that of the first installment of the series on dactylogyrids of the Lutjanidae by KRITSKY et al. (2009a), it should be noted that members of other monogenoidean groups were encountered on the examined lutjanid hosts. Species of the Capsalidae (on L. russellii and L. argentimaculatus), the Udonellidae (on $L$. synagris and L. griseus), the Dactylogyridae (on L. russellii and L. sebae), the Diplectanidae (on L. quinquelineatus, L. vitta, $L$. fulviflamma and L. kasmira), the Microcotylinea (on L. griseus, L. fulviflamma, L. russellii, L. fulvus, L. malabaricus, L. rivulatus and Rhomboplites aurorubens) and the Gastrocotylinea (on $R$. aurorubens) were collected. These specimens were generally insufficient in number and quality for species identification.

\section{A note on Haliotrematoides species on the mangrove red snapper off China}

In the first installment dealing with the dactylogyrid parasites of snappers (Kritsky et al. 2009a), a new species, Haliotrematoides nagibinae Kritsky, Yang \& Sun, 2009, was described from the gills of the mangrove red snapper, $L$. argentimaculatus, collected from the Gulf of Tonkin and Dapeng Bay in the South China Sea off China. While searching for old records of Euryhaliotrema spp. for the present study, a paper was found in which Haliotrema tukerhamatus Li \& Yan, 2007 was described from the mangrove red snapper and the blackhead seabream, Sparus macrocephalus (now Acanthopagrus s. schlegelii), obtained from a market in Guangzhou, China (LI \& YAN 2007). Comparison of LI \& YAN's (2007) figures with those provided for H. nagibinae by KRITSKY et al. (2009a) clearly shows that the two nominal species are synonyms. Thus, Haliotrema tukerhamatus is transferred to Haliotrematoides as Haliotrematoides tukerhamatus (Li \& Yan, 2007) comb. nov., and Haliotrematoides nagibinae is considered its junior subjective synonym.

\section{ACKNOWLEDGMENTS}

This study could not have been completed without the major assistance of many colleagues and friends. The author gratefully acknowledges the following for their support: Micah D. Bakenhaster, Florida Fish and Wildlife Conservation Commission, St. Petersburg, Florida; Stephen A. Bullard, Auburn University, Auburn, Alabama; Paolo Galli, University of MilanoBicocca, Milano, Italy; Jean-Lou Justine (and his students in New Caledonia), Muséum National d'Histoire Naturelle, Paris, France; Edgar Mendoza-Franco, CINVESTAV, IPN, Merida,
Mexico; Otto Sey (retired), University of Pécs, Pécs, Hungary; and Yang Tingbao, Zhongshan University, Guangzhou, China, collected host and parasite specimens and contributed to the descriptions of new species found within their respective collections. Dr. Yang also provided frequent translations of the Chinese literature; Pavel Gerasev, Russian Academy of Sciences, St. Petersburg, Russia, provided information on the holotype of E. longibaculum; Sven Klimpel, Heinrich-Heine University, Düsseldorf, Germany, attempted to locate the lost type specimens of Daitreosoma chaetodontis Reichenbach-Klinke, 1959; Nirupama Agrawal, University of Lucknow, Lucknow, India, found that the types of some dactylogyrid species described from India no longer existed; David Gibson, The Natural History Museum, London, United Kingdom, reviewed the Latinized endings of the specific names of the new species and provided copies of some of the Chinese literature; J. Richard Arthur, Maurice Lamontagne Institute, Mont-Joli, Quebec, Canada, provided literature on parasites of snappers in Malaysia; Eric Hoberg and Pat Pilitt, U. S. National Parasite Collection, Beltsville, Maryland, and Eileen Harris, The Natural History Museum, London, United Kingdom, provided loans of type and voucher specimens; Bob Overstreet, Gulf Coast Research Laboratory, Ocean Springs, Mississippi, kindly provided the facilities of the Gulf Coast Research Laboratory during collections of lutjanids from the Gulf of Mexico; and Tom Cribb, University of Queensland, Brisbane, Australia, hosted the author and along with his students provided invaluable support during collections of lutjanids off Heron Island, Australia.

\section{LITERATURE CITED}

Allen, G.R. 1985. FAO species catalogue. Vol. 6. Snappers of the world. An annotated and illustrated catalogue of lutjanid species known to date. FAO Fisheries Synopsis 6 (125): 1-208.

Anonymous. 1991. Malaysia, p. 169-179. In: Fish health management in Asia-Pacific. Report on a regional study and workshop on fish disease and fish health management. Bangkok, ADB Agriculture Department Report Ser. No. 1, Network of Aquaculture Centres in Asia-Pacific.

Bosques Rodríguez, L.J. 2004. Metazoan parasites of snappers, Lutjanidae (Pisces) from Puerto Rico. Mayagüez, Master of Science Thesis, University of Puerto Rico, 178p.

Bullard, S.A.; R.R. Payne \& J.S. Braswell. 2004. New genus with two new species of capsalid monogeneans from dasyatids in the Gulf of California. Journal of Parasitology 90: 1412-1427.

Dang, B.T.; A. Levsen; C. Schander \& G. Bristow. 2010. Some Haliotrema (Monogenea: Dactylogyridae) from cultured grouper (Epinephelus spp.) with emphasis on the phylogenetic position of Haliotrema cromileptis. Journal of Parasitology 96: 30-39.

Eschmeyer, W.N. \& R. Fricke. 2011. Catalog of Fishes, electronic version 20 November 2011. Available on line at: http:// research.calacademy.org/ichthyology/catalog/fishcatmain.asp. [Accessed: 30/XII/2011] 
Fehlauer, K.H. \& W.A. Boeger. 2005. Neotropical Monogenoidea: Euryhaliotrema dontykoleos n. sp. (Dactylogyridae) from the gills of the freshwater sciaenid, Pachyurus junki (Perciformes). Journal of Parasitology 91: 1025-1027.

Fuentes Zambrano, J.L. \& C.L. Silva Rojas. 2006. Una nueva especie de Euryhaliotrema Kritsky y Boeger, 2002 (Monogenea) encontrada en branquias de Lutjanus griseus (Perciformes: Lutjanidae) de la Isla de Margarita, Venezuela. Boletin del Instituto Oceanográfico de Venezuela, Universidad de Oriente 45: 3-7.

Fuentes Zambrano, J.L.; C. Silva Rojas. \& Y. Reyes León. 2003. Parásitos en juveniles de Lutjanus griseus (Pisces: Lutjanidae) de la Laguna de la Restinga, Isla de Margarita, Venezuela. Interciencia 28: 463-468.

Froese, R. \& E. Pauly. 2011. FishBase. Available on line from: http://www.fishbase.org [Accessed: 30/XII/2011].

GalLi, P. \& D.C. KRITSKY. 2008. Three new species of Protogyrodactylus Johnston \& Tiegs, 1922 (Monogenoidea: Dactylogyridae) from the gills of the longtail silverbiddy Gerres longirostris (Teleostei: Gerreidae) in the Red Sea. Systematic Parasitology 69: 221-231.

García-Vargas, F.; E.J. Fajer-Ávilla \& M.R. Lamothe-Argumedo. 2008. Two new species of Dactylogyridae (Monogenoidea) on rose spotted snapper, Lutjanus guttatus (Osteichthyes: Lutjanidae), from the coasts of Nayarit and Sinaloa, Mexico. Zootaxa 1729: 61-68.

Gupta, N.K. \& M. KhANNA. 1974. On some of the monogenetic trematodes of marine fishes from Port-Blair (Andaman and Nicobar Islands, India) Part I. Revista Ibérica de Parasitologia 34: 257-272.

Humason, G.L. 1979. Animal Tissue Techniques. San Francisco, W.H. Freeman and Company, $4^{\text {th }}$ ed., 661p.

Kritsky, D.C. 2012. Revision of Parancylodiscoides Caballero y C. \& Bravo-Hollis, 1961 (Monogenoidea: Dactylogyridae), with a redescription of $P$. longiphallus (MacCallum, 1915) from the Atlantic spadefish Chaetodipterus faber (Broussonet) (Acanthuroidei: Ephippidae) in the Gulf of Mexico. Systematic Parasitology 81: 97-108.

Kritsky, D.C. \& W.A. Boeger. 2002. Neotropical Monogenoidea. 41: New and previously described species of Dactylogyridae (Platyhelminthes) from the gills of marine and freshwater perciform fishes (Teleostei) with proposal of a new genus and a hypothesis on phylogeny. Zoosystema 24: 7-40.

Kritsky, D.C.; W.A. Boeger \& V.E. Thatcher. 1985. Neotropical Monogenea. 7. Parasites of the pirarucu, Arapaima gigas (Cuvier), with descriptions of two new species and redescription of Dawestrema cycloancistrium Price and Nowlin, 1967 (Dactylogyridae: Ancyrocephalinae). Proceedings of the Biological Society of Washington 98: 321-331.

KrITSKY, D.C.; P. Galli \& YANG T. 2007. Dactylogyrids (Monogenoidea) parasitizing the gills of spinefoots (Teleostei, Siganidae): revision of Tetrancistrum Goto and Kikuchi, 1917, with descriptions of two new species from Siganus spp. of the Red Sea and Celebes. Journal of Natural History 41: 1513-1551.

Kritsky, D.C.; P.D. Leiby \& R.J. Kayton. 1978. A rapid stain technique for the haptoral bars of Gyrodactylus species
(Monogenea). Journal of Parasitology 64: 172-174.

Kritsky, D.C. \& E.F. Mendoza-Franco. 2008. Revision of Aristocleidus (Monogenoidea: Dactylogyridae), rediscovery of Aristocleidus hastatus, and description of Aristocleidus lamothei $\mathrm{n}$. sp. from the Peruvian mojarra Diapterus peruvianus (Teleostei: Gerreidae) in Mexico. Revista Mexicana de Biodiversidad 79: 75S-82S.

Kritsky, D.C.; E.F. Mendoza-Franco; S.A. Bullard \& V.M. VidalMartínez. 2009b. Revision of the amphiamerican Neotetraonchus Bravo-Hollis, 1968 (Monogenoidea: Dactylogyridae), with a description of $N$. vegrandis $\mathrm{n}$. sp. from the gill lamellae of the blue sea catfish Ariopsis guatemalensis (Siluriformes: Ariidae) off the Pacific Coast of Mexico. Systematic Parasitology 74: 1-15.

KRTTSKY, D.C.; YANG T. \& Sun Y. 2009a. Dactylogyrids (Monogenoidea, Polyonchoinea) parasitizing the gills of snappers (Perciformes, Lutjanidae): Proposal of Haliotrematoides n. gen. and descriptions of new and previously described species from marine fishes of the Red Sea, the eastern and Indo-west Pacific Ocean, Gulf of Mexico and Caribbean Sea. Zootaxa 1970: 1-51.

LeONG T.-S. \& Wong S.-Y. 1987a. Bacterial pathogens and parasites in greasy grouper, Epinephelus salmoides Maxwell, silver seabass, Lates calcarifer Bloch and golden snapper, Lutianus johni Bloch, cultured in floating netcages in Penang, Perak and Kedah, Peninsular Malaysia. Ottawa, International Development Research Centre, Final Report 84-0344, 105p.

LEONG T.-S. \& Wong S.-Y. 1987b. Parasites of wild and diseased golden snapper, Lutjanus johni (Bloch), in floating cages in Penang, Malaysia. Asian Fisheries Science 1: 83-90.

Leong T.-S. \& Wong S.-Y. 1989. Parasites of wild and cultured golden snapper, Lutjanus johni (Bloch), in Malaysia. Tropical Biomedicine 6: 73-76.

LEONG T.-S. \& Wong S.-Y. 1992. Control of diseases in cultured marine fishes, p. 281-282. In: Y.W. Ho; M.K. Vidyadaran; N. Abdullah; M.R. Jainudeen \& A.R. Bahaman. (Eds). Proceedings of the National IRPA (Intensification of Research in Priority Areas) Seminar (Agriculture Sector). Kuala Lumpur, 6-11 January 1992, Ministry of Science, Technology \& Environment Malaysia, vol. 2.

Li H.-Y. 2005. [Description of two species (including a new one) in Euryhaliotrema Kritsky \& Boeger, 2002]. Journal of Dalian Fisheries University 20: 186-191.

Li H.-Y. 2006. [One new species the genus Euryhaliotrema (Monogenea, Ancyrocephalidae)]. Acta Zootaxonomica Sinica 31: 317-320.

Li H.-Y. \& YAN X.-M. 2007. [Description of two species (including one new species) of genus Haliotrema and one species of genus Euryhaliotrema.] Journal of Guangxi Normal University (Natural Science Edition) 25: 97-100.

Li H.-Y.; Yan X.-Z.; Yu L.-W.; Lan Q.-L. \& Huang X.-Y. 2005. [Description of two new species of Ancyrocephalidae (Monogenoidea)]. Journal of Guangxi Normal University (Natural Science Edition) 23: 86-89. 
Li Z.; YAN P.; LiU L. \& YU X. 1995. [Monogenoid of Chinese marine fishs. V. Some monogenean of the families Diplectanidae and Ancyrocephalidae from sparid and serranid in South China Sea (sic).] Proceedings of the Tenth Anniversary of the Founding of China Parasitological Society (1985-1995). Beijing, Science Press, p. 88-92.

Liang K.-S. \& LeONG T.-S. 1991. The distribution of gill monogeneans in cultured golden snapper, Lutjanus johni Bloch. Tropical Biomedicine 8: 131-140.

LiANG K.-S. \& LeONG T.-S. 1992. Treatment of cultured golden snapper, Lutjanus johni Bloch, infected with monogeneans. Aquaculture 106: 1-8.

Lin L. \& Y Z.-S. 1993. A new record of Haliotrema on the gills of Sparus macrocephalus (Basilewsky) from China. Annual Bulletin of the Society of Parasitology of Guangdong Province 14-15: 312.

Malmberg, G. 1970. The excretory systems and the marginal hooks as a basis for the systematics of Gyrodactylus (Trematoda, Monogenea). Arkiv för Zoologi 23: 1-235.

Mendoza-Franco, E.F.; J. Violante-González \& D.G. Roche. 2009. Interoceanic occurrence of species of Aristocleidus Mueller, 1936 (Monogenoidea: Dactylogyridae) parasitizing the gills of gerreid fishes in the neotropics. Parasitology Research 105: 703-708.

Mizelle, J.D. 1936. New species of trematodes from the gills of Illinois fishes. American Midland Naturalist 17: 785-806.

Mizelle, J.D. \& C.E. Price. 1963. Additional haptoral hooks in the genus Dactylogyrus. Journal of Parasitology 49: 1028-1029.

OgaWA, K. \& S. Egusa. 1978. Haliotrema kurodai n. sp. (Monogenea: Dactylogyridae, Ancyrocephalinae), a monogenean parasite obtained from the Japanese black sea bream, Acanthopagrus schlegeli (Bleeker). Bulletin of the Japanese Society of Scientific Fisheries 44: 1329-1332.

PAN J. 2000. [Monogenoidea of marine fishes from Hainan Island. IV. Two new species of Haliotrema from South China Sea]. Tropic Oceanology 19: 33-38.

PAN J. \& Zhang J. 2006. Monogenea of marine fishes from Hainan Island, China. VIII. Two new species of Euryhaliotrema Kritsky \& Boeger, 2002 (Dactylogyridae) from Lutjanus argentimaculatus (Teleostei: Lutjanidae). Systematic Parasitology 64: 125-130.

Plaisance, L. \& D.C. KRITSKY. 2004. Dactylogyrids (Platyhelminthes: Monogenoidea) parasitizing butterfly fishes (Teleostei: Chaetodontidae) from the coral reefs of Palau, Moorea, Wallis, New Caledonia, and Australia: species of Euryhaliotrematoides n. gen. and Aliatrema n. gen. Journal of Parasitology 90: 328-341.

Plaisance, L.; D.T.J. Littlewood; P.D. Olson \& S. Morand. 2005. Molecular phylogeny of gill monogeneans (Platyhelminthes, Monogenea, Dactylogyridae) and colonization of Indo-west Pacific butterflyfish hosts (Perciformes, Chaetodontidae). Zoologica Scripta 34: 425-436.

Reichenbach-Klinke, H.-H. 1959. Zwei neue Tetraonchinen aus Südostasien (Trematoda: Monogenea: Dactylogyridae). Zeitschrift für Parasitenkunde 19: 364-367.

Soler-Jiménez, L.C.; A. Garcia-Gasca \& E.J. Fajer-Ávila. 2012. A new species of Euryhaliotrematoides Plaisance \& Kritsky, 2004 (Monogenea: Dactylogyridae) from the gills of spotted rose snapper Lutjanus guttatus (Steindachner) (Perciformes: Lutjanidae). Systematic Parasitology 82: 113-119.

Soler-Jiménez, L.C. \& E.J. Fajer-Ávila. 2012. The microecology of dactylogyrids (Monogenea: Dactylogyridae) on the gills of wild spotted rose snapper Lutjanus guttatus (Lutjanidae) from Mazatlan Bay, Mexico. Folia Parasitologica 59: 53-59.

Tripathi, Y.R. 1959. Monogenetic trematodes from fishes of India. Indian Journal of Helminthology 9: 1-149.

Vignon, M.; P. SASAL; M.C. Rigby \& R. Galzin. 2009. Multiple parasite introduction and host management plan: case study of lutjanid fish in the Hawaiian Archipelago. Diseases of Aquatic Organisms 85: 133-145.

WANG, J. 1997. [Monogenea of Chinese marine fishes. XV. Three new records of Haliotrema from marine fishes from the Guangxi]. Annual Bulletin of the Society of Parasitology, Guangdong Province 19: 38-41.

Wu X.-Y.; Zhu X.-Q.; XIE, M.-Q. \& Li A.-X. 2006. The radiation of Haliotrema (Monogenea: Dactylogyridae: Ancyrocephalinae): molecular evidence and explanation inferred from LSU rDNA sequences. Parasitology 132: 659-668.

Wu X.-Y; Zhu X.-Q.; XIE M.-Q. \& Li A.-X. 2007. The evaluation for generic-level monophyly of Ancyrocephalinae (Monogenea, Dactylogyridae) using ribosomal DNA sequence data. Molecular Phylogenetics and Evolution 44: 530-544.

Yamaguti, S. 1953. Parasitic worms mainly from the Celebes. Part 2. Monogenetic trematodes of fishes. Acta Medicinae Okayama 8: 203-256.

YounG, P.C. 1968. Ten new species of Haliotrema (Monogenoidea: Dactylogyridae) from Australian fish and a revision of the genus. Journal of Zoology 154: 41-75.

Zhang J.-Y. 2001. Chapter 10. Ancyrocephalidae Bychowsky \& Nagibina, 1978, p. 79-178. In: Zhang J.-Y.; YANG T.; LiU L. (Eds). Monogeneans of Chinese Marine Fishes. Beijing, China, Agriculture Press, 400p.

Zhang J.-Y.; Ding X.-J.; Lin L. \& Yu X.-D. 1994. Monogenoidea of Chinese marine fishes. II. One new species and five new Chinese records of Dactylogyridea. Proceedings of the Sixtieth Anniversary of the Foundings of China Zoological Society 1934-1994. Beijing, Chinese Scientific and Technical Publishers, p. 568-573.

Zhuкоv, E. V. 1976. [New monogenean species of the genus Haliotrema Johnston and Tiegs, 1922, from the Gulf of Mexico fishes of the fam. Lutianidae (sic), p. 33-47. In: B.I. Lebedev \& L.M. Yu (Eds). Fauna, Systematics and Phylogeny of Monogenoidea. Proceedings, Institute of Biology and Pedology, Far-East Science Centre, Academy of Sciences of the U.S.S.R., New Series 35.

Submitted: 29.III.2012; Accepted: 10.V.2012. Editorial responsibility: Walter A.P. Boeger 